\title{
THE MECHANISM, MEASUREMENT, AND INFLUENCE OF PROPERTIES ON THE GALLING OF METALS
}

L. K. Ives

M. B. Peterson

E. P. Whitenton

Propared by

U.S. DEPARTMENT OF COMMERCE

Natlonal Instltute of Standards

and Technology

Materlals Sclence and Engineorling

Laboratory

Coramlce Divlsion

Galthersburg, MD 20899

under

Contract Number:DE-A105-830R21322

for

Oak Ridge Natlonal Laboratory

Oak Ridge, TN 37831

operated by

Martin Marletta Energy Systems, Inc.

for the

U.S. Department of Energy

Under contract No. DE-AC05-84OR21400

U.S. DEPARTMENT OF COMMERCE Robert A. Mosbacher, Secretary

Leo Mercer, Deputy Under Secratary for Technolosy

MATIONAL INSTITUTE OF STANDARDS AND TECHNOLOGY

Raymond G. Kammor, Acting Director 
Printed in the United States of America. Available from National Technical Information Service

U.S. Department of Commerce

5285 Port Royal Road, Springfield, Virginia 22161

NTIS price codes--Printed Copy: A06 Microfiche A01

This report was prepared as an account of work sponsored by an agency of the United States Government. Neither the United States Government nor any agency thereof, nor any of their employees, makes any warranty, express or implied, or assumes any legal liability or responsibility for the accuracy, completeness, or usefulness of any information, apparatus, product, or process disclosed, or represents that its use would not infringe privately owned rights. Reference herein to any specific commercial product, process, or service by trade name, trademark, manufacturer, or otherwise, does not necessarily constitute or imply its endorsement, recommendation, or favoring by the United States Government of any agency thereof. The views and opinions of authors expressed herein do not necessarily state or reflect those of the United States Government or any agency thereof. 
ORNL/S U b / 83-21322/01

\section{THE MECHANISM, MEASUREMENT, AND INFLUENCE OF PROPERTIES ON THE GALLING OF METALS}

\author{
L. K. Ives \\ M. B. Peterson \\ E. P. Whitenton
}

Research sponsored by the

U.S. Department of Energy

Advanced Research and Technology

Development

Fossll Energy Materlals Program

Prepared by

U.S. DEPARTMENT OF COMMERCE

Natlonal Instltute of Standards

and Tochnology

Materlale Sclence and Englneering

Laboratory

Ceramlcs Dlvislon

Galthersburg, MD 20899

under

Contract Number DE-A105-830R21322

for

Oak RIdge Natlonal Laboratory

Oak RIdge, TN 37831

oporated by

MartIn Marletta Energy Systems, Inc.

for the

U.S. Department of Energy

Under contract No. DE-AC05-840R21400

December 1989

Final Report

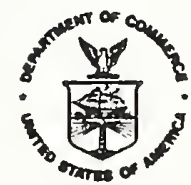

U.S. DEPARTMENT OF COMMERCE Robert A. Mosbacher, Secretary

Leo Morcer, Deputy Under Secretary for Tochnoloty

MATIONAL INSTITUTE OF STANDARDS

AND TECHNOLOGY

Raymond G. Kammer, Acting Director 
"Research sponsored by the U.S. Department of Energy, AR\&TD Fossil

Energy Materials Program, DOE/FE AA 1510100 , Work Breakdown

Structure Element NIST-3"

\section{ABSTRACT}

This report presents the results of an extensive investigation of the process of galling. The work was motivated by the need to develop a better understanding of the process of galling as it affects various fossil energy related systems, and by the need to find solutions to the problem of galling in these systems. Three areas were emphasized: 1) the elucidation of the mechanism of galling, 2) the quantitative characterization and measurement of the amount of damage associated with galling, and 3 ) the determination of relationship between galling and materials properties. On the basis of a review of the literature and experiments on a variety of different metals it was concluded that the primary event in the process of galling is that of prow or wedge formation. A method based on surface topography was developed to measure quantitatively the amount and character of galling. By studying a range of pure metals and selected experimental alloys it was demonstrated that among the most important properties influencing galling are crystal structure and stacking fault energy. Hardness and strength do not in general correlate with galling severity, but it was shown that hardening steels by heat treatment is an effective means of reducing the damage due to galling. Carburizing and nitriding were also shown to diminish significantly the damage due to galling.

Key words: adhesive wear; carburized; $\mathrm{Cu}-\mathrm{Al}$; $\mathrm{Cu}-\mathrm{Ge}$; friction; galling; nitrided; profilometry; prow formation; stacking fault energy; steel; wear. 
\begin{tabular}{lr} 
& Page \\
\cline { 2 - 2 } & \\
Table of Contents & vit \\
List of Figures & vii \\
List of Tables & xii \\
Executive Summary & xiv
\end{tabular}

1. Introduction 1

2. Literature Review 2

3. Test Method 3

3.1 Test Machines 5

3.2 Specimen Preparation 7

4. Damage Measurement Method 9

4.1 Damage Parameters 11

5. Galling of Pure Metals 15

6. Galling of Nonself-Mated Pure Metals. 24

$6.1 \mathrm{Cu}$ vs. $\mathrm{Ni} 26$

$6.2 \mathrm{Ag}$ vs. $\mathrm{Ni}$

$6.3 \mathrm{Ag}$ vs. Co and $\mathrm{Cu}$ vs. Co 37

6.4 Summary of Results on Nonself-Mated Combinations 37

7. The Effect of Stacking Fault Energy 40

8. Galling of Alloys 51

8.1 Effect of Heat Treatment 51

8.2 Effect of Carburizing and Nitriding 56

8.3 Corrosion Resistant and Other Alloys 68

9. Effect of Hardness for Self-Mated Metals 74

10. Mechanism of Galling 75

11. Summary and Conclusions 86

12. Acknowledgments 88

13. References 88

Distribution List $\quad 91$ 
Fig. 1. Pin-on-flat test configuration.

Fig. 2. Schematic drawing of hydraulically operated galling 6 test machine.

Fig. 3. Schematic drawing of screw-driven test machine with 6 dead-weight loading.

Fig. 4. Test specimens dimensions.

Fig. 5. Diagram of automated profilometer system.

Fig. 6. Schematic drawing of profilometer stylus drive and specimen translation stage.

Fig. 7. Stylus profilometer traces showing topography of track on flat in oblique projection.

Fig. 8. High resolution tracing of damage on flat.

Fig. 9. Arrangement of profile data matrix used in the calculation of damage parameters.

Fig. 10. Representation of surface topography shown on computer screen (a) after transforming to "zerolevel" reference plane and (b) area selected for parameter determination.

Fig. 11. Flats of 12 different pure metals after self-mated tests at $130 \mathrm{~N}$.

Fig. 12. SEM micrograph of initial section of galled track on $\mathrm{Fe}$ flat. $130 \mathrm{~N}$ load.

Fig. 13. Damage at approximately one-half centimeter from beginning of track on Fe flat.

Fig. 14. Prow located $3 \mathrm{~cm}$ from start of track on Fe flat.

Fig. 15. Prow at the end of the track on Fe flat.

Fig. 16. Dimple structure in track on Fe flat.

Fig. 17. Initial damage on Mo flat.

Fig. 18. Optical micrograph of part of track on Co flat. Nomarski interference contrast. 
Fig. 19. SEM micrograph of section of track on $\mathrm{Zn}$ flat.

Fig. 20. Damage severity measured in terms of $\bar{R}_{t}$ plotted as a function of hardness for pure metal specimens.

Fig. 21. Optical photographs of (a) Ni flat against which $\mathrm{Cu}$ pin was slid and (b) $\mathrm{Cu}$ flat against which a $\mathrm{Ni}$ pin was slid. Sliding was initiated at the left.

Fig. 22. SEM micrographs showing (a) start and (b) end sections of track on $\mathrm{Ni}$ flat against which $\mathrm{Cu}$ pin was slid and (c) start and (d) end of track on $\mathrm{Cu}$ flat against which $\mathrm{Ni}$ pin was slid.

Fig. 23. SEM micrograph of scar on (a) Cu pin after sliding against $\mathrm{Ni}$ flat and (b) $\mathrm{Ni}$ pin after sliding against $\mathrm{Cu}$ flat. Leading edge is at right.

Fig. 24. SEM micrograph of damage on $\mathrm{Ni}$ flat. Direction of motion of $\mathrm{Cu}$ pin was from left to right.

Fig. 25. SEM micrograph of damage on Cu flat. Direction of motion of $\mathrm{Ni}$ pin was from left to right.

Fig. 26. Coefficient of friction plotted as a function of sliding distance for $\mathrm{Ni}$ vs. $\mathrm{Cu}$ pin and flat combinations.

Fig. 27. Curves show volume above and below original surface in track on (a) $\mathrm{Ni}$ flat after sliding against $\mathrm{Cu}$ pin and (b) $\mathrm{Cu}$ flat after sliding against $\mathrm{Ni}$ pin plotted as a function of sliding distance.

Fig. 28. Optical photograph of track on Ni flat after sliding against Ag pin.

Fig. 29. Patches of transferred Ag on $\mathrm{Ni}$ flat (a) near beginning of track and (b) near end of track.

Fig. 30. Optical micrograph of scar on Ag pin after sliding against $\mathrm{Ni}$ flat. Leading edge of scar is at right.

Fig. 31. Coefficient of friction plotted as a function of sliding distance for a $\mathrm{Ag}$ pin slid against a $\mathrm{Ni}$ flat.

Fig. 32. Maximum peak to valley height, $R_{t}$, plotted as a function of sliding distance for track on $\mathrm{Ni}$ flat after sliding against a $\mathrm{Ag}$ pin. 
Fig. 33. Photographs of scars on (a) $\mathrm{Ag}$ and (b) $\mathrm{Cu}$ pins after sliding against Co flats. Leading edge is at right.

Fig. 34. Coefficient of friction traces for $\mathrm{Cu}$ and $\mathrm{Ag}$ sliding against co flats.

Fig. 35. Average maximum peak to valley damage parameter,

$\bar{R}_{t}$, for different pin and flat specimen combinations. The metal identified at the left refers to the pin and the metal at the right refers to the flat.

Fig. 36. Optical photographs of sliding tracks on $\mathrm{Cu}-\mathrm{Al}$ flats. Sliding was initiated at the top.

Fig. 37. SEM micrographs of wear scars on pins slid against flats shown in Fig. 36. The leading edge of each scar is at the left.

Fig. 38. SEM micrographs of initial section of tracks on (a) $\mathrm{Cu}$ and (b) $\mathrm{Cu}-8 \mathrm{Al}$ flats.

Fig. 39. SEM micrographs of damage on (a) $\mathrm{Cu}$ and (b) $\mathrm{Cu}-8 \mathrm{Al}$ flats near-midsection of tracks. Motion of pin was from left to right.

Fig. 40. SEM micrographs of the ends of the tracks on (a) $\mathrm{Cu}$ and (b) $\mathrm{Cu}-8 \mathrm{Al}$ flats.

Fig. 41. Coefficient of friction traces for specimens in Cu-Al series.

Fig. 42. Maximum peak to valley height, $R_{t}$, of damage on flats in Cu-Al series plotted as function of sliding distance. (a) - (d).

Fig. 43. Parameters used to characterize damage are plotted as a function of stacking fault energy for flats in $\mathrm{Cu}-\mathrm{Al}$ series.

Fig. 44. Damage parameter, $\overline{\mathrm{R}}_{\mathrm{t}}$, plotted as a function of load comparing hot rolled and quenched 1541 steel.

Fig. 45. Damage on quenched 1541 steel flat in self-mated test at $1500 \mathrm{~N}$. Arrow indicates direction of pin motion.

Fig. 46. Damage on hot rolled 1541 steel flat after self-mated 56 test at $1500 \mathrm{~N}$ load. Arrow indicates direction of pin motion. 
Fig. 47. Hardness profile across carburized case on 8620 steel.

Fig. 48. Prow on 8620 steel flat produced by sliding against a quenched 1541 steel pin at $1500 \mathrm{~N}$. A and B identify locations analyzed by EDS. Arrow indicates direction of pin motion.

Fig. 49. Comparison of damage results for different steel combinations in tests at $1500 \mathrm{~N}$.

Fig. 50. Variation in displaced volume parameter, DV, with applied load on flats for different sliding combinations.

Fig. 51. Variation in average maximum peak to valley parameter, 62 $\bar{R}_{t}$, with applied load for different sliding combinations.

Fig. 52. Variation $R_{t}$ (rms) as a function of applied load for different sliding combinations.

Fig. 53. Variation in aspect ratio parameter, AR, as a function of applied load for specimen flats. The low values, all $<<1$, indicate damage is primarily in the form of long grooves and ridges parallel to the direction of sliding.

Fig. 54. Optical micrographs (Nomarski contrast) showing section of track on nitrided 4140 specimen flat after sliding against 1541 pin. (a) $1500 \mathrm{~N}$ load. (b) $3000 \mathrm{~N}$ load. (c) $6000 \mathrm{~N}$ load.

Fig. 55. Transverse cracks in wear track on nitrided 4140 specimen flat after sliding against 1541 steel pin at $1500 \mathrm{~N}$. Nomarski contrast. Arrow indicates direction of pin motion.

Fig. 56. Optical micrograph (Nomarski contrast) showing section of track on nitrided 4140 specimen flat after sliding against nitrided 4140 pin at $6000 \mathrm{~N}$ load. Arrow indicates direction of pin motion.

Fig. 57. Optical micrographs of scar on 1541 pin after sliding on nitrided 4140 flat. (a) Front part of contact showing transferred lumps and oxide. (b) Oxide near center of contact area on pin. 
Fig. 58. (a) Optical photograph of track on an aluminum bronze flat. (b) Profilometer tracing of damage.

(c) Plot of the maximum peak-to-valley heights as a function of distance along the track. (d) Coefficient of friction plotted as a function of sliding distance.

Fig. 59. (a) SEM micrograph of initial part of track on aluminum bronze flat. (b) Small prows present at beginning of track. (c) Typical appearance of track past initiation point.

Fig. 60. Damage severity, $\bar{R}_{t}$, plotted against pretest hardness for self-mated metals at $130 \mathrm{~N}$.

Fig. 61. Schematic drawing illustrating basic wedge formation process responsible for galling.

Fig. 62. Variation in normal component of stress $\sigma_{x}$ in contact plane for spherical indenter: (a) with out tangential force and (b) with tangential force.

Fig. 63. Similar appearance of damage at different scales: (a) $\mathrm{Ni}$ flat and (b) aluminum-bronze flat. $130 \mathrm{~N}$ load.

Fig. 64. Slip-line field models used by Black, Koplansky and oxley [20] to study the different regimes of sliding deformation: (a) plastic wave formation, (b) wave removal, and (c) chip formation. 
Table 1. Standard test conditions 4

Table 2. Pure metals and properties 16

Table 3. Metal combinations tested 26

Table 4. Cu Alloys for the study of galling vs. SFE 40

Table 5. Bulk compositions of steels (wt. 8 ) 51

Table 6. Results for 1541 Steel 52

Table 7. Effect of aging on damage for 18Ni(300) steel 54

Table 8. Carburizing and nitriding treatments 56

Table 9. Results on carburized and nitrided steels 58

Table 10. Nominal Compositions of Alloys (wt.o principal 68 elements)

Table 11. Damage Results for some commercial alloys 69 
Galling (a form of severe damage at sliding surfaces) is a problem in advanced fossil energy conversion systems, especially those that operate at high temperatures using corrosion resistant materials. Accordingly, a program was initiated to develop a better understanding of the galling process and the factors which affect it.

\section{Literature Review}

As a first step in the program a comprehensive review of the literature was conducted. Approximately 250 references pertinent to galling were reviewed. Relatively few of these references ".." ifically identified galling as the process under consideration. This is due to the fact that there is no widely recognized and agreed upon definition for the term galling. Other terms such as adhesive wear, scuffing, scoring and seizure are often used to described essentially the same process. Thus, the majority of the applicable references were identified by these and other terminology. A principal focus of the review concerned the relationship between galling and plastic deformation. Conclusions and deductions based on the review are summarized in this report. One important conclusion concerned the fact that most of the results on galling were reported in qualitative rather than quantitative terms. Describing galling in quantitative terms became an important aspect of the program.

\section{Test Method Development}

A test method was developed and suitable equipment was designed and constructed. A simple pin-on-flat specimen configuration operated in a linear sliding mode was selected. Pins with spherically shaped tips were used. This geometry avoids the problem of achieving precise specimen alignment that is encountered with many other geometries. Also, as an added advantage, the contact stresses under static conditions are easily calculated using the Hertz equations. 
Measurement of Galling Severity

A method to quantitatively measure the amount of damage was developed. Consistent with the fact that the most prominent feature of galling is a significant increase in surface roughness, parameters based on surface topography were used to characterize galling damage. Surface topography was measured by means of stylus profilometry. A computer controlled, automated profilometer system capable of three-dimensional measurement was designed and constructed. Parameters were evaluated that might adequately reflect the nature of the galling process. After considerable study four parameters were found to be appropriate. They were:

1. Average maximum peak-to-valley height, $\bar{R}_{t}$

2. Root-mean-square of the maximum peak-to-valley heights, $R_{\mathrm{t}}$ (rms)

3. Displaced volume, DV

4. Aspect ratio of topographic features, AR.

These damage parameters were plotted against the various tribological and materials variables as a means of indicating the influence of those variables on the galling process.

\section{Galling Behavior of Metals}

The galling behavior of a number of different pure metals and alloys was studied using the pin-on-flat test method and the topography based measurement method to characterize the surface damage. Extensive use was also made of optical and scanning electron microscopy in the analysis of the damage. Galling damage was evaluated as a function of materials properties and operating parameters. The results are summarized as follows:

1. Crystal Structure. The galling behavior of twelve different pure metals was studied. Among the different properties of these metals, crystal structure was found to have a substantial effect. There was much less damage with hexagonal-close-packed metals than with body- 
centered or face-centered cubic metals. In fact, it could be said that the hexagonal-close-packed metals cobalt and magnesium were non-galling.

2. Nonself-Mated Combinations. When two different materials are slid against each other, relative hardness and adhesion influences the severity of galling. For pure metals, mixed combinations gave less galling than self-mated ones. For example, Ni/Cu combinations gave less galling than either $\mathrm{Ni} / \mathrm{Ni}$ or $\mathrm{Cu} / \mathrm{Cu}$.

Perhaps the most important factor influencing the response of different metal combinations was the relative hardness of the component specimens. With a sufficiently large difference in hardness, the harder specimen was not plastically deformed during sliding. In this case damage to the harder specimen took the form of transferred material from the softer.

Nonself-mated couples of pure metals were selected to examine the effect of chemical compatibility. The chemically incompatible combinations $\mathrm{Ag}$ and $\mathrm{Cu}$ sliding against Co were compared with the compatible combinations $\mathrm{Ag}$ and $\mathrm{Cu}$ sliding against $\mathrm{Ni}$. In this comparison more damage was found for the compatible pairs, demonstrating the importance of adhesion in the galling process.

\section{Stacking Fault Energy. Three series of $\mathrm{Cu}$ based solid solution} alloys, $\mathrm{Cu}-\mathrm{Al}, \mathrm{Cu}-\mathrm{Ge}$, and $\mathrm{Cu}-\mathrm{Ni}$, were studied to determine the effect of stacking fault energy on damage severity. With $A l$ and Ge additions to $\mathrm{Cu}$, the stacking fault energy decreases with increasing solute concentration. Alloying with $\mathrm{Ni}$, however, results in an increase in stacking fault energy. Self-mated tests with these alloys showed that damage severity decreased with decreasing stacking fault energy with the greatest effect observed at relatively low stacking fault energies.

4. Heat Treatment. The effect of heat treatment was studied using AISI 1541 steel and $18 \mathrm{Ni}(300)$ maraging steel. When heat treatment resulted in an increase in hardness, there was also an accompanying decrease in galling severity. With the maraging steel it was demonstrated by overaging and underaging to the same hardness level that significant 
differences in galling severity could be obtained. Thus, in evaluating the effects of heat treatment on galling, other properties in addition to hardness must be considered.

5. Carburizing and Nitriding. The effect of carburizing 8620 steel and nitriding 4140 steel were studied. In both cases carburizing and nitriding resulted in significant reductions in galling severity.

6. Alloys. Experiments were conducted on a number of corrosion resistant alloys having hardness values between 200 and $360 \mathrm{~kg} / \mathrm{mm}^{2}$. Of the alloys studied, two, aluminum bronze and Nitronic 60 , gave significantly lower damage values than the other alloys. Detailed studies of the aluminum bronze alloy showed that its galling resistance was not due to the presence of a unique surface film but is related to the deformation response of the material. The low stacking fault energies of these two alloys (a major component phase in the case of the multi-phase aluminum bronze alloy) is almost certainly responsible for their high resistance to galling.

7. Effect of Load. Results showed that the amount of galling damage increased almost linearly with load at the lower loads; at the highest loads tested $(10,000 \mathrm{~N})$ the damage tended to level off.

8. Effect of Finish. Galling severity was found to depend on surface finish. Polished surfaces galled more severely than ground surfaces. In general, galling decreased as the surface roughness increased.

A surface lay parallel to the sliding direction resulted in less damage than a lay perpendicular to the sliding direction. This reduction in damage is attributed to the fact that the lateral growth of junctions is restricted when the lay is parallel to the sliding direction.

9. Hardness. For a wide range of different self-mated metal combinations tested at a load of $130 \mathrm{~N}$, the galling severity, $\overline{\mathrm{R}}_{t}$, plotted against the pretest hardness of the metal showed no unique functional relationship. There was, however, an upper bound to the damage values that decreased 
with increasing hardness. In the range $350-450 \mathrm{~kg} / \mathrm{mm}^{2}$ this upper bound or envelope fell to a low level.

10. Mechanism of Galling. Identifying and understanding the mechanism of galling was an underlying focus throughout the investigation. Galling was found to be a surface deformation process determined by the response of a material to the stresses imposed by load and contact geometry and the friction stresses due to adhesion. A primary event in the galling process is the formation of a prow or wedge between the contacting surfaces. Formation of the wedge or prow requires the prior establishment of an appropriate junction. Any material property together with finish, size of contact area, and microstructure which limits junction formation and growth will limit galling. Any material property which reduces adhesion will reduce or eliminate galling. Once a junction is formed, whether or not a wedge or prow also forms, i.e., galling occurs, depends on the work hardening and flow characteristics of the materials. 


\section{INTRODUCTION}

Galling has been encountered in a number of components employed in fossil energy related systems. Valves which control the flow of fluid streams are a notable example. The most prominent consequence of galling is a significant increase in surface roughness. As a result, when galling occurs at the sealing face of a valve, an increased rate of leakage is almost inevitable. If particles are present in the fluid stream, as is often the case in fossil energy related systems, the dimensions of the leak path may be increased by impingement erosion, thus accelerating the deterioration in performance. A common means of addressing the problem of galling is to introduce an appropriate lubricant or perhaps to reduce the severity of the operating conditions, for example, by decreasing the applied load. In some systems such steps may not be feasible. In a fluid stream, if the fluid itself does not have lubricating properties for the valve face material, it will be necessary to depend on the valve materials themselves to prevent galling, i.e., materials with sufficient resistance to galling will have to be selected.

An additional problem is frequently encountered in fossil energy processing and utilization systems. In such systems the materials often must be capable of withstanding severe elevated-temperature corrosion and oxidation conditions. Stainless steels and other high nickel high chromium containing alloys are employed. Many of these materials are found to be especially prone to galling.

Accordingly, a project was initiated to gain a better understanding of the galling process. The main purpose of the project was to advance the fundamental understanding of the process of galling. The ultimate intention being that an improved understanding would lead both to better criteria for the selection of materials to resist galling and to a rational basis for the development of improved materials.

The scope of the work included the following:

- A comprehensive review of the literature 
o Development of a test method and construction of suitable test equipment

- Development of a method to measure sliding surface damage quantitatively

- Evaluation of the galling behavior of a number of different pure metals and alloys

- Evaluation of the effects of significant test and materials variables

\section{LITERATURE REVIEW}

An extensive review of the literature on galling was conducted. [1] Approximately 250 references pertinent to galling were reviewed. A principal focus of the review concerned the relationship between galling and plastic deformation. It was found that no generally accepted definition of the term galling exists nor is there a recognized model for the process. Many investigators use other such as seizure or severe adhesive wear to describe a process that is essentially identical to galling. For some, the transfer of material from one surface to another is a necessary condition for galling to occur. The latter concept seems to be especially prevalent among those working in the field of metal forming. It was also revealed in the review that relatively few papers on galling were concerned with the damage process itself: most dealt with the conditions that led up to or caused galling. The latter preoccupation is understandable since in the majority of practical applications the onset of galling represents the failure of the bearing surface.

When the process of galling is viewed in the broader context of tribology in general, then it is clear that much of the research that has been directed towards understanding friction and wear at sliding contacts is also applicable to galling. In the following, a few of the most important findings and deductions based on the survey are summarized briefly. More details are given in reference [1] and in the original papers cited therein. 
- The term galling does not have a widely recognized and agreed upon definition and quite often other terms such as adhesive wear, scuffing, scoring, seizure and junction growth probably describe essentially the same process but each may vary as to degree of damage or its appearance. It is generally agreed that galling is a form of severe wear resulting in severely roughened surfaces.

- The onset and severity of galling are determined by the stress field at the contact and the response of contacting materials to the stresses. Thus, applied load, surface adhesion, surface topography, and the flow and fracture properties of the materials are critical factors in the process.

o Prow or wedge formation is a primary event in the process of galling.

- Higher hardness reduces galling severity by limiting the amount of plastic deformation which can occur. Work hardening increases galling if it increases the extent of deformation.

- Low surface adhesion reduces galling by limiting the amount of deformation that occurs before slip takes place at the interface. Low adhesion is indicated by low solubility, low surface energy, low d-band character, high atomic plane density, and weak interfacial bond types.

- Galling severity increases with load, reduced surface roughness, vacuum operation, clean surfaces, and higher temperatures (unless protective oxide films are formed).

- Metals having a hexagonal crystal structure or low stacking fault energy may have less tendency to gall.

The difficulty with most of these conclusions is that they are based on qualitative observations rather than quantitative measurements. It is desirable to know more precisely how changes in one variable (roughness, load, hardness, etc.) change the severity of galling. Thus, development of a quantitative approach became an important focus of the study.

\section{TEST METHOD}

The pin-on-flat specimen configuration employed for the majority of the galling tests carried out in this investigation is shown in Fig. 1. The pin with a spherically shaped tip is loaded against the flat. 


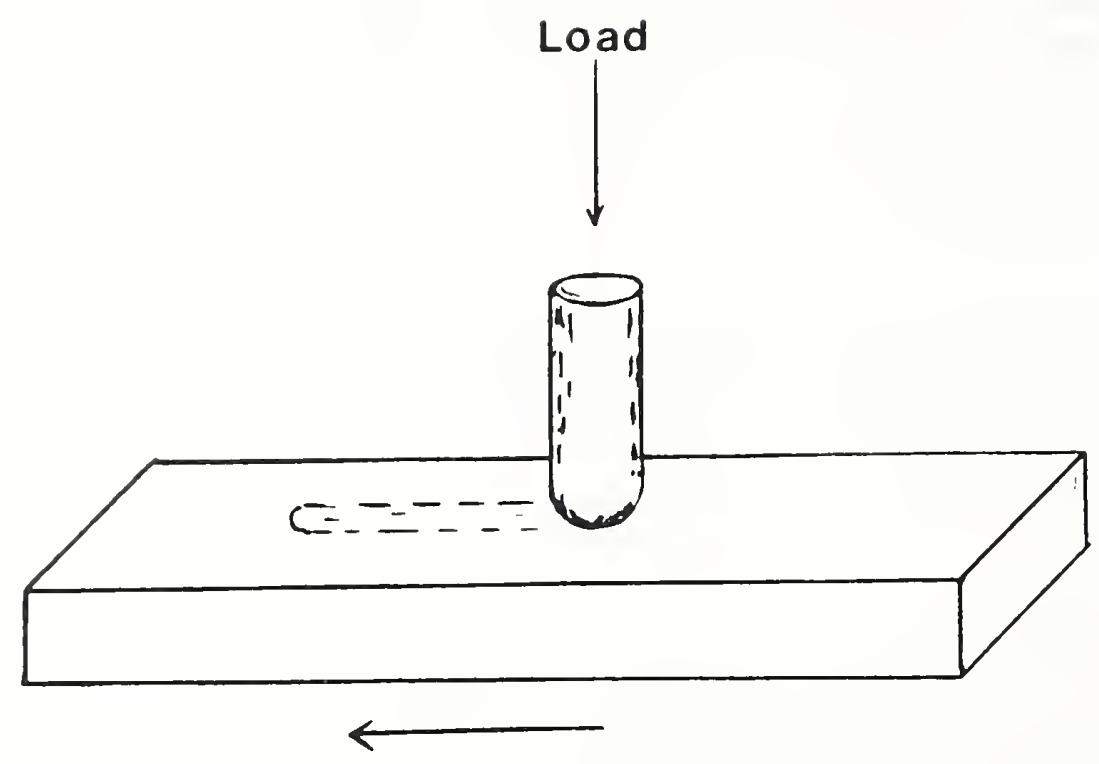

Fig. 1. Pin-on-flat test configuration.

The flat is translated linearly beneath the pin. A complete test consists of a single pass. The chosen configuration has several important features. One of the most important concerns specimen alignment. In some initial experiments a pin with a flat tip was employed. With this geometry precise alignment of the pin and flat are required; this was essentially impossible to obtain because of practical problems associated with accurate mounting of specimens, deflections in the machine, and the demands of precise grinding and polishing. Furthermore, it is necessary to provide a radius or chamfer of precisely controlled dimensions on the edge of the pin. A sharp edge or corner, which would be difficult to obtain at best, represents an unacceptable stress singularity. With a spherically shaped pin there is no difficulty with alignment, and machining and polishing are easily accomplished. In addition, the stresses associated with the sphere-on-flat geometry under static, normal loading can be calculated by means of the Hertz equations, and by the equations of Hamilton and Goodman [2] for combined normal and tangential (frictional) loading.

With the pin-on-flat arrangement under linear sliding it is possible to follow the progress of damage generation on the flat from initiation 
to termination. With the often used rotating cylinder, or button-onblock test, and some flat-on-flat tests, the site at which damage begins within the contact region is not known a priori and sliding may take place continuously over the damaged area of both contacting specimens, complicating the detailed analysis of the damage process. Finally, as will be seen in the next section, the linear track on the flat specimen surface is a convenient geometry for the measurement and analysis of the surface topography and damage characteristics.

\subsection{Test Machines}

Two test machines of somewhat different design were employed. One was a large load capacity hydraulically operated machine; the other was a lower load capacity screw driven machine. With the hydraulic machine, Fig. 2, both specimen translation and load application were by means of hydraulic cylinders except at a load of $130 \mathrm{~N}$ where dead weight loading (the weight of the specimen holder assembly) was employed in some tests. When applied by the hydraulic cylinder, loads as high as $135 \mathrm{kN}$ were possible. Under hydraulic operation the desired normal load was first applied and monitored by means of a load cell during the test. Displacements associated with galling and wear of the pin and flat resulted in some fluctuation in the load. There was no provision for maintaining the load at the preset value once the test was commenced other than through the elasticity of the hydraulic fluid, connecting hoses, and other components in the system. In practice the changes were small, amounting to no more than a few percent of the initial load.

With the second machine, Fig. 3, load was applied by means of weights suspended from a lever arm. A motorized, screw driven translation stage was employed to move the flat. Except for some early tests, the screw driven machine was employed when loads less than $1500 \mathrm{~N}$ were required.

Both machines were equipped for measurement of displacement and friction force. Values of these quantities were recorded simultaneously during each test. It was therefore possible to plot friction force, or the derived friction coefficient values, as a function of sliding 


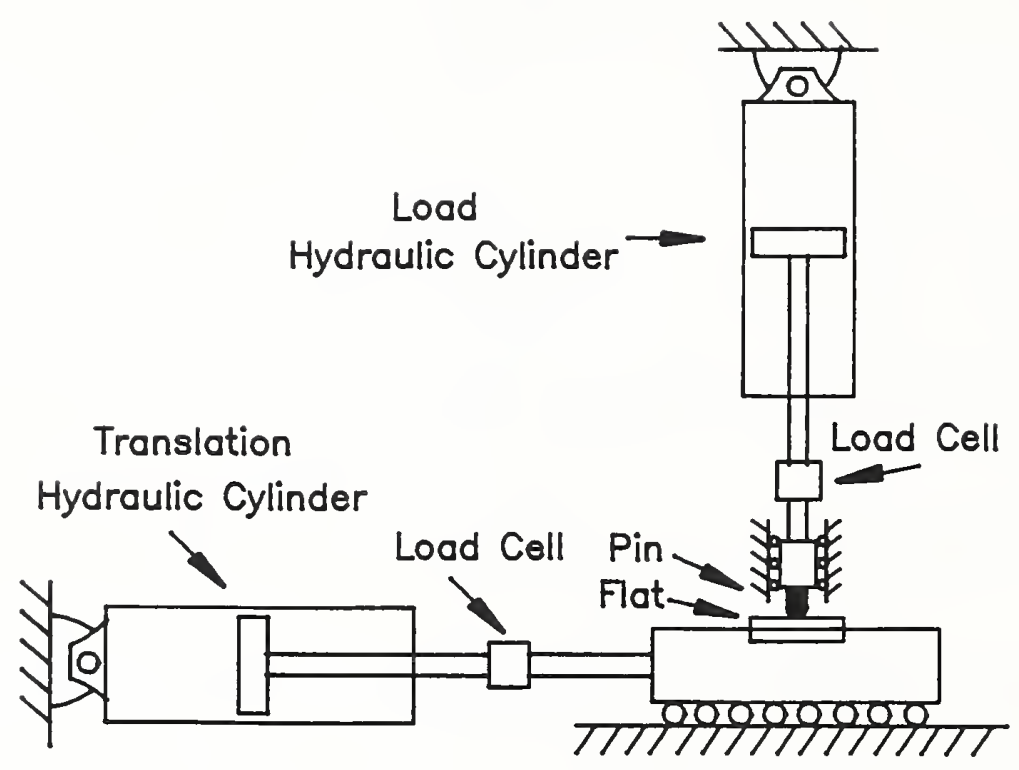

Fig. 2. Schematic drawing of hydraulically operated galling test machine.

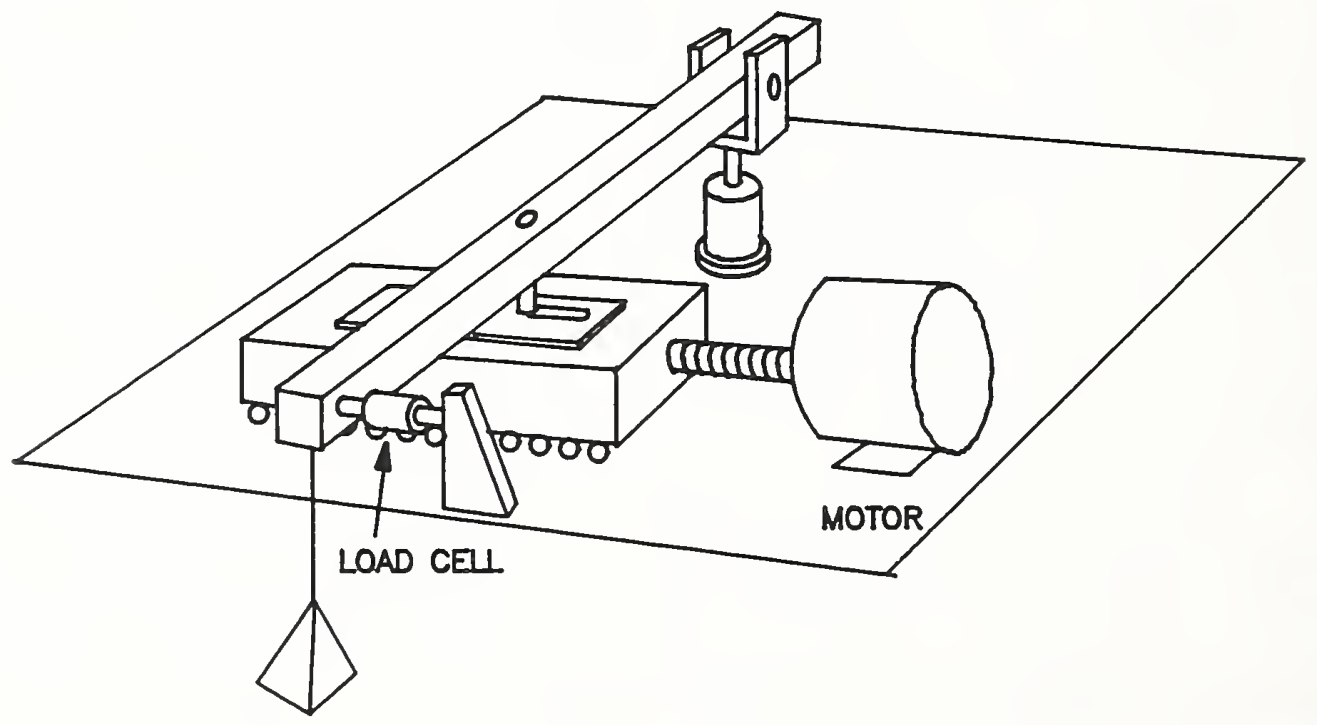

Fig. 3. Schematic drawing of screw-driven test machine with dead-weight loading. 
distance. As will be described later, the variations in friction force were also compared to variations in topography measured along the length of the track by means of stylus profilometry.

\subsection{Specimen Preparation}

Typical specimen dimensions are indicated in Fig. 4. A wide tolerance on the length and thickness of the flat was allowed; the actual dimensions within the prescribed size limits were determined by available stock material. When possible, stock material was acquired in the form of $12.7 \mathrm{~mm}$ ( $0.5 \mathrm{inch}$ ) diameter rod. Most commercial alloys are readily available in this form and machining of both flats and pins is easily accomplished.

PIN

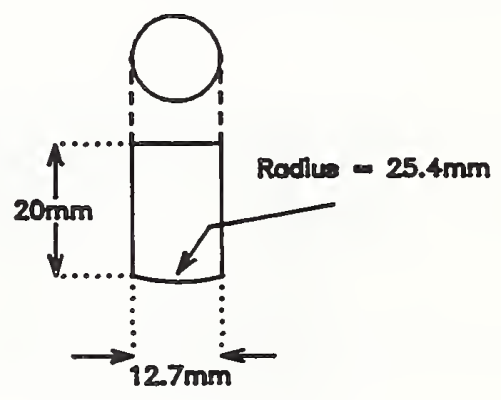

FLT

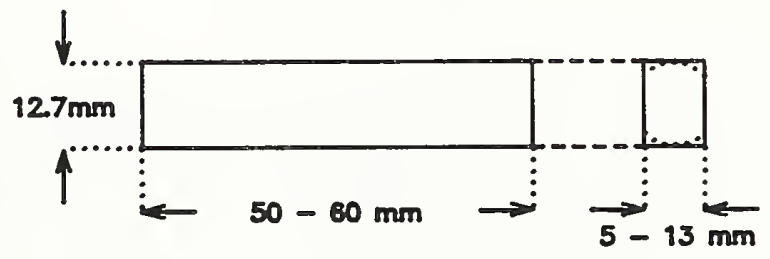

Fig. 4. Test specimens dimensions.

The condition of the contact surfaces can have a significant effect on galling behavior. For this reason considerable care was taken both in preparing the surfaces and cleaning the specimens prior to testing. For the majority of the tests the following standard procedure was adopted: The specimens were first machined to the required dimensions and the test surfaces were ground on water lubricated SiC 
abrasive papers starting with 240 grit and proceeding with 320,400 , and ending with 600 grit. Final polishing was done with $6 \mu \mathrm{m}$ diamond paste on a nylon cloth lap; mineral spirits was used as the lubricant. The cleaning procedure consisted of first swabbing the surfaces with cotton soaked in ethyl alcohol, and then ultrasonic agitation twice each in hexanes, acetone, and last in methyl alcohol. In general, the specimens were tested within a few minutes after cleaning. In some cases when surface treatments such as nitriding or carburizing were carried out, only final polishing with $6 \mu \mathrm{m}$ diamond compound was employed prior to cleaning. Also, some specimens were annealed after final finishing, and grinding on SiC abrasive paper was not repeated. Solvent cleaning was always performed except in a few experiments where the specimens were electropolished prior to testing.

The standard test conditions used for the majority of the specimens are briefly summarized in Table 1 below.

Table 1.

Standard test conditions

LOAD - - 130 to $6000 \mathrm{~N}$

SPEED - - $0.2 \mathrm{~cm} / \mathrm{s}$

DISTANCE - - $40 \mathrm{~mm}$

TEMPERATURE - - $22^{\circ} \mathrm{C}$

ATMOSPHERE -- - AIR (20-60\% R.H.)

SURFACE FINISH --- $6 \mu \mathrm{m}$ diamond polish

In evaluating the galling characteristics of a given material, for example, material $A$, the results can depend strongly on the properties of the material, $B$, against which it is slid. When $A$ and $B$ are the same, the term self-mated will be used. When they are different, the sliding couple will be referred to as nonself-mated. In an asymmetrical specimen arrangement, such as the pin-on-flat configuration use here, the outcome of a nonself-mated test will depend on which material, $A$ or $B$, is the pin and which is the flat. 


\section{DAMAGE MEASUREMENT METHOD}

As has already been pointed out, a major effort was mounted in this program to develop a suitable method for the quantitative characterization of galling damage. As was indicated, the approach involved the measurement of surface topography by means of stylus profilometry and the calculation of appropriate parameters to indicate the amount and nature of the damage. Measurement of the surface topography was done by means of an automated, computer-controlled profilometer system. A schematic diagram of the system is shown in Fig. 5. Details of the stylus and specimen translation arrangement are shown in Fig. 6 .

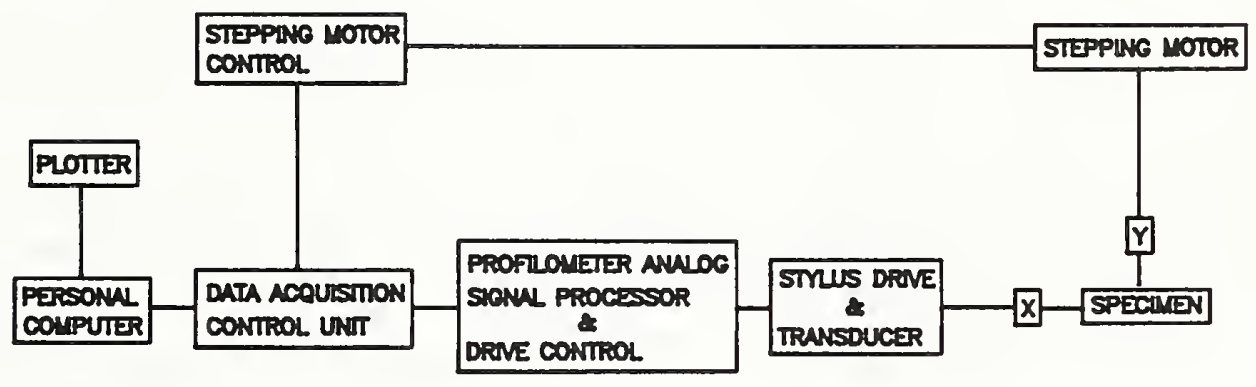

Fig. 5. Diagram of automated profilometer system.

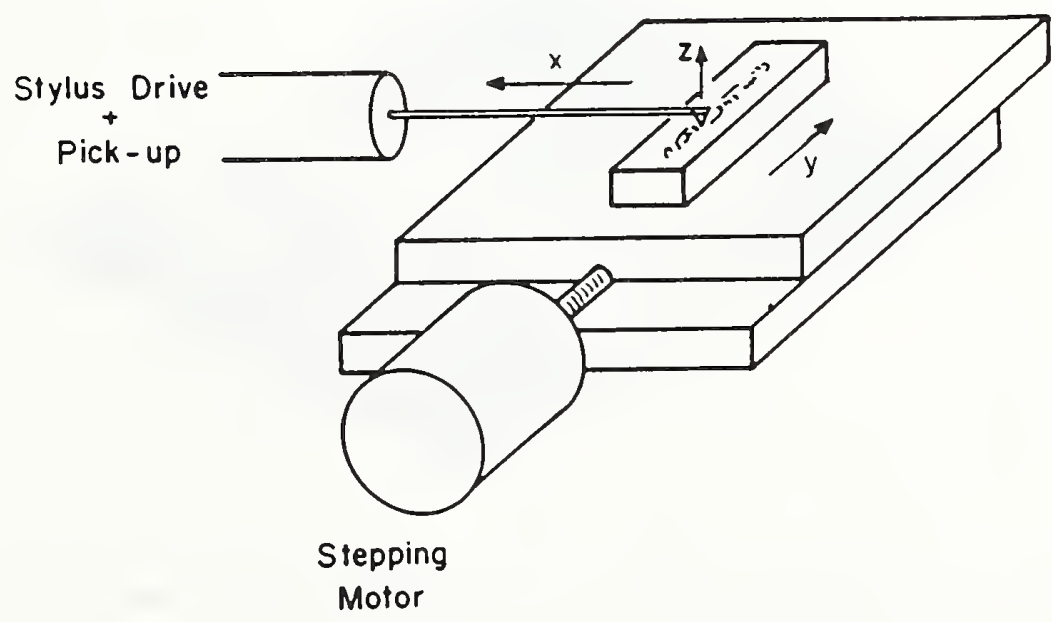

Fig. 6. Schematic drawing of profilometer stylus drive and specimen translation stage. 
With reference to Fig. 6 , the $x$-coordinate is assigned to the tracing direction of the stylus, $y$ to the direction of specimen translation (parallel to the track on the flat), and $z$ to the vertical direction indicating the height of topographic features. In conducting a measurement, the trace length, number of points per trace, and the spacing between traces are selected. Computer memory and software limitations restricted the total number of points that could be handled to about 27k. A typical track on a specimen-flat has a length of about $40 \mathrm{~mm}$ and width of $<3 \mathrm{~mm}$. Approximately 150 parallel traces at a spacing of $300 \mu \mathrm{m}$ are taken perpendicular to the track. The traces are allowed to extend beyond the edges of the track on both sides. The extra length is employed to establish the location of the original surface which acts as a reference plane in various computations. The spacing between points within a trace is normally set to $20 \mu \mathrm{m}$. An example of a traced track with the surface presented in an oblique projection, is shown in Fig. 7. Because of the relatively large spacing between traces the resolution along the length of the track is low. A small section of the track could, of course, be traced at much higher resolution. An example of a high resolution tracing is shown in Fig. 8 .

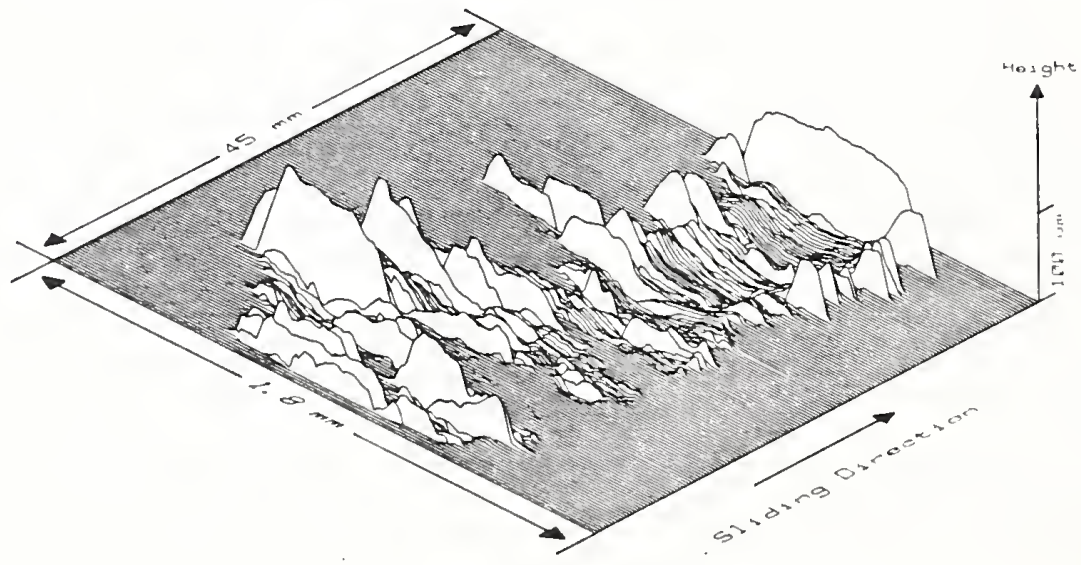

Fig. 7. Stylus profilometer traces showing topography of track on flat in oblique projection. 


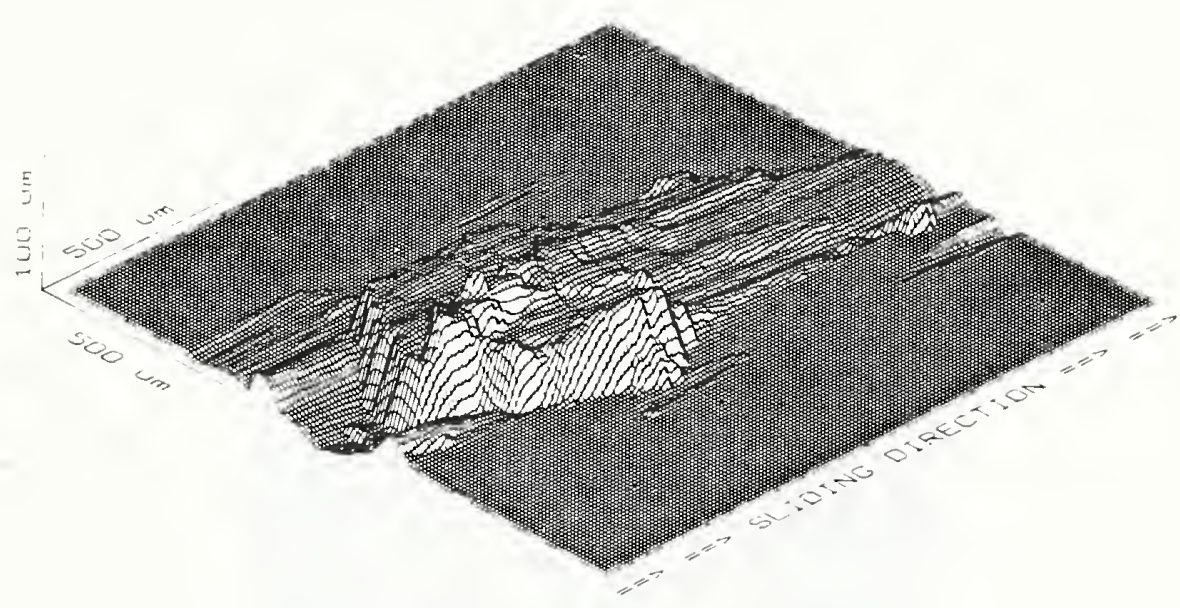

Fig. 8. High resolution tracing of damage on flat.

\subsection{Damage Parameters}

Topographic data were recorded in the form of a matrix of $z$-values as illustrated in Fig. 9. These values together with the constant incremental spacings $\Delta \mathrm{x}$ and $\Delta \mathrm{y}$ between points in the $\mathrm{x}$ - and $\mathrm{y}$-directions were the raw data describing the surface topography. In practice the surface plane of the flat was never precisely parallel to the $x y$-tracing plane. Once the data was collected, however, it was a relatively simple procedure to transform the original data so that the undamaged surface of the flat was coincident with the plane, $z=0$. Recalling that each trace across the wear track in the $x$-direction consists of points on either side of the track, a straight line was fitted to these bounding points. Subtracting this line from the original traced curve left $z$-values that indicated elevations above and below a $z=0$ plane. Calculations of the various damage parameters were based on these data. Errors will of course result if the original surface is not perfectly flat and smooth, as was always the case. For such surfaces $z$-values would represent original topography as well as changes due to sliding damage. For severely damaged, i.e., galled surfaces, the errors were not significant. However, when the damage was small, the errors could be relatively large, with some parameters being more sensitive than 


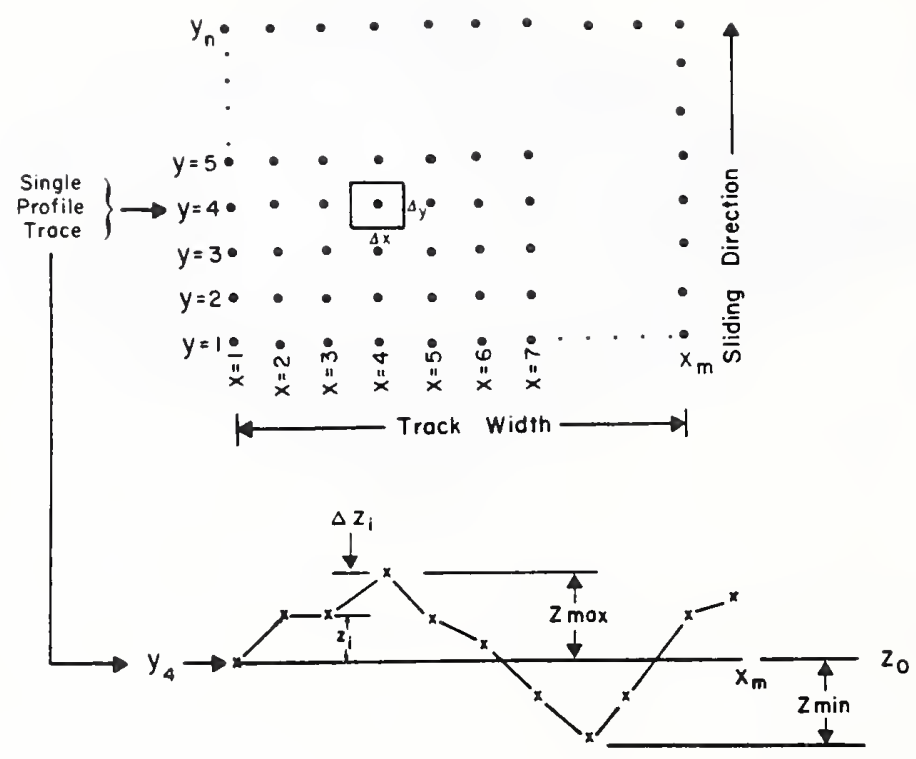

Fig. 9. Arrangement of profile data matrix used in the calculation of damage parameters.

others. One means of minimizing these errors was to confine the area of analysis as closely as possible to the sliding track. Thus in computing the volume above the $z=0$ plane, for example, curved or rough regions outside the track would not contribute. Since the track itself was often of quite variable and unpredictable width, a simple geometrical approach was not adequate. The means to restricting the region of analysis to the damaged area was by employing a computer graphics method. A map of the surface topography was displayed on the computer screen with different elevations coded by color. A program was written which allowed the damaged area to be outlined by moving the cursor. Data within the outlined region were retained for subsequent analyses. An example of a computer screen with elevations represented by different grey levels is shown in Fig. 10a. The outlined region, chosen because of a recognizable pattern of elevation change associated with damage, is shown in Fig. $10 \mathrm{~b}$. 

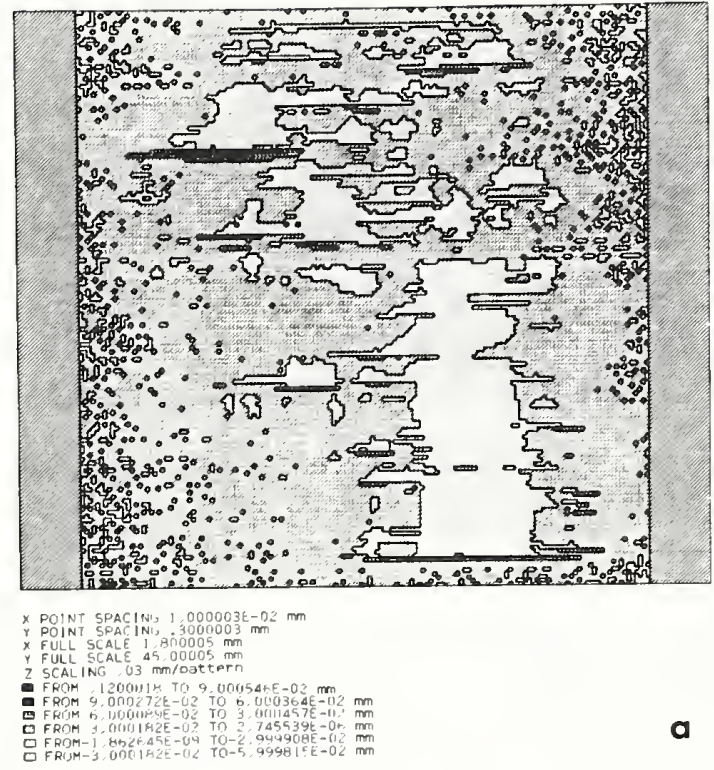

a
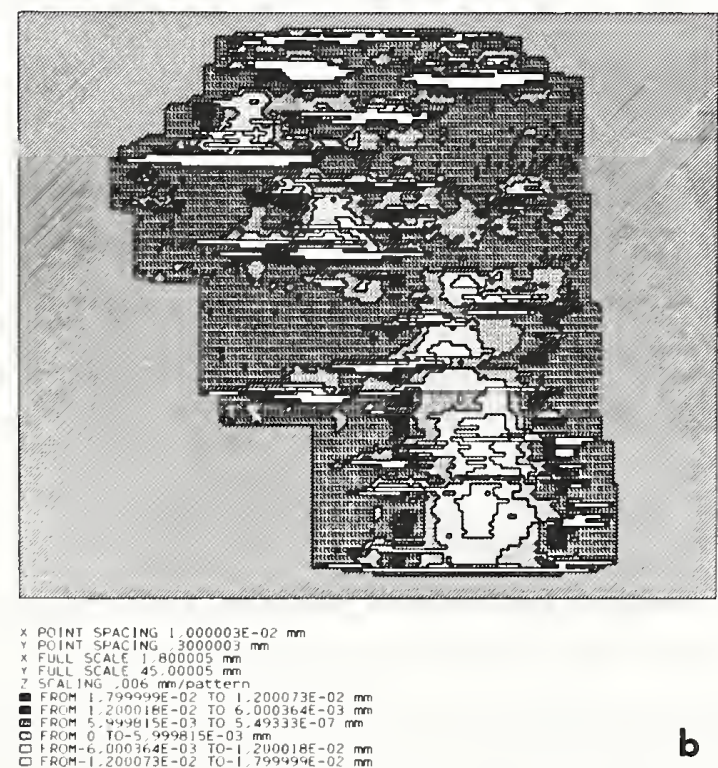

b

Fig. 10. Representation of surface topography shown on computer screen

(a) after transforming to "zero-level" reference plane and (b) area selected for parameter determination. 
A number of parameters were derived for the characterization of damage. A detailed discussion of these can be found in whitenton et al. [3]. A list of the parameters and their defining equations that have been found to be most useful is given below:

$$
\begin{aligned}
& \text { Average Maximum Peak-to-Valley, } \\
& \qquad \bar{R}_{t}=(1 / n) \Sigma\left(R_{t}\right)_{j} \quad(j=1 \text { to } n) \\
& \text { Root-mean-square of } R_{t} \\
& \qquad R_{t} \text { (rms) }=\sqrt{\frac{\Sigma\left[\left(R_{t}\right)_{j}-R_{t}\right]^{2}}{n}}
\end{aligned}
$$

Displaced Volume,

$$
D V=\Delta x \Delta y \underset{j=1}{n} \sum_{i=1}^{m}\left|z_{i j}\right|
$$

Aspect Ratio,

$$
A R=\frac{\Delta x \sum_{i=1}^{m} \sum_{j=1}^{n-1}\left|z_{i j}-z_{i, j+1}\right|}{\Delta y \sum_{j=1}^{n} \sum_{i=1}^{m-1}\left|z_{i j}-z_{i+1, j}\right|}
$$

In these equations $\mathrm{n}$ indicates the total number of traces taken across the wear track and $m$ is the number of points in each trace. Also, $x$ is in the trace direction, $y$ is parallel to the track, and $z$ is the distance above or below the original surface plane as already defined above. $R_{t}$ is the maximum peak-to-valley distance determined for each trace.

The significance of the parameters defined above may be summarized as follows: The average maximum peak-to-valley parameter, $\bar{R}_{t}$, is the average value of the maximum peak-to-valley distances for the $\mathrm{n}$ traces taken across the wear track. This parameter reflects the importance of the large lumps and deep gouges that are characteristic of galling. 
The root-mean-square (rms) average of the $R_{t}$ values also reflects the importance of the highest peaks and deepest valleys. However, in some cases the damage may consist of a single relatively smooth groove in the surface. This is most likely to occur when the flat is highly resistant to galling and the slider is harder than the flat. Here, plowing rather than galling is likely to occur. For such a track, $\bar{R}_{t}$ might be the same as for a track that consisted of lumps and gouges associated with galling. $R_{t}$ (rms), on the other hand, would tend to be small for the smooth groove and large for the irregularly roughened, galled surface.

The displaced volume parameter, DV, is the sum of the volumes of the peaks above the original surface and of the valleys below the surface. When the peak and valley volumes are compared separately, an indication of the amount of transfer that has taken place can sometimes be obtained. [4]

While the above parameters are used primarily to indicate the magnitude or severity of the damage, the aspect ratio parameter, $A R$, provides a measure of the average shape of the surface topographic features with respect to the sliding direction. A value of $A R \quad<1$ would be obtained if the damage consisted predominately of long grooves or ridges parallel to the sliding direction. A value $>1$ would indicate a predominance of features elongated perpendicular to the sliding direction, and $A R=1$ would be obtained for equiaxed features or a balance of the other features. In practice AR was always less than 1.

In addition to computing the above parameters for the entire track, values also could be determined as a function of sliding distance.[3] In this way it was possible, for example, to compare variations in one of the damage parameters with corresponding changes in friction coefficient, revealing the relationship between these variables.

\section{GALLING OF PURE METALS}

The galling behavior of twelve different pure metals was studied. The metals, together with some important properties, are listed in Table 2. Included are four fcc metals ( $\mathrm{Ag}, \mathrm{Al}, \mathrm{Cu}, \mathrm{Ni}$ ), four bcc metals ( $\mathrm{Fe}, \mathrm{Mo}, \mathrm{Nb}, \mathrm{Ta}$ ), and four hcp metals (Co, $\mathrm{Mg}, \mathrm{Ti}, \mathrm{Zn}$ ). The 
last column in the table gives the critical Hertz load for each metal. This is the load, computed from the Hertz equations for a spherical indentor, at which the maximum shear stress occurring at a depth of about one half the radius of the contact circle below the surface just equals the yield stress of the material.[5]

For each test in this series the pin and flat were of the same material (self-mated test). In a later series, nonself-mated tests

Table 2.

Pure metals and properties.

\begin{tabular}{|c|c|c|c|c|c|c|}
\hline Metal & $\begin{array}{l}\text { Purity } \\
\text { (wt. } 8 \text { ) }\end{array}$ & $\begin{array}{c}\text { Crystal } \\
\text { Structure }\end{array}$ & $c / a$ & $\begin{array}{c}\text { Hardness } \\
\left(\mathrm{kg} / \mathrm{mm}^{2}\right)\end{array}$ & $\begin{array}{l}\text { Elastic } \\
\text { Modulus } \\
\left(\mathrm{Kg} / \mathrm{mm}^{2}\right)\end{array}$ & $\begin{array}{c}\text { Critical } \\
\text { Hertz } \\
\text { Load } \\
(\mathrm{N})\end{array}$ \\
\hline $\mathrm{Ag}$ & 99.999 & fcc & 1.633 & 44 & $7.7 \mathrm{E} 3$ & 14 \\
\hline $\mathrm{Al}$ & 99.99 & $f c c$ & 1.633 & 28 & $7.4 \mathrm{E} 3$ & 9.7 \\
\hline $\mathrm{Cu}$ & 99.99 & $f c c$ & 1.633 & 123 & $12.3 \mathrm{E} 3$ & 30 \\
\hline $\mathrm{Ni}$ & 99.5 & $f c c$ & 1.633 & 318 & $21.4 \mathrm{E} 3$ & 55 \\
\hline $\mathrm{Fe}$ & 99.98 & $\mathrm{bcc}$ & - - & 179 & $21.1 \mathrm{E} 3$ & 31 \\
\hline Mo & 99.5 & $b c c$ & -- & 259 & $29.5 \mathrm{E} 3$ & 36 \\
\hline $\mathrm{Nb}$ & 99.9 & $\mathrm{bcc}$ & - & 108 & $10.5 \mathrm{E} 3$ & 29 \\
\hline $\mathrm{Ta}$ & 99.9 & bcc & - - & 182 & $19.0 \mathrm{E} 3$ & 34 \\
\hline $\mathrm{Ti}$ & 99.2 & hcp & 1.587 & 216 & $11.2 \mathrm{E} 3$ & 57 \\
\hline Co & 99.998 & hcp & 1.624 & 243 & $21.1 \mathrm{E} 3$ & 43 \\
\hline $\mathrm{Mg}$ & 99.95 & hcp & 1.624 & 34 & $4.6 \mathrm{E} 3$ & 16 \\
\hline $\mathrm{Zn}$ & 99.995 & hcp & 1.856 & 45 & $9.8 \mathrm{E} 3$ & 12 \\
\hline
\end{tabular}

were conducted on some of the pure metals. Those results are described in the next section. The specimen surfaces were prepared in the standard way with respect to finishing and cleaning. The applied load was 130 N. It may be noted that for all of the metals this load is considerably greater than the critical Hertz load listed in Table 2. As a consequence, bulk plastic deformation is expected to have occurred on application of the load, even before sliding commenced. Figure 11 shows the sliding damage on a flat of each of the pure metals. As displayed in the figure, sliding began at the top of the flat and was terminated after a single stroke at the bottom.

Although the pattern of damage differs in detail among the various fcc and bcc metals, all exhibit features that are characteristic of galling and are consistent with the wedge formation process described 


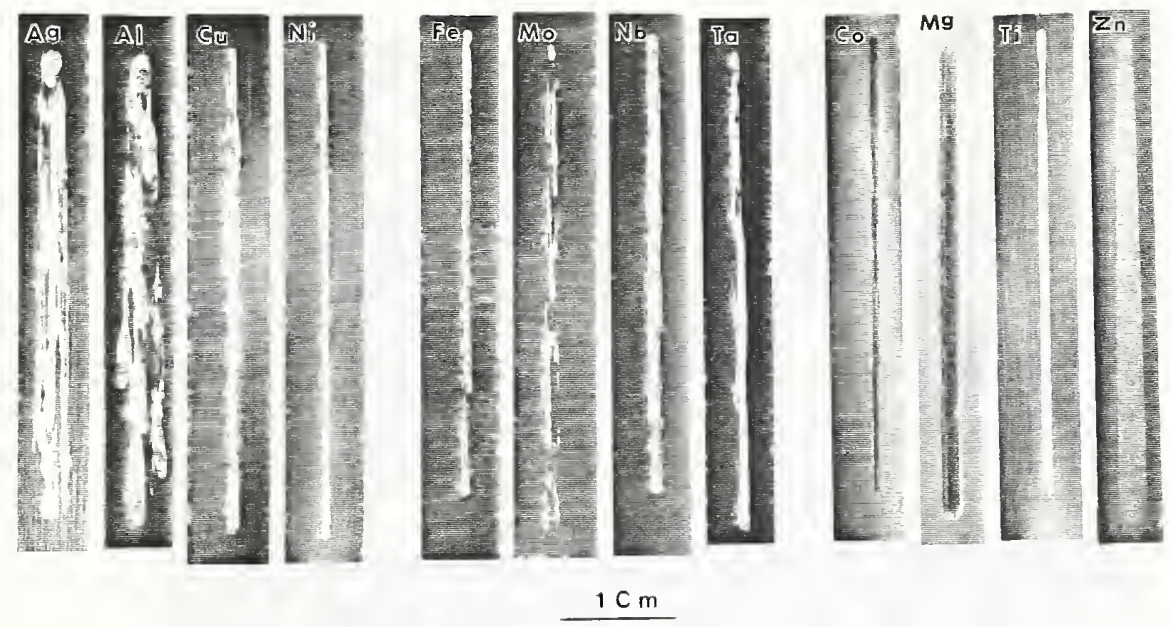

Fig. 11. Flats of 12 different pure metals after self-mated tests at $130 \mathrm{~N}$.

by Cocks $[6,7]$. (The descriptive term "prow" is now commonly used instead of "wedge".) A detailed discussion of the prow formation process is presented in Section 10 on the mechanism of galling. However, to illustrate the process here, SEM micrographs of damage features are shown for one of the metals, Fe, in Figs. 12 - 16. Similar features were observed in this investigation for all metals that exhibited galling.

Figure 12 shows the initial part of the track on the Fe flat. The damage can be accounted for as follows: As sliding commenced, a volume of material within the flat lying beneath the pin was plastically deformed and displaced to form a prow. Sliding took place by a shearfracture process, accumulating material into the prow. With continued sliding the prow grew in size, both forward of the pin and perpendicular to the surface. This increase in size, together with strain hardening, resulted in the eventual, partial failure of the prow, leaving the raised lip seen in Fig. 12. The remaining part of the prow was still attached to the pin. The prow growth and failure process was then repeated as the pin moved along the flat. Figure 13 shows three lips approximately one-half centimeter from the beginning of the track occurring as a result of three repetitions of prow growth and failure. In some cases nearly the entire prow was left in the track. This is 


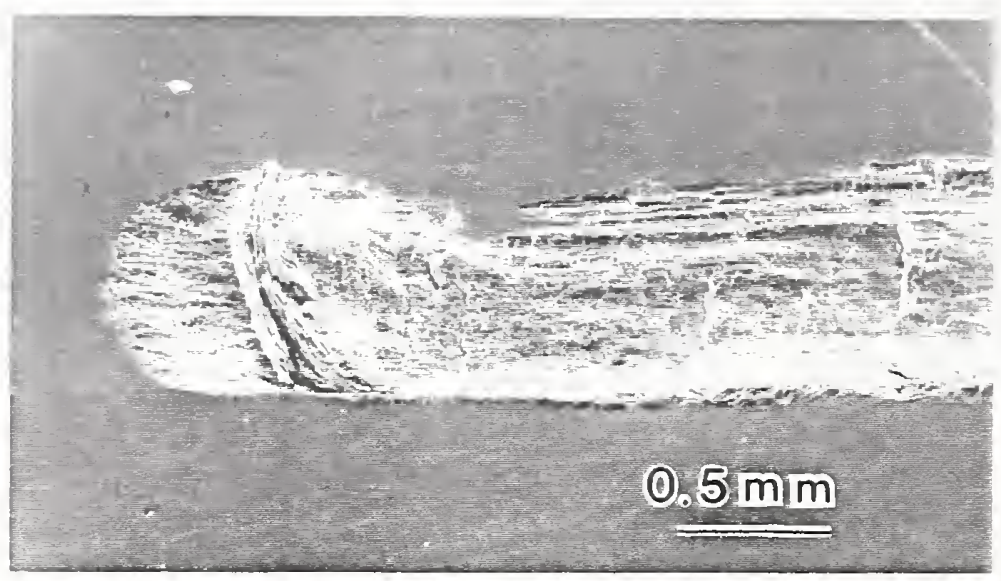

Fig. 12. SEM micrograph of initial section of galled track on Fe flat. $130 \mathrm{~N}$ load.

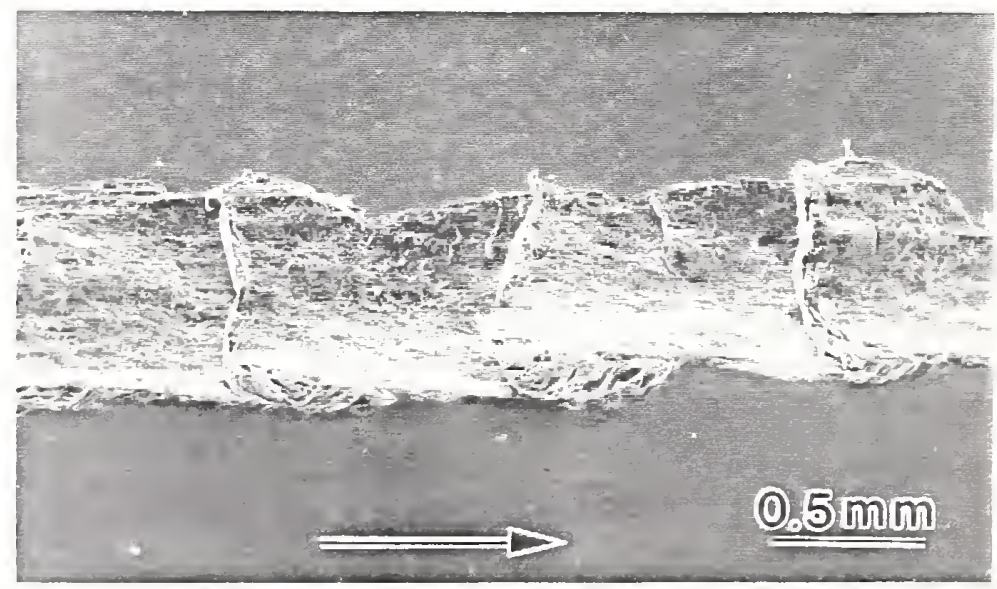

Fig. 13. Damage at approximately one-half centimeter from beginning of track on Fe flat. 


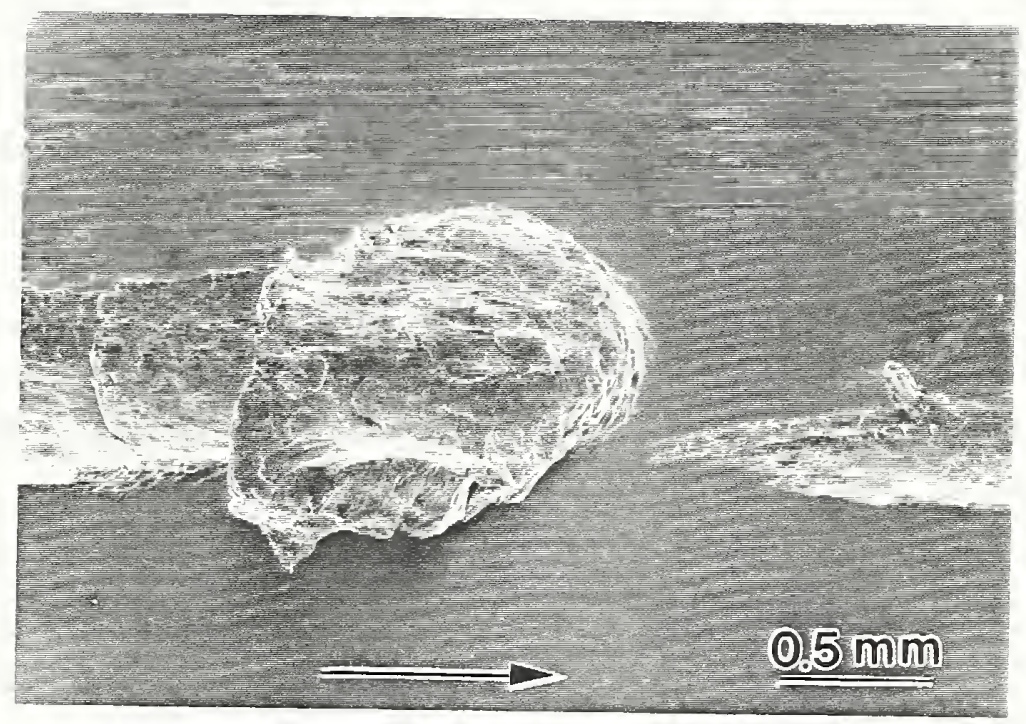

Fig. 14. Prow located $3 \mathrm{~cm}$ from start of track on Fe flat.

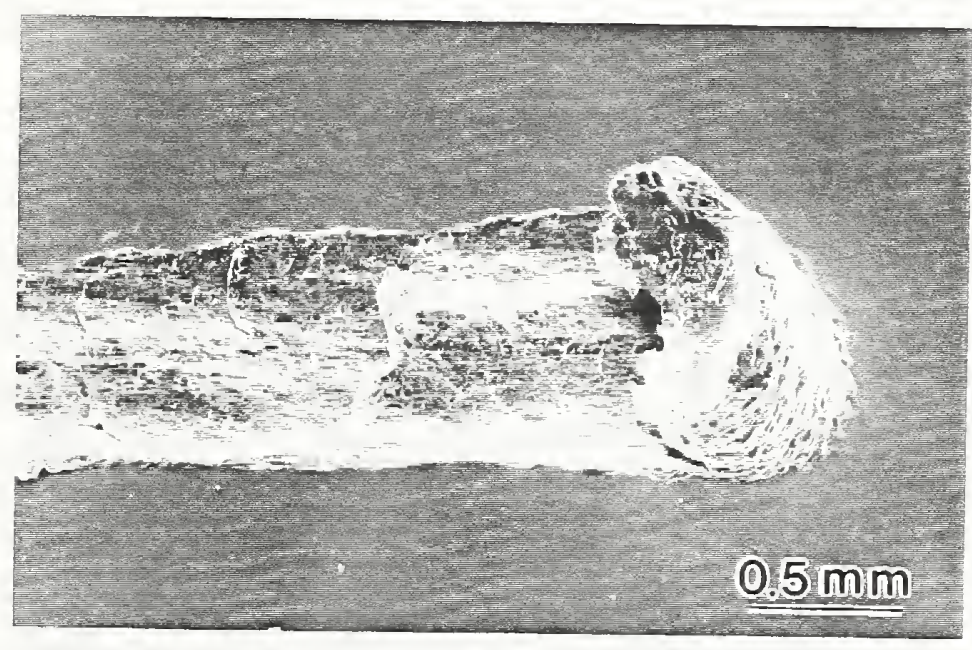

Fig. 15. Prow at the end of the track on Fe flat. 
illustrated in Fig. 14. Here, the pin broke away from the prow and slid across it; contact with the surface of the flat was made a short distance beyond the prow leaving a small gap in the track. With some specimens there were many of these prow-and-gap features along the $40 \mathrm{~mm}$ length of the track while with others there were none.

Figure 15 shows the prow left at the end of the track on the Fe flat when sliding was terminated. The presence of ridges at the front of the prow suggests that the prow consists of layers and was formed in a way that is characteristic of chip formation in machining with a tool having a high negative rake angle.

During sliding the material towards the front of the prow will be under compression, while material at the rear may experience a tensile stress. Evidence of a tensile state of stress is indicated by the observation of surface topography having a dimple-like structure. An example of this dimple structure is shown in Fig. 16. The fracture surfaces of ductile metals which fail in tension typically exhibit a dimple structure.

The above discussion has focussed on the damage topography of the flat. The pin in these self-mated tests also sustained considerable damage. In some cases a prow formed simultaneously on both the pin and flat. The prow on the pin was torn away and left attached to the prow on the flat. An example of this behavior can be seen in Fig. 17 showing the initial part of the track on the Mo flat. Having been damaged in this way, the tip of the pin was no longer spherical, and, of course, the subsequent shape of the track was affected correspondingly (see photograph of Mo flat in Fig. 11).

Damage to the hcp metals was significantly less than for the fcc and bcc metals, and in two cases, $\mathrm{Mg}$ and $\mathrm{Co}$, there was almost no evidence of galling. Very small prows were present at the beginning of the track, but thereafter the track was smooth without prows. Figure 18 is an optical micrograph of a portion of the track on a Co specimen. This specimen is not shown in Fig. 11 but was a specimen that had been electropolished prior to testing to better reveal the extent and details of the damage. The micrograph in Fig. 18 was taken under Nomarski interference contrast conditions to display the slight variations in topography. The damage 


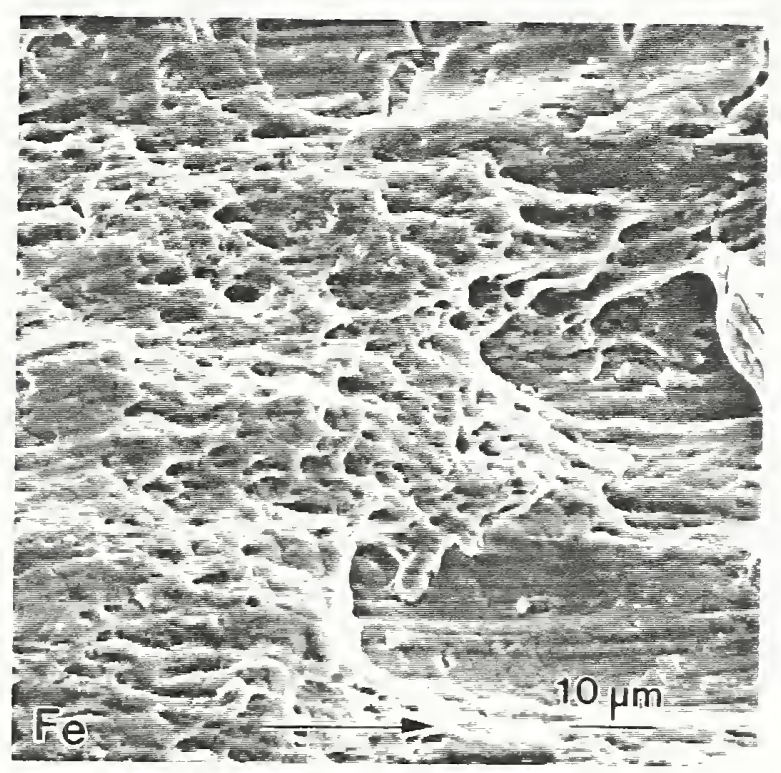

Fig. 16. Dimple structure in track on Fe flat.

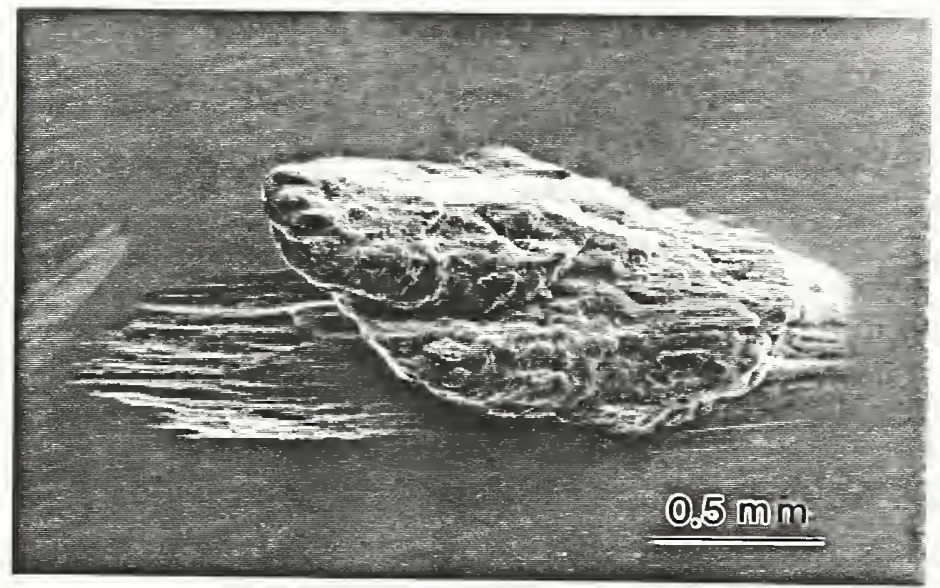

Fig. 17. Initial damage on Mo flat. 
consists of very fine, smooth, alternating grooves and ridges parallel to the sliding direction. A small amount of grain relief was also present and this is visible in the micrograph. Even when a test was conducted at a load of $1400 \mathrm{~N}$ (compared to $130 \mathrm{~N}$ for Fig. 18), the surface was essentially the same as that shown in Fig. 18.

Although the damage was less than for $\mathrm{fcc}$ and bcc metals, both Ti and $\mathrm{Zn}$ were found to gall. For $\mathrm{Ti}$ the damage was quite similar to that observed with the $\mathrm{fcc}$ and $\mathrm{bcc}$ metals. For $\mathrm{Zn}$ the damage was not only very small but differed somewhat in character from the other metals that exhibited galling. A SEM micrograph of a section of the track on the $\mathrm{Zn}$ specimen is shown in Fig. 19. The damage consists of numerous small prows rather than a few large prows. Each prow was sustained for

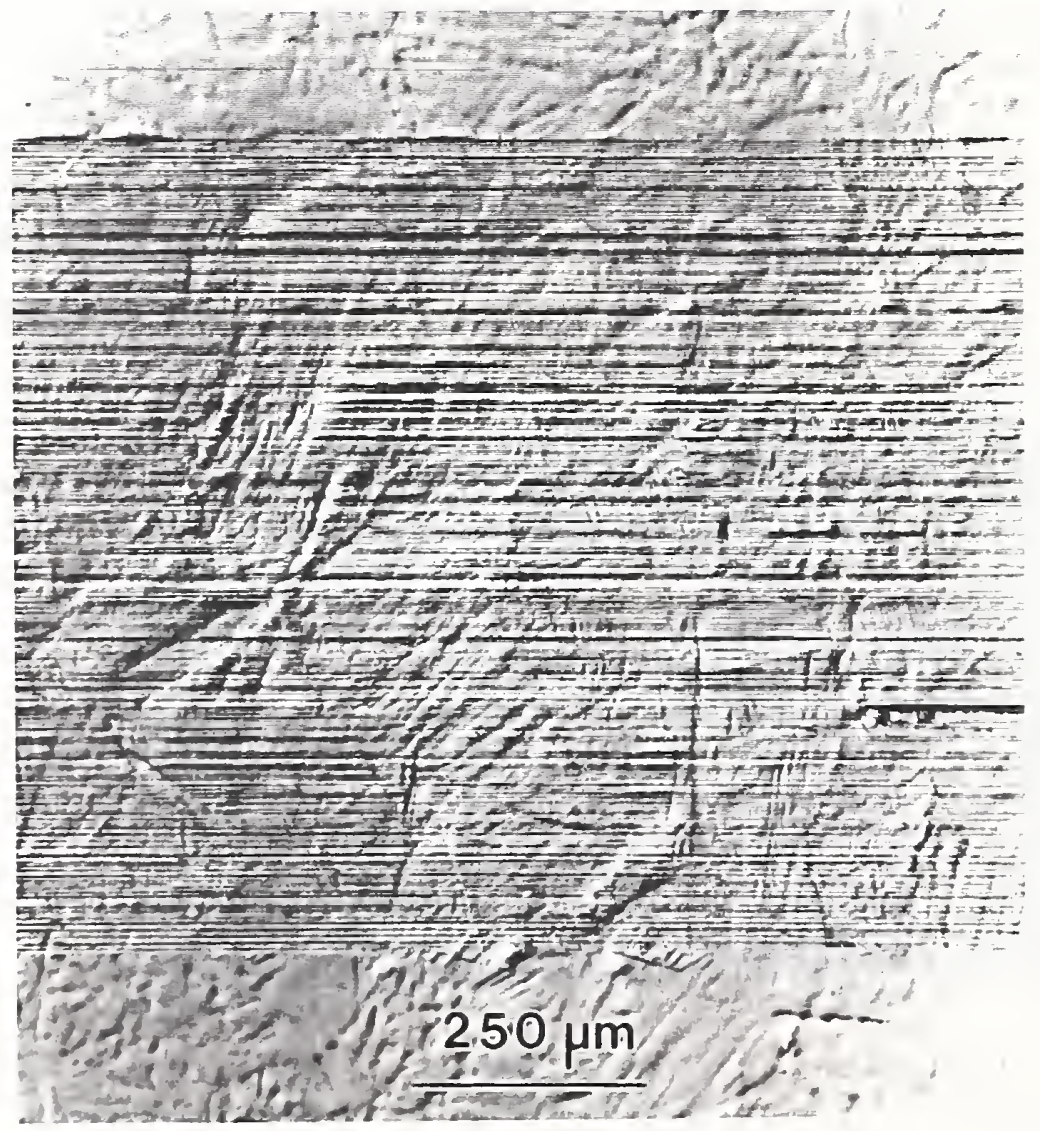

Fig. 18. Optical micrograph of part of track on Co flat. Nomarski interference contrast. 


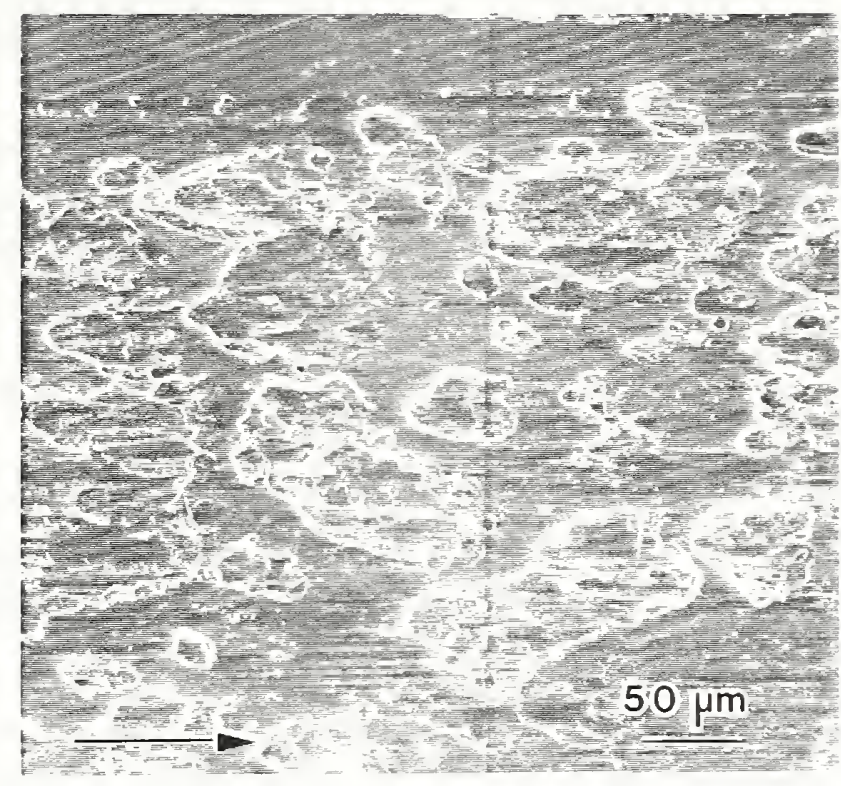

Fig. 19. SEM micrograph of section of track on $\mathrm{Zn}$ flat.

only a short distance during sliding and was then left behind. The process appeared to have occurred simultaneously on both flat and pin.

In Fig. 20, damage severity, indicated by the average maximum peak to valley parameter, $\bar{R}_{t}$, is plotted as a function of hardness for all the pure metals studied. It is clear that there is no overall correlation between damage severity and hardness. The $\bar{R}_{t}$ value for $A l$ is very high while that for $\mathrm{Mg}$ is quite low, despite the fact that $\mathrm{Mg}$ is nearly as soft as Al. Similarly, the Mo and Co specimens differ only slightly in hardness but have significantly different $\bar{R}_{t}$ values. In connection with these data it should be pointed out that all specimens were tested in the as-received condition. The grain sizes and amount of work hardening introduced during processing were not all the same. Both of these factors could have some affect on individual damage severities but not enough to change the general relationship with respect to hardness.

The main factor which appears to influence galling severity among these metals is crystal structure. The damage severity for the hcp metals is, in all cases, lower than for the $\mathrm{fcc}$ and $\mathrm{bcc}$ metals, although for Ti it is only slightly lower. Ti differs from the other hcp metals 
studied in that the lowest critical resolved shear stress is on the pyramidal planes rather than on the basal plane.

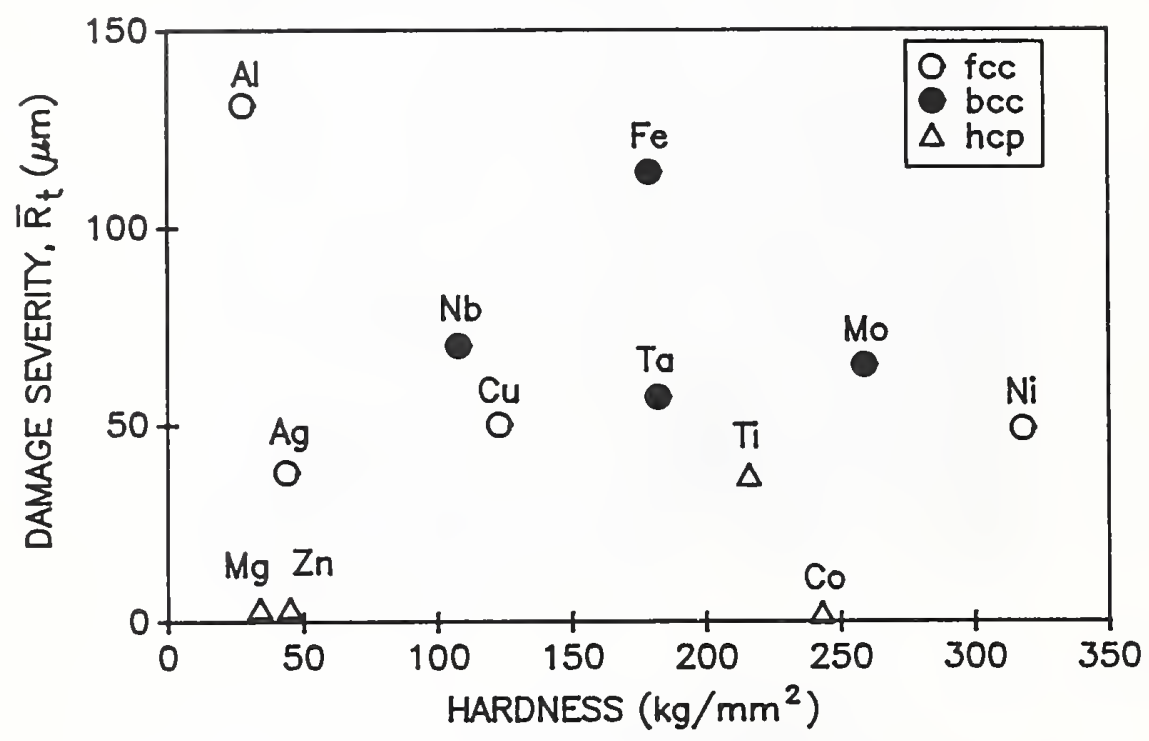

Fig. 20. Damage severity measured in terms of $\bar{R}_{t}$ plotted as a function of hardness for pure metal specimens.

\section{GALLING OF NONSELF-MATED PURE METALS}

"Compatibility" is often cited as being an important criteria in selecting sliding materials to achieve a relatively low coefficient of friction, to avoid severe wear, and to prevent galling. To a first approximation, compatible materials are those that are highly soluble in one another. Incompatible materials, on the other hand, exhibit little or no mutual solubility. The compatibility concept is based on the adhesive theory of wear. Following that theory it may be reasoned that materials which are mutually soluble will adhere strongly or cold weld when brought into contact, and consequently, during sliding will exhibit high coefficients of friction and correspondingly high wear rates. In contrast, insoluble couples will show little tendency to adhere, and therefore the coefficient of friction and wear rate for these will be low. Although the compatibility criteria has been found to hold in some limited studies, more complete evaluations have revealed notable 
exceptions. Thus, the criteria was made more restrictive. For example, incompatible materials were not only considered to be those that are insoluble, but an additional constraint required that one member of the sliding pair must come from the B-subgroup in the periodic table of elements. [8] When a broad range of materials are considered, incompatibility may be a sufficient condition for low friction and low wear, but it is not a necessary condition. For example, it has already been demonstrated here that many hexagonal-close-packed metals exhibit low damage severities, with cobalt being a most notable example. Also, in the next section it will be demonstrated that metals with low stacking fault energies exhibit low coefficients of friction and are highly resistant to galling. This occurs for self-mated couples, i.e. for couples that are completely soluble and therefore ideally compatible.

In an investigation of the galling behavior of nonself-mated pure metals, the influence of a variety of different properties could be considered. In fact, a rather large matrix can be constructed of different combinations of properties, for example, hard vs. soft metals, hexagonal-close-packed vs. face-centered-cubic metals, etc. In principle one would like to demonstrate the effect of varying a single property while all others remain the same for the metals selected. This, of course, is not possible, since the pair of metals chosen will almost certainly differ with respect to several properties and not just one. This difficulty is encountered in the investigation of the effect of stacking fault energy: Not only does the stacking fault energy change with alloying but also the hardness and many other properties as well are affected. Thus, it is necessary to study a number of different alloys, to obtain convincing evidence of the influence of a given property. Bearing this in mind, pure metal combinations were chosen for galling experiments which were considered to offer the best opportunity to demonstrate the effect of the selected properties. Finally, in addition to bulk properties, one must always be aware of the importance of surface effects, especially those associated with oxide and contaminant films, which can have a significant influence on galling response.

Table 3 lists the metal combinations studied. Galling tests were conducted at an applied load of $130 \mathrm{~N}$ using the standard preparation 
conditions. Except as indicated, all specimens were tested in the annealed state. Among the group of metals listed in Table 3, Co was selected because it showed the least damage of all the pure metals studied under

Table 3. Metal combinations tested.

$\begin{array}{lr}\frac{\mathrm{Pin}}{{ }^{*} \mathrm{Ni}} & \frac{\text { Flat }}{{ }^{*} \mathrm{Cu}} \\ { }^{*} \mathrm{Cu} & { }^{*} \mathrm{Ni} \\ \mathrm{Ag} & \mathrm{Ni} \\ \mathrm{Ag} & \mathrm{Co} \\ \mathrm{Cu} & \mathrm{Co} \\ { }^{*} \mathrm{cold} \text { drawn } & \end{array}$

self-mated conditions; essentially, it did not gall. The remaining metals $\mathrm{Cu}, \mathrm{Ni}$, and $\mathrm{Ag}^{-}$all exhibited severe galling in self-mated tests.

$6.1 \mathrm{Cu}$ vs. $\mathrm{Ni}$

$\mathrm{Cu}$ and $\mathrm{Ni}$ are compatible metals; that is, they are mutually soluble, and in fact form a solid solution over the entire range of concentrations. They differ, however, in that $\mathrm{Ni}$ is considerably harder than $\mathrm{Cu}$. For this pair of metals, tests were conducted with both a $\mathrm{Cu}$ pin sliding against a $\mathrm{Ni}$ flat and for the reverse combination, a $\mathrm{Ni}$ pin against a $\mathrm{Cu}$ flat. Photographs of the flats from these two permutations are shown in Fig. 21. Damage to the two flats differs both on a large scale and microscopically. The track on the Ni flat, Fig. 21a, becomes wider with increasing sliding distance while the track on the $\mathrm{Cu}$ flat, Fig. $21 \mathrm{~b}$, decreases in width.

SEM micrographs of the beginning and end sections of the tracks on the $\mathrm{Ni}$ and $\mathrm{Cu}$ flats are shown in Fig. 22. Figure 23 shows micrographs of the mating pin tips. For the Ni flat, Figs. 22a and b, the visible damage is due entirely to transfer from the $\mathrm{Cu}$ pin. In the optical microscope the copper color of the transferred metal is quite apparent. Transfer from the pin, of course, explains why the width of the track on the $\mathrm{Ni}$ flat increases with increasing sliding distance. As the spherical tip on the pin is worn away, the contact diameter becomes 


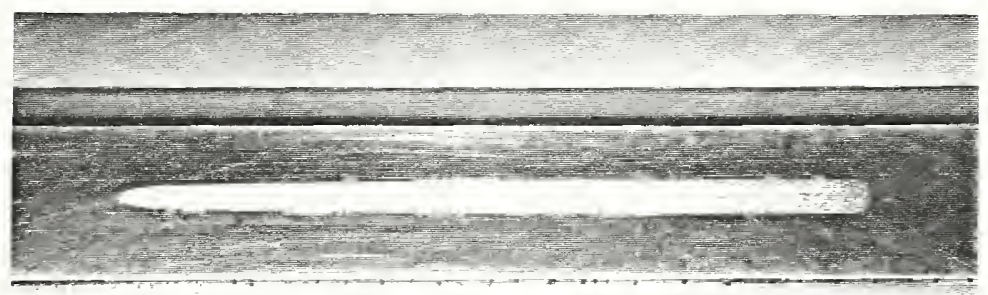

a

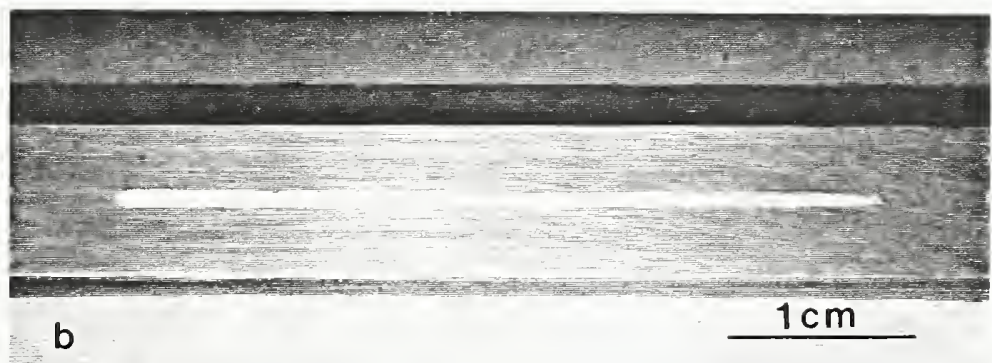

Fig. 21. Optical photographs of (a) Ni flat against which $\mathrm{Cu}$ pin was slid and (b) $\mathrm{Cu}$ flat against which a $\mathrm{Ni}$ pin was slid. Sliding was initiated at the left.

larger, finally reaching the size shown in Fig. 23a. At the beginning of the track, Fig. 22a, the $\mathrm{Ni}$ surface is almost entirely overlaid with a layer of transferred $\mathrm{Cu}$. At the end of the track, however, only isolated patches of $\mathrm{Cu}$ in the form of small prows are seen. This is shown at higher magnification in Fig. 24 where fine scratches from polishing identify the original $\mathrm{Ni}$ surface.

When a $\mathrm{Ni}$ pin was slid against a $\mathrm{Cu} f l a t$, initially, damage to the $\mathrm{Cu}$ flat, Fig. 22c, appears to consist of a series of relatively small, parallel grooves. Examination at higher magnifications indicated that the grooves were produced by the motion of small prows. Several of the prows are shown in Fig. 25. At the end of the track on the Cu flat, Fig. 22d, a single rather large prow is present. No such prow was formed at the end of the track on the $\mathrm{Ni}$ flat, Fig. 22b. With the Ni pin vs. $\mathrm{Cu}$ flat arrangement, $\mathrm{Cu}$ is transferred to the pin. Thus, the damage to the $\mathrm{Ni}$ pin seen in Fig. 23b is actually a layer of transferred $\mathrm{Cu}$. In this case, shortly after sliding is initiated, contact is mainly $\mathrm{Cu}$ against $\mathrm{Cu}$. During the course of sliding, $\mathrm{Cu}$ is both accumulated 

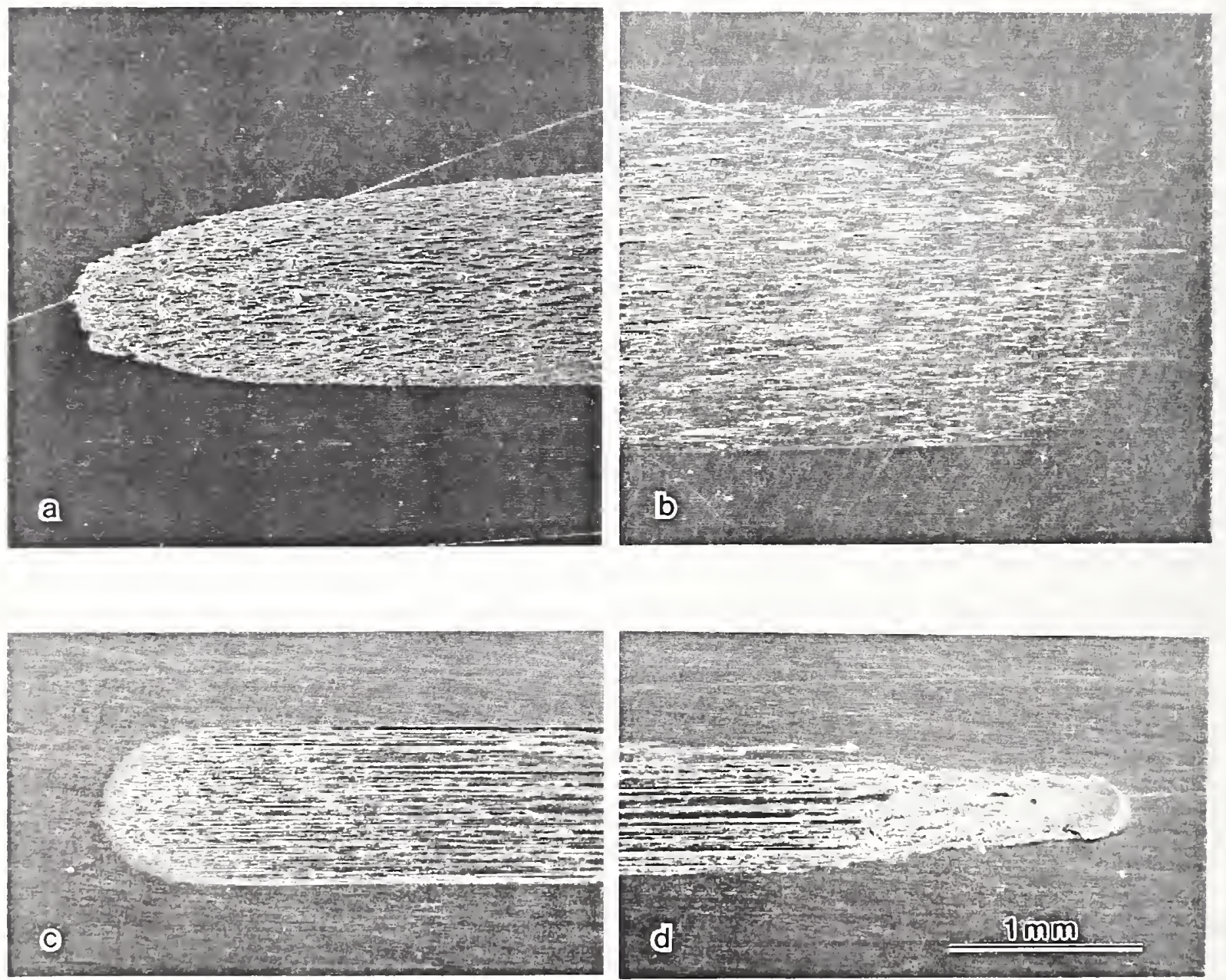

Fig. 22. SEM micrographs showing (a) start and (b) end sections of track on $\mathrm{Ni}$ flat against which $\mathrm{Cu}$ pin was slid and (c) start and (d) end of track on $\mathrm{Cu}$ flat against which $\mathrm{Ni}$ pin was slid. 

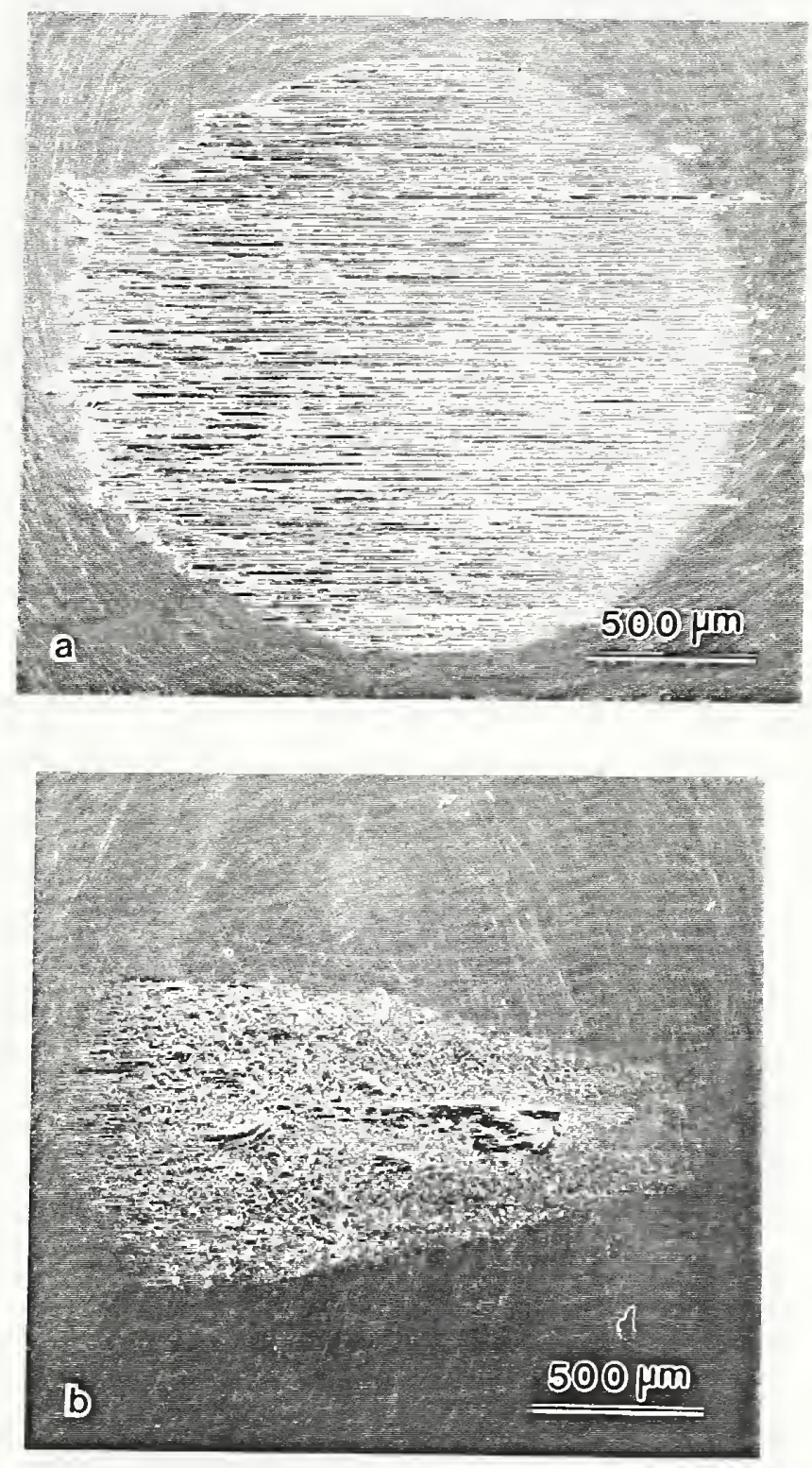

Fig. 23. SEM micrograph of scar on (a) Cu pin after sliding against Ni flat and (b) Ni pin after sliding against $\mathrm{Cu}$ flat. Leading edge is at right. 


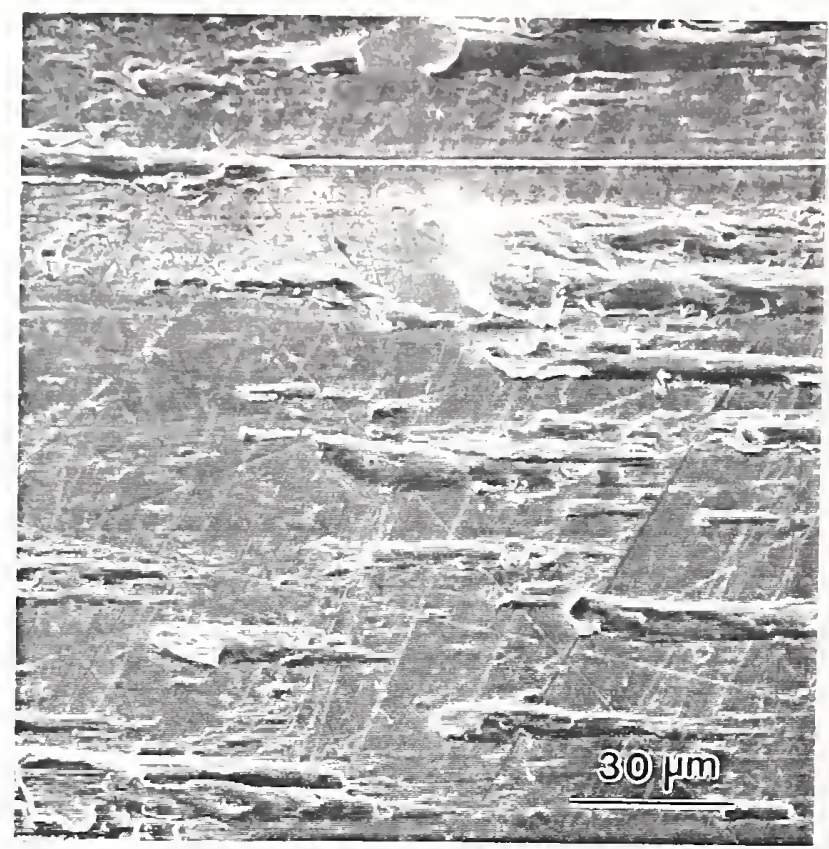

Fig. 24. SEM micrograph of damage on $\mathrm{Ni}$ flat. Direction of motion of Cu pin was from left to right.

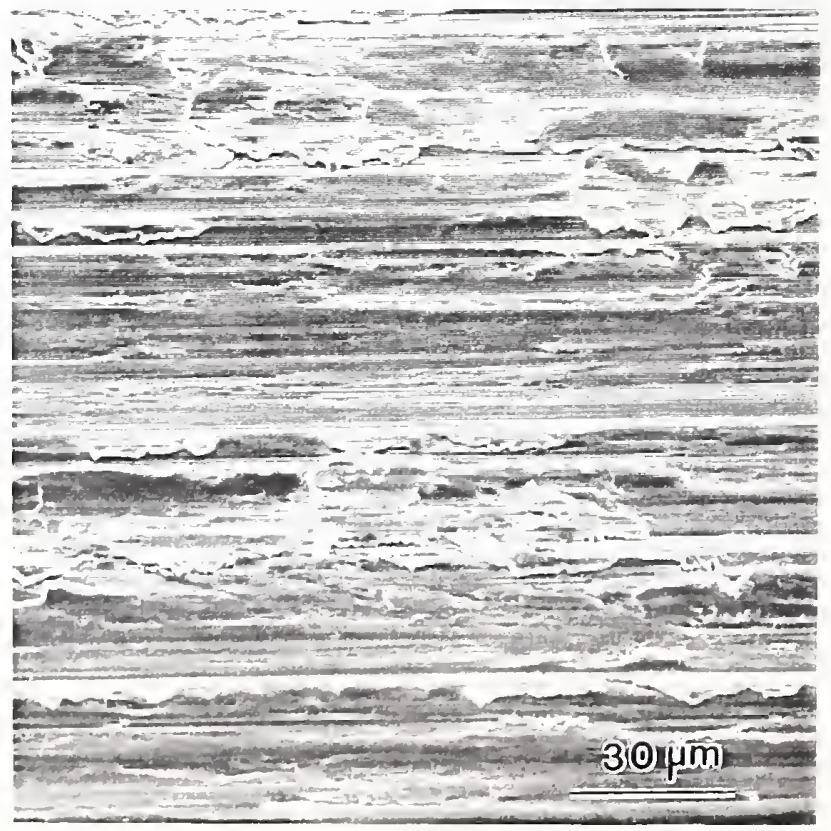

Fig. 25. SEM micrograph of damage on Cu flat. Direction of motion of $\mathrm{Ni}$ pin was from left to right. 
on and lost from the pin tip so that the amount of transferred $\mathrm{Cu}$ is limited to some more-or-less steady state quantity. Comparing the pin tips shown in Fig. 23, the contact region on the $\mathrm{Ni}$ pin is an elongated patch of transferred $\mathrm{Cu}$, while on the $\mathrm{Cu}$ pin the contact region is a worn, circular, flat area. It may be noted that the fine structure of the scar on the $\mathrm{Cu}$ pin, Fig. 23a, is similar in appearance to the structure in the initial part of the track on the $\mathrm{Cu}$ flat shown in Fig. $22 c$.

In Fig. 26 the coefficient of friction is plotted as a function of sliding distance for both arrangements of $\mathrm{Cu}$ vs. Ni. Initially, the coefficient of friction is about 0.9 for both combinations. For the $\mathrm{Cu}$ pin on $\mathrm{Ni}$ flat, it gradually decreases with sliding distance, while it is nominally constant for the $\mathrm{Ni}$ pin sliding against the $\mathrm{Cu}$ flat.

The variation in damage volume, both above the original (reference) surface (peak volume) and below that surface (valley volume), are plotted as a function of sliding distance in Fig. 27 for the two flats. Here, each volume value corresponds to an increment of track length centered about the distance coordinate. For the Ni flat, Fig. 27a, a large positive peak occurs initially. Subsequently, the volume decreases with increasing sliding distance indicating that less $\mathrm{Cu}$ is being transferred.

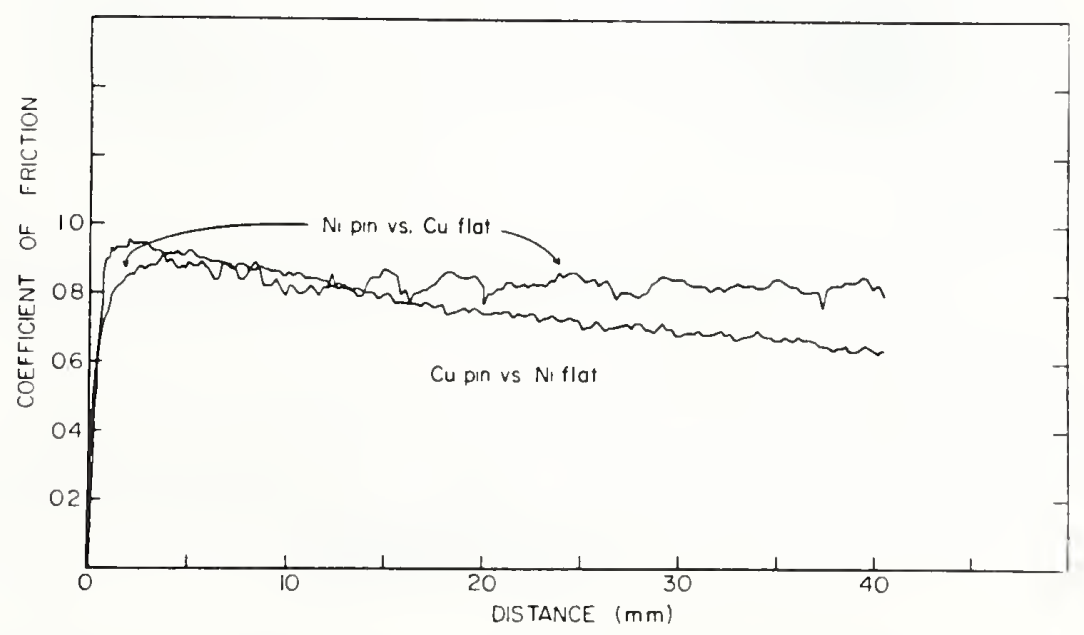

Fig. 26. Coefficient of friction plotted as a function of sliding distance for $\mathrm{Ni}$ vs. $\mathrm{Cu}$ pin and flat combinations. 

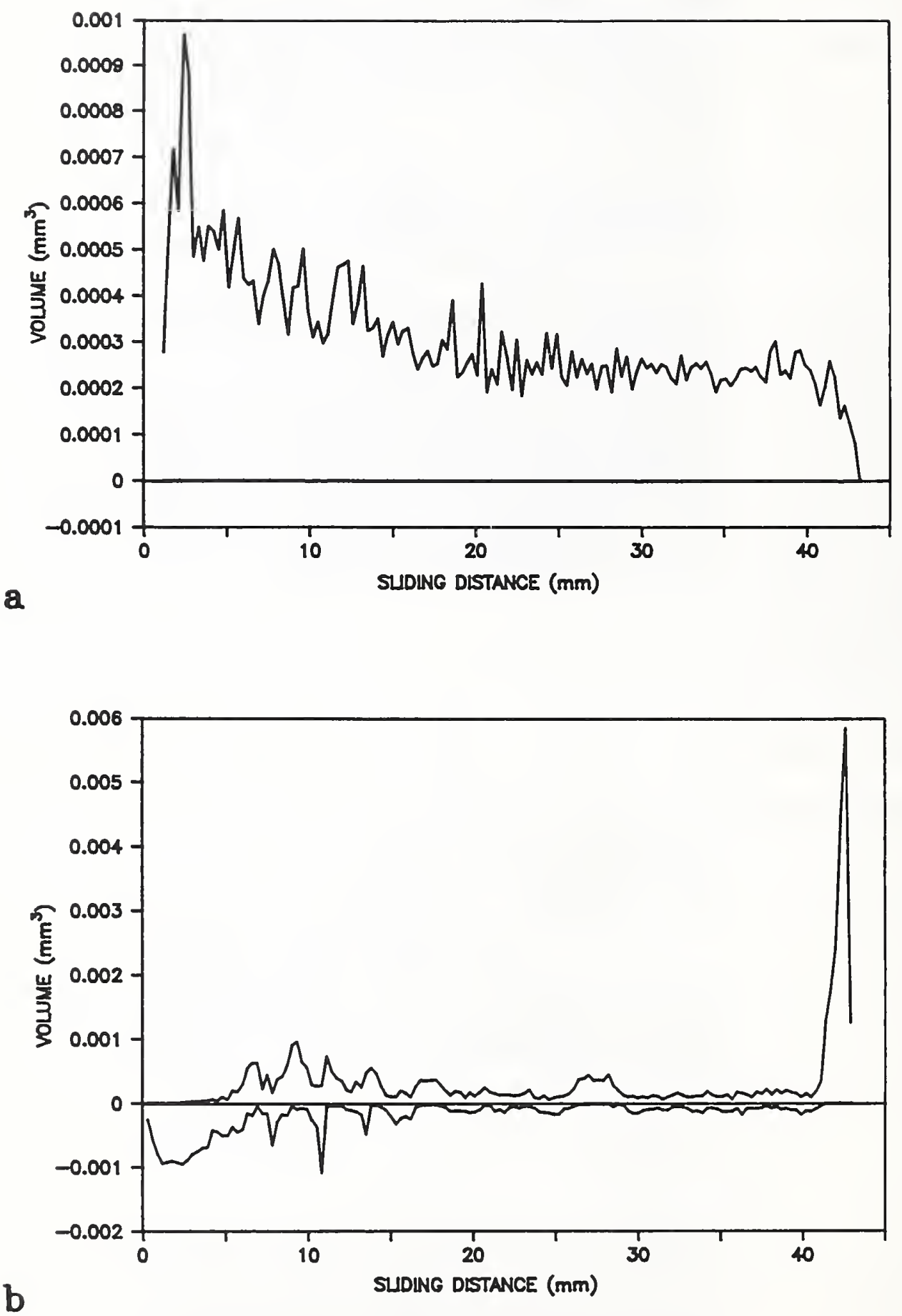

Fig. 27. Curves show volume above and below original surface in track on (a) Ni flat after sliding against $\mathrm{Cu}$ pin and (b) $\mathrm{Cu}$ flat after sliding against $\mathrm{Ni}$ pin plotted as a function of sliding distance. 
There is essentially no negative (valley) volume because the $\mathrm{Ni}$ flat is not measurably damaged by the $\mathrm{Cu}$ pin. For the $\mathrm{Cu}$ flat, Fig. 27b, the valley volume is seen to be large initially. Peak and valley volumes tend to fluctuate such that when valley volume is large, peak volume is small and conversely when peak volume is large valley volume is small. The large increase in peak volume at termination corresponds to the prow at the end of the track which is shown in Fig. $22 \mathrm{~d}$.

\section{$6.2 \mathrm{Ag}$ vs. $\mathrm{Ni}$}

While $\mathrm{Cu}$ and $\mathrm{Ni}$ are mutually soluble, $\mathrm{Ag}$ and $\mathrm{Ni}$ are essentially insoluble. Ag, like $\mathrm{Cu}$, is considerably softer than Ni. Only the arrangement, Ag pin vs. Ni flat, was studied. A photograph of the track on the $\mathrm{Ni}$ flat is shown in Fig. 28. The damage is quite small, especially at the beginning of the track, and consists almost entirely of transferred Ag. The amount of Ag transferred increased with sliding distance. It may be recalled for the $\mathrm{Cu}$ pin on $\mathrm{Ni}$ flat discussed above, the amount of transfer decreased with sliding distance.

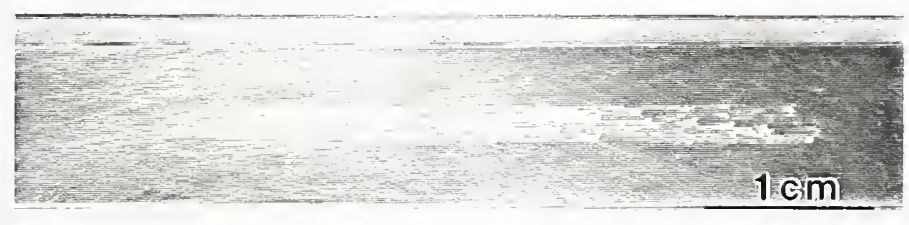

Fig. 28. Optical photograph of track on Ni flat after sliding against Ag pin.

Figure 29a shows some small patches of transferred silver near the beginning of the track on the Ni flat. Polishing scratches in the $\mathrm{Ni}$ surface appear to have a significant influence on the incidence of transfer, an effect that was also noticed in the case of $\mathrm{Cu}$ on $\mathrm{Ni}$. A much larger patch of transferred $\mathrm{Ag}$ near the end of the track is shown in Fig. 29b. The influence of scratches in the $\mathrm{Ni}$ surface is also quite evident here. 

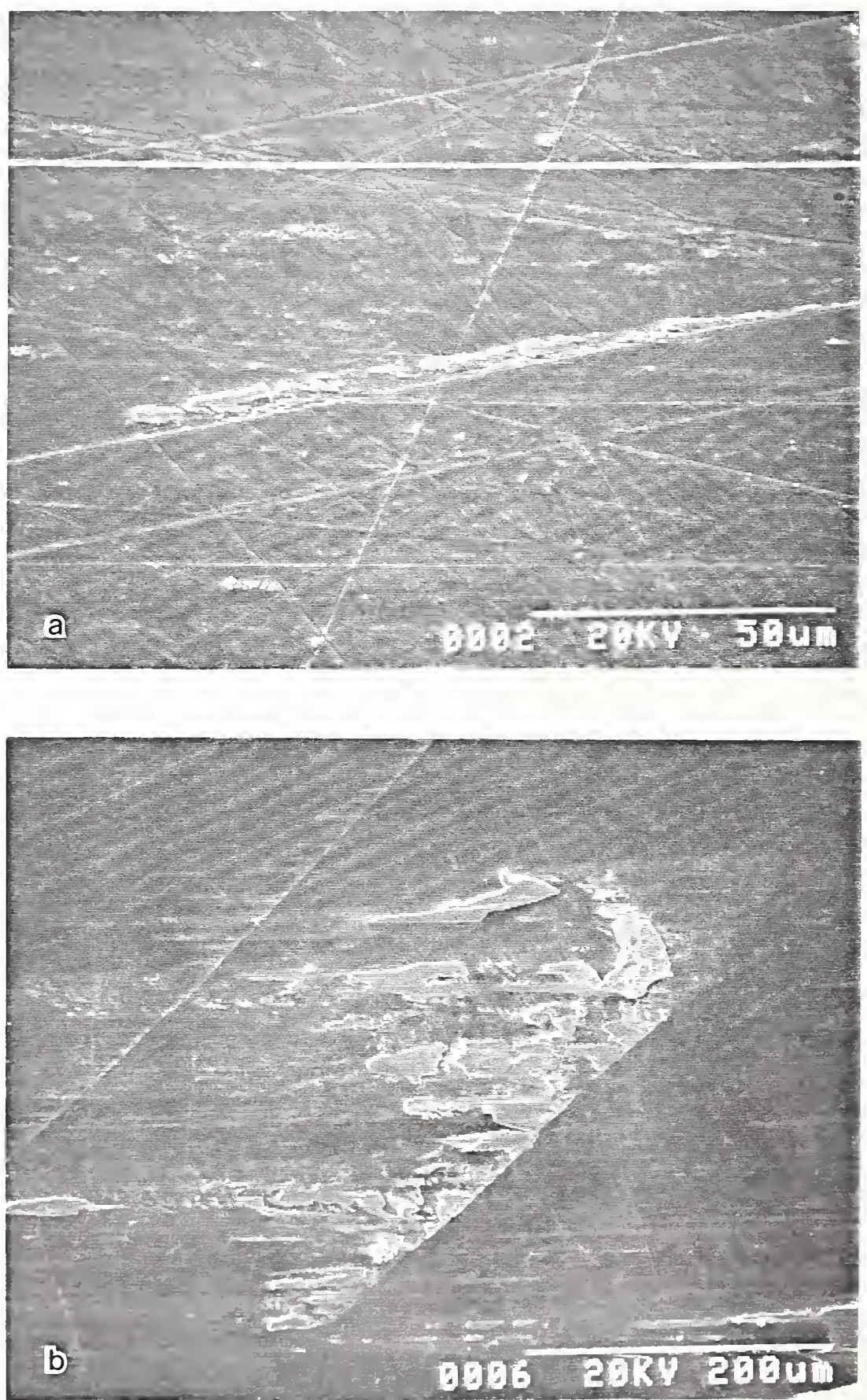

Fig. 29. Patches of transferred $\mathrm{Ag}$ on $\mathrm{Ni}$ flat (a) near beginning of track and (b) near end of track. 
A photograph of the wear scar on the Ag pin is shown in Fig. 30. The front portion of the scar is relatively smooth, while galling has clearly occurred towards the rear. This effect is probably associated with the growth of transferred patches on the Ni flat.

The coefficient of friction trace for Ag vs. Ni is shown in Fig. 31. Initially, the coefficient of friction is low and rises somewhat as sliding progresses. The curve is fairly smooth with only small fluctuations. For comparison, the variation in the peak to valley parameter $R_{t}$ with sliding distance is plotted in Fig. 32 for the flat. At the beginning, $R_{t}$ is quite small but increases with increasing sliding distance in a way that is consistent with the observed transfer of $\mathrm{Ag}$ on the flat. The increase is also consistent with the increase in coefficient of friction shown in Fig. 31.

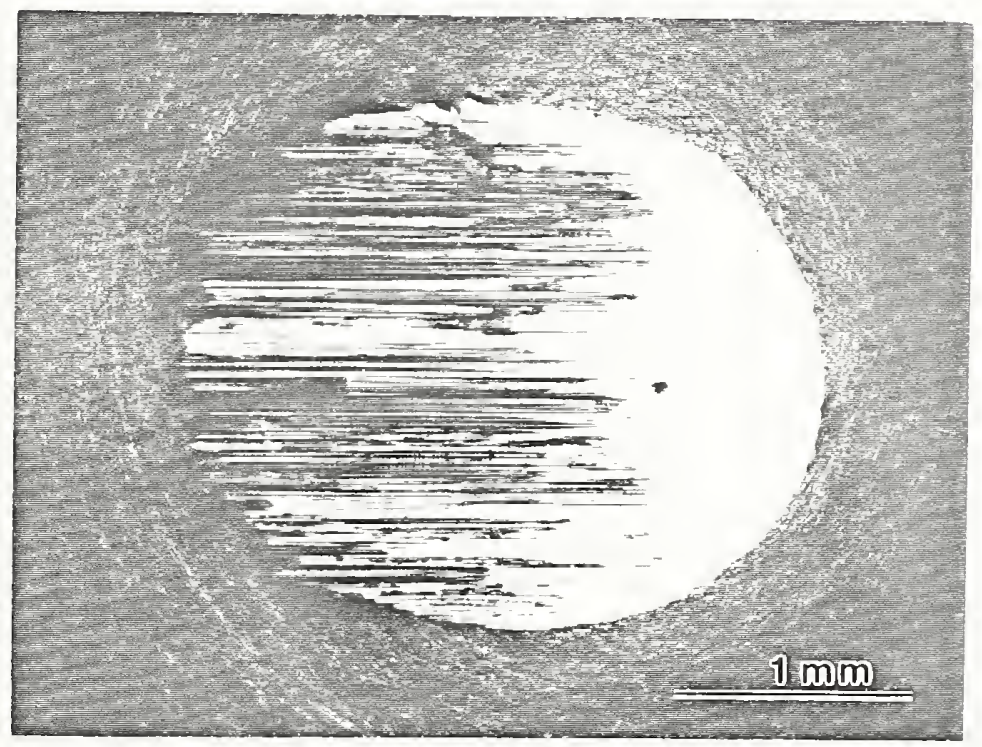

Fig. 30. Optical microglaph of scar un Ag pin after sliding against Ni flat. Leading edge of scar is at right. 


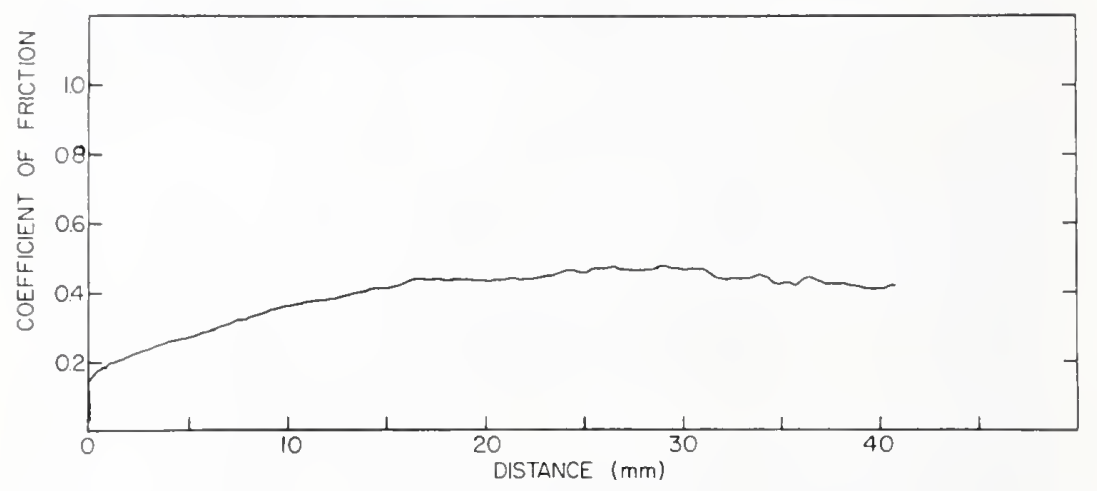

Fig. 31. Coefficient of friction plotted as a function of sliding distance for a Ag pin slid against a $\mathrm{Ni}$ flat.

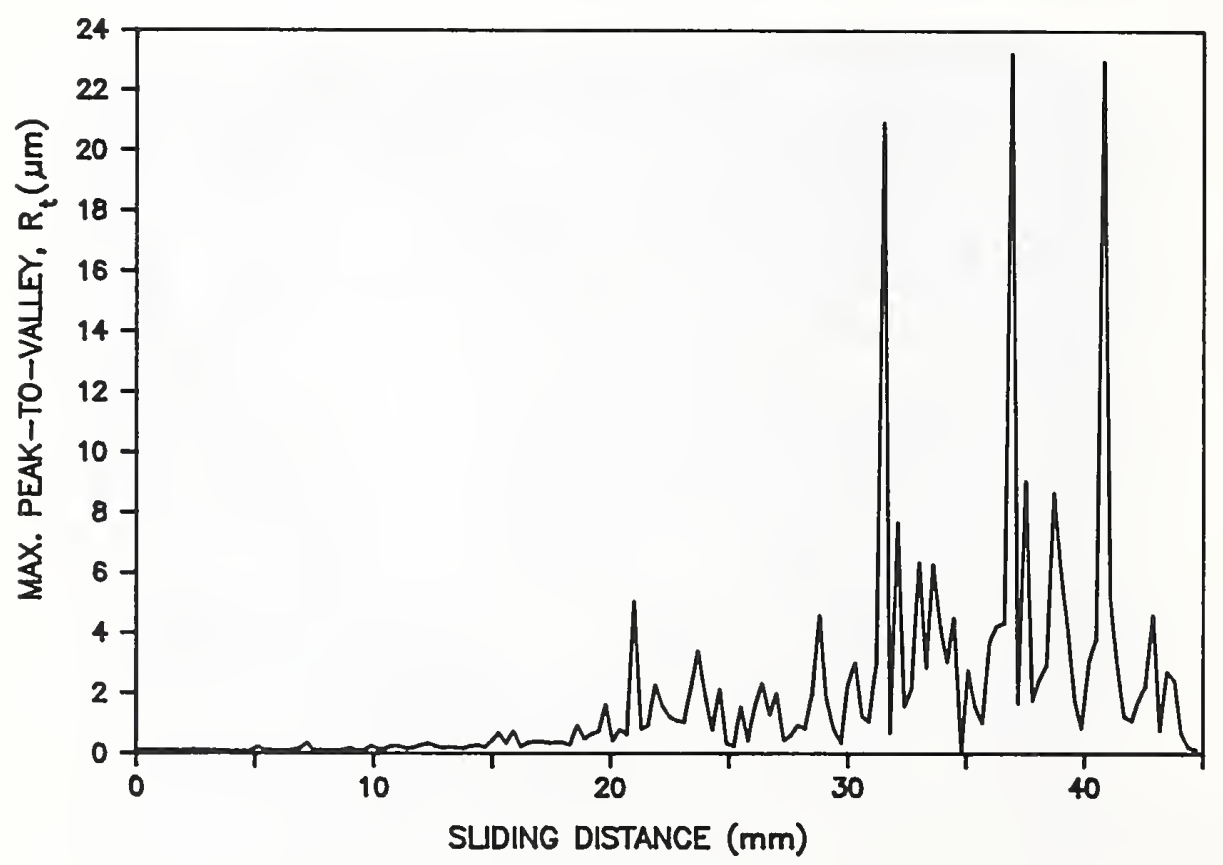

Fig. 32. Maximum peak to valley height, $R_{t}$, plotted as a function of sliding distance for track on $\mathrm{Ni}$ flat after sliding against a Ag pin. 
$6.3 \mathrm{Ag}$ vs. Co and $\mathrm{Cu}$ vs. Co

$\mathrm{Ag}$ and $\mathrm{Cu}$ pins were slid against Co flats. Ag is insoluble in Co while $\mathrm{Cu}$ has some solubility in $\mathrm{Co}$. Both $\mathrm{Ag}$ and $\mathrm{Cu}$ are softer than Co. In both cases the damage to the Co flat was primarily the result of transfer from the pin. Considerably more transfer occurred with the $\mathrm{Cu}$ pin. For the Ag pin, the amount of transfer was very small along the initial portion of the track but increased towards the end, similar to Ag vs. Ni. Photographs of the pin scars are shown in Fig. 33. The wear scar on the Ag pin is smooth with the exception of a few grooves and is similar in appearance to the scar on the Ag pin slid against Ni. The scar on the $\mathrm{Cu}$ pin, on the other hand, is quite rough but is also similar to the scar on the $\mathrm{Cu}$ pin which was slid against $\mathrm{Ni}$.

Traces of the coefficient of friction vs. distance for $\mathrm{Ag}$ and $\mathrm{Cu}$ slid against Co are shown in Fig. 34. For $\mathrm{Cu}$ against Co the coefficient of friction is relatively high and not nearly as smooth as for Ag against Co. Again, the behavior is similar to the case where $\mathrm{Ni}$ was the counterface.

The above results give a clear indication that mutual solubility can play an important roll in determining damage severity.

\subsection{Summary of Results on Nonself-Mated combinations}

Figure 35 provides a summary and comparison of the damage results for the different metal combinations. In this figure, damage is represented in terms of the average maximum peak-to-valley parameter. However, a similar result would have been obtained for any of the other damage severity parameters. For reference, values for the self-mated couples Ag, $\mathrm{Cu}, \mathrm{Ni}$, and $\mathrm{Co}$ are also included in Fig. 35. The combinations, $\mathrm{Ag}$ vs. Co and Ag vs $\mathrm{Ni}$, comprise incompatible couples, both in terms of solubility - Ag is insoluble in $\mathrm{Ni}$ and in $\mathrm{Co}$ - and in terms of at least one element belonging to the B-subgroup - Ag belongs to the B-subgroup. The damage obtained for these couples is lower than for the compatible couples, $\mathrm{Cu}$ vs. $\mathrm{Ni}$ and $\mathrm{Cu}$ vs. Co. However, damage for the compatible couple, Co vs. Co, is also equally low. Thus, as was stated earlier, 

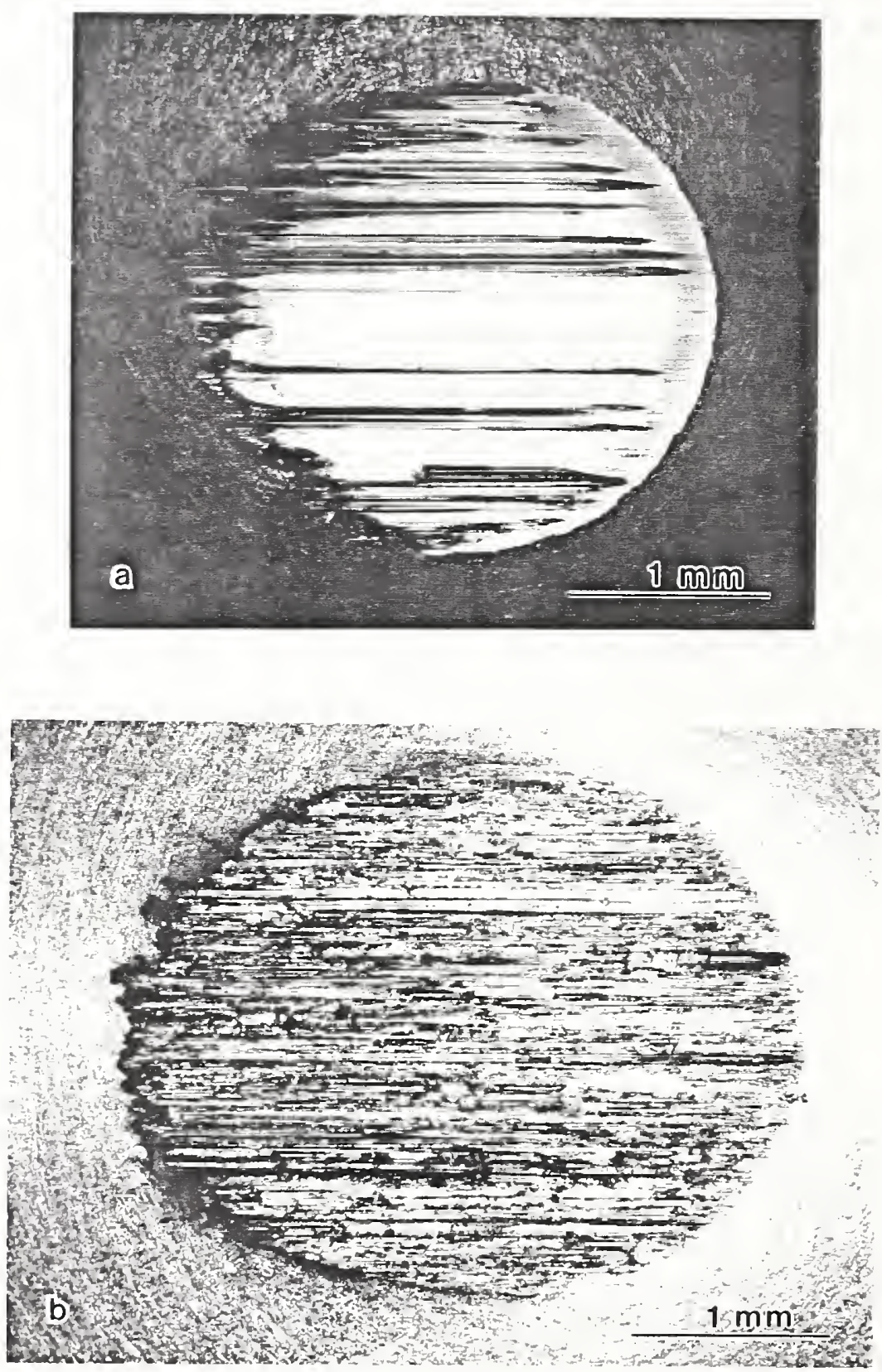

Fig. 33. Photographs of scars on (a) $\mathrm{Ag}$ and (b) $\mathrm{Cu}$ pins after sliding against co flats. Leading edge is at right. 


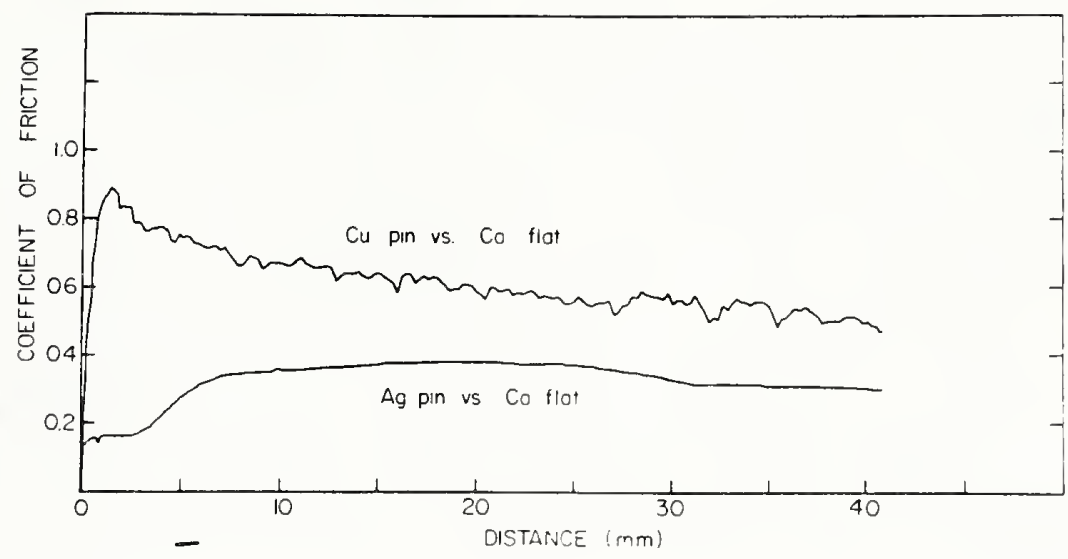

Fig. 34. Coefficient of friction traces for $\mathrm{Cu}$ and $\mathrm{Ag}$ sliding against Co flats.

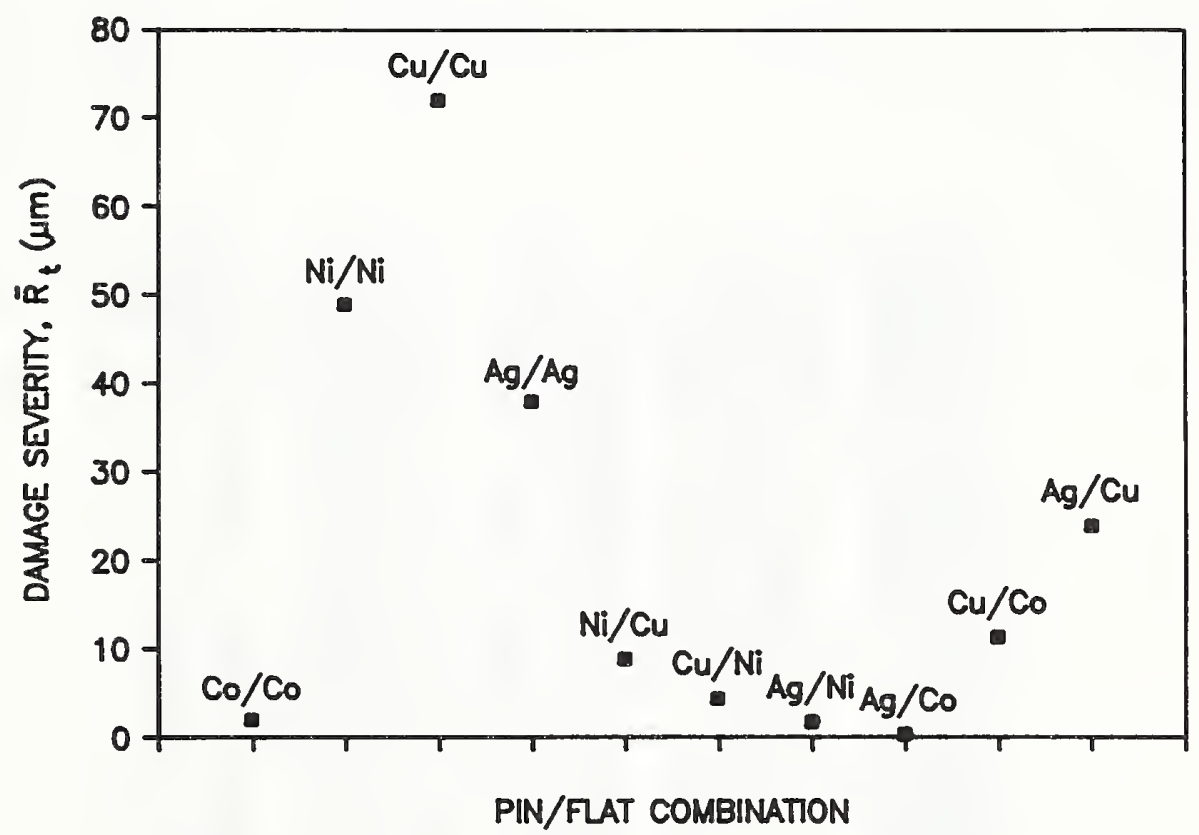

Fig. 35. Average maximum peak to valley damage parameter, $\bar{R}_{t}$, for different pin and flat specimen combinations. The metal identified at the left refers to the pin and the metal at the right refers to the flat. 
deformation behavior, which for Co is dictated by its hexagonal-closepacked crystal structure, is also a strong factor affecting galling.

Finally, it may be noticed that although $\mathrm{Ni}$ and $\mathrm{Cu}$ are entirely soluble, damage for these nonself-mated couples is far less than for either of the self-mated pairs, Cu vs. Cu or Ni vs. Ni. The basis for this difference probably lies in the large hardness difference of the metals comprising the couple. When a relatively hard metal such as $\mathrm{Ni}$ is slid on a softer metal such as $\mathrm{Cu}$, only the softer metal sustains significant damage. Furthermore, the damage to the softer metal is likely to be reduced because there is not the interplay that occurs when both specimens are damaged, as would be the case for pairs of equal hardness.

\section{THE EFFECT OF STACKING FAULT ENERGY}

Bhansali and Miller [9] hypothesized that materials with low stacking fault energies (SFE) should be more resistant to galling than materials with high stacking fault energies. In order to test this hypothesis, experiments were conducted on a series of $\mathrm{Cu}-\mathrm{Al}, \mathrm{Cu}-\mathrm{Ge}$, and $\mathrm{Cu}-\mathrm{Ni}$ alloys with different stacking fault energies. The alloys studied, together with some of their pertinent properties, are listed in Table 4. The pure metals, $\mathrm{Cu}$ and $\mathrm{Ni}$, were included to complete the series.

Table 4.

$\mathrm{Cu}$ Alloys for the study of galling vs. SFE.

\begin{tabular}{|c|c|c|c|c|}
\hline & Metal & $\begin{array}{c}\text { Solute } \\
\text { Concentration } \\
\text { (at. } z)\end{array}$ & $\begin{array}{c}\mathrm{SFE} \\
\left(\mathrm{mJ} / \mathrm{m}^{2}\right)\end{array}$ & $\begin{array}{c}\text { Hardness } \\
\left(\mathrm{Kg} / \mathrm{mm}^{2}\right)\end{array}$ \\
\hline $\mathrm{Cu}$ & & 0 & 41 & 34 \\
\hline $\mathrm{Cu}$ & $-2 \mathrm{Al}$ & 4.59 & 27 & 51 \\
\hline $\mathrm{Cu}$ & $-4 \mathrm{Al}$ & 8.94 & 12 & 52 \\
\hline $\mathrm{Cu}$ & $-6 \mathrm{Al}$ & 13.07 & 7 & 61 \\
\hline $\mathrm{Cu}$ & $-8 \mathrm{Al}$ & 17.00 & 4 & 76 \\
\hline $\mathrm{Cu}$ & $-2 \mathrm{Ge}$ & 1.75 & 35 & 50 \\
\hline $\mathrm{Cu}$ & $-6 \mathrm{Ge}$ & 5.29 & 16 & 60 \\
\hline $\mathrm{Cu}$ & $-10 \mathrm{Ge}$ & 8.86 & 6 & 88 \\
\hline $\mathrm{Cu}$ & $-20 \mathrm{Ni}$ & 21.29 & -85 & 73 \\
\hline $\mathrm{Ni}$ & & 0 & -250 & 92 \\
\hline
\end{tabular}


The stacking fault energy values for copper and the $\mathrm{Cu}-\mathrm{Al}$ alloys were obtained from the data of Carter and Ray [10]; values for the Cu-Ge alloys were obtained from Gallagher [11]. A precise value for the stacking fault energy of $\mathrm{Ni}$ is not available; however, Gallagher [11] estimates that a value of $250 \mathrm{~mJ} / \mathrm{m}^{2}$ is reasonable and this was used here. The value for $\mathrm{Cu}-20 \mathrm{Ni}$ was obtained by linear interpolation between values for pure $\mathrm{Cu}$ and pure $\mathrm{Ni}$.

All alloys were solution treated at $900^{\circ} \mathrm{C}$ for 5 days. Pure $\mathrm{Cu}$ was annealed at $1000^{\circ} \mathrm{C}$ for 1 day and $\mathrm{Ni}$ was annealed at $1100^{\circ} \mathrm{C}$ for 1 day. The specimens were prepared in the standard way and galling tests conducted at a load of $130 \mathrm{~N}$. Only self-mated pairs were studied.

Photographs of the tracks on the Cu-Al alloy flats are shown in Fig. 36. It is apparent that the damage is substantially greater for metals with high stacking fault energies (low concentrations of $\mathrm{Al}$ ) than for those with low stacking fault energies. Photographs of the tips of the $\mathrm{Cu}$ and $\mathrm{Cu}-\mathrm{Al}$ pin specimens are shown in Fig. 37. Again, the damage appears to be greater when the stacking fault energy is higher.
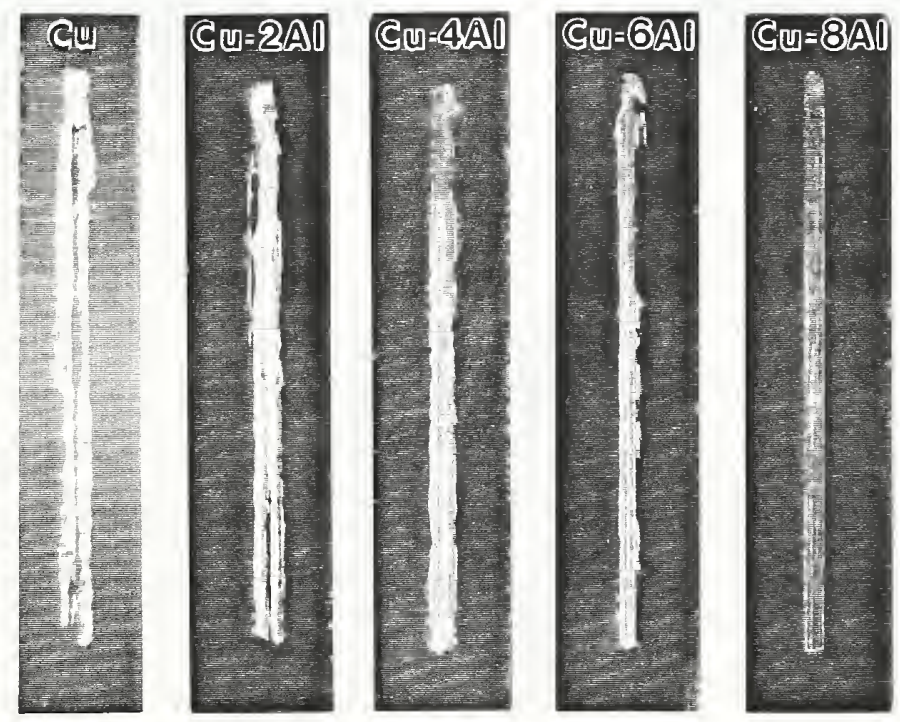

Fig. 36. Optical photographs of sliding tracks on Cu-Al flats. Sliding was initiated at the top. 

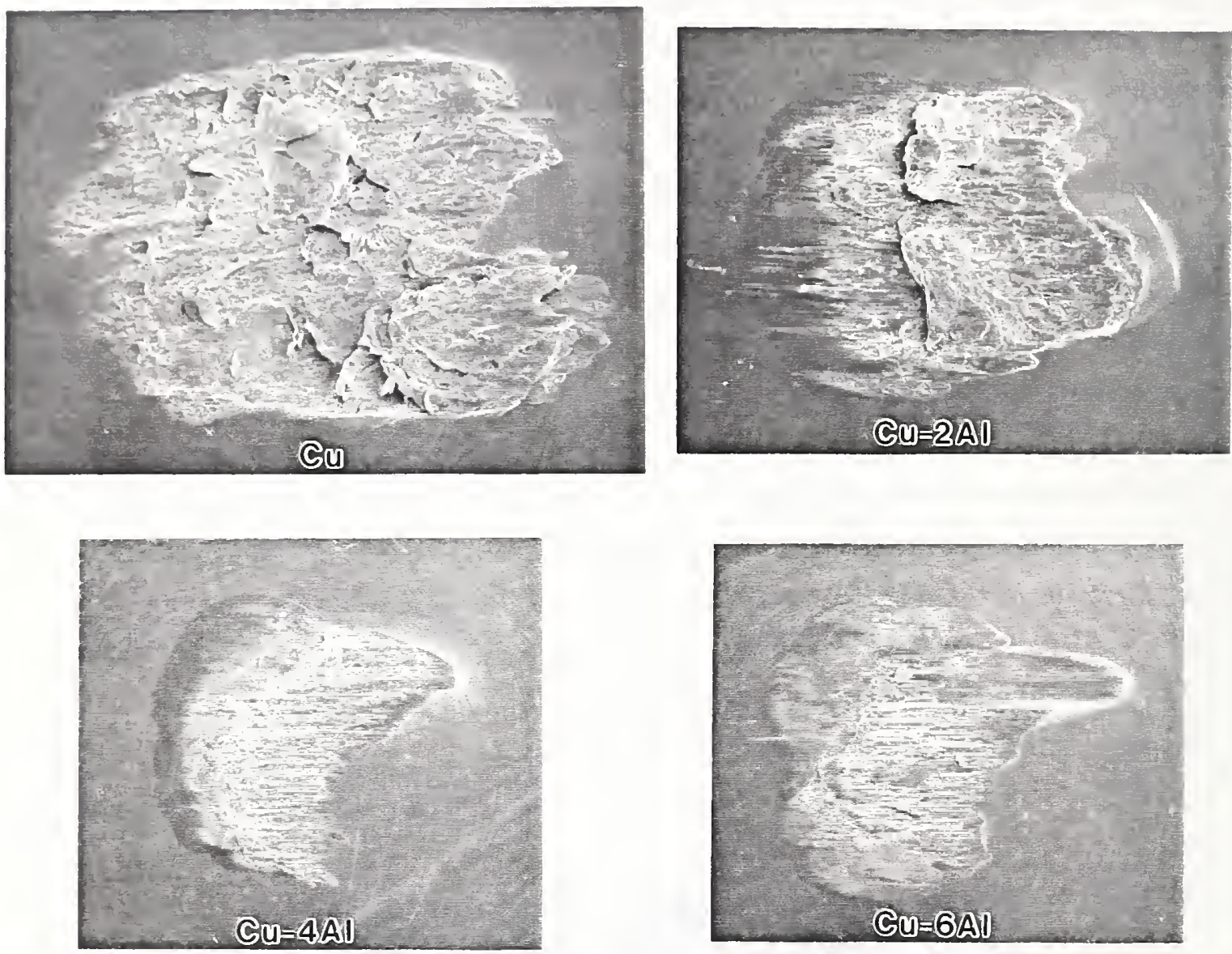

\section{$1 \mathrm{~cm}$}

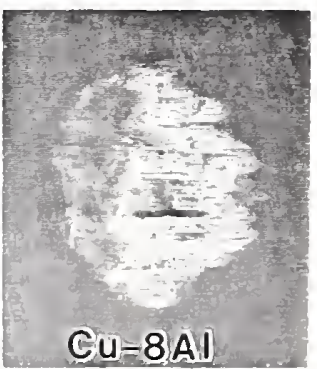

Fig. 37. SEM micrographs of wear scars on pins slid against flats shown in Fig. 36. The leading edge of each scar is at the left. 
SEM micrographs of damage features present on two of the flats, Cu, which exhibits severe damage, and $\mathrm{Cu}-8 \mathrm{Al}$, the most galling resistant metal in the series, are shown in Figs. 38-40. The damage exhibited by $\mathrm{Cu}$ is typical of metals that are prone to severe galling and, of course, is similar to $F e$ described in detail previously. A remnant of an initial prow on the $\mathrm{Cu}$ flat can be seen in Fig. 38a. Such a large prow is not seen in the corresponding micrograph of the initial section of the track on the $\mathrm{Cu}-8 \mathrm{Al}$ flat in Fig. 38b. Instead there is a small amount of damage associated with the formation of small prows similar to those observed on Co. Near the midsection of the track the damage continues to be quite severe for copper and, again, a large prow is present, shown in Fig. 39a. With Cu-8Al the surface is relatively smooth with fine grooves parallel to the direction of sliding. Original polishing scratches are sometimes still present as seen in Fig. 39b. At the end of the track in the case of $\mathrm{Cu}, \mathrm{Fig}$. 40a, damage to the pin has so altered the tip geometry that contact occurs at three separate locations with prow formation occurring at each. The final section of the track on $\mathrm{Cu}-8 \mathrm{Al}$, Fig. 40b, shows little change; there is a small ridge of accumulated material at the end of the track that was left when the pin was lifted from the flat.

Coefficient of friction traces for the alloys in the Cu-Al series, recorded as a function of sliding distance during each test, are shown in Fig. 41. Both the magnitude of the coefficient of friction and the size of the fluctuations appear to correlate in a general way with surface damage. Very large fluctuations and a high coefficient of friction are obtained for $\mathrm{Cu}$, while at the other extreme, for $\mathrm{Cu}-8 \mathrm{Al}$, the coefficient of friction is relatively low and the fluctuations are small. The coefficient of friction traces can also be compared with the maximum peak-to-valley values, $R_{t}$, along the length of the track. These curves are shown in Fig. 42. The curve for each metal, both in terms of its relative height and the amplitudes of fluctuations, is similar to the corresponding friction trace shown in Fig. 41. Thus, surface damage and coefficient of friction, as would be expected, are closely related in these experiments. Although not shown here, the relationship for the other metals was similar to $\mathrm{Cu}-\mathrm{Al}$. 

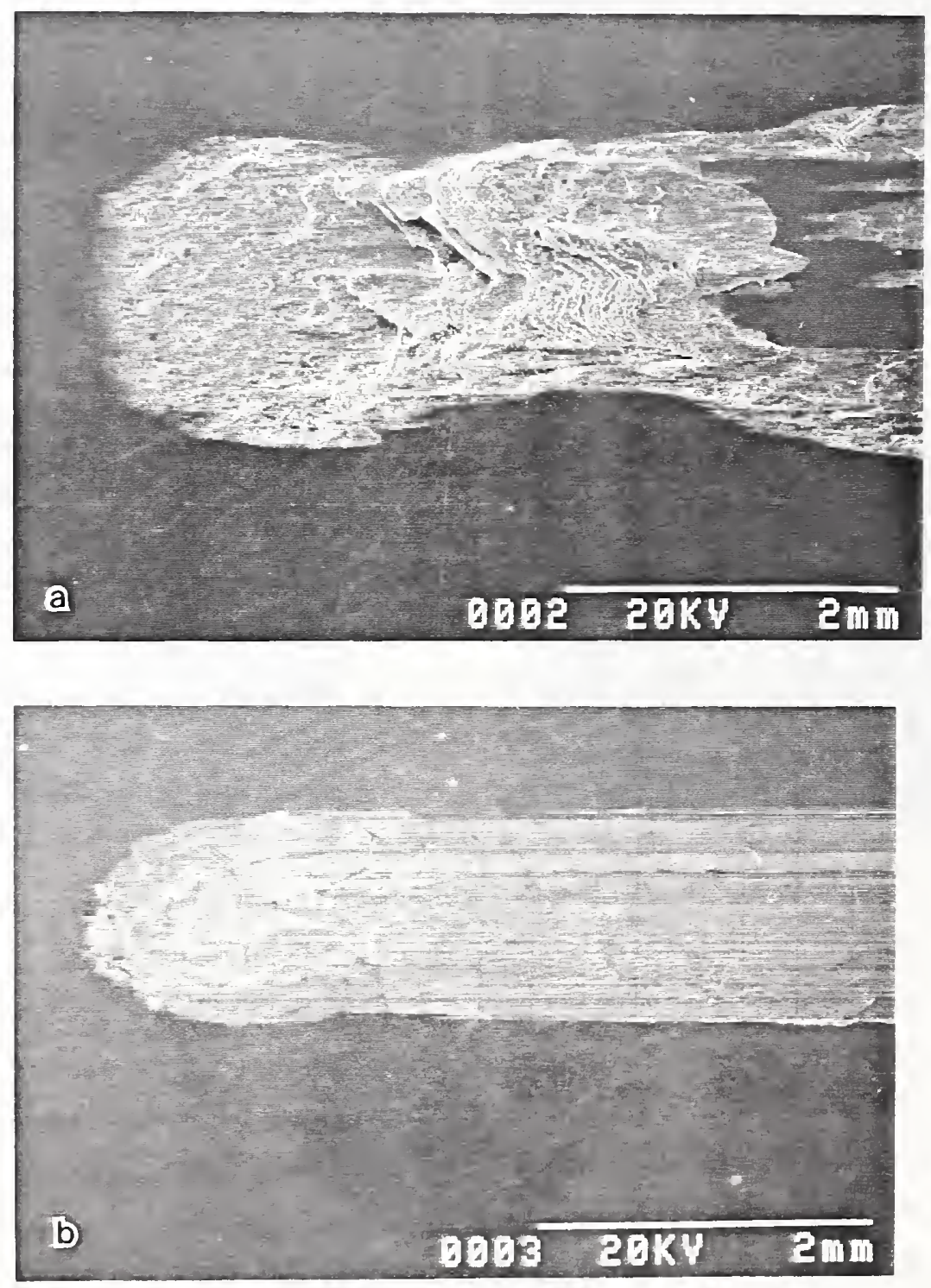

Fig. 38. SEM micrographs of initial section of tracks on (a) $\mathrm{Cu}$ and (b) Cu-8Al flats. 

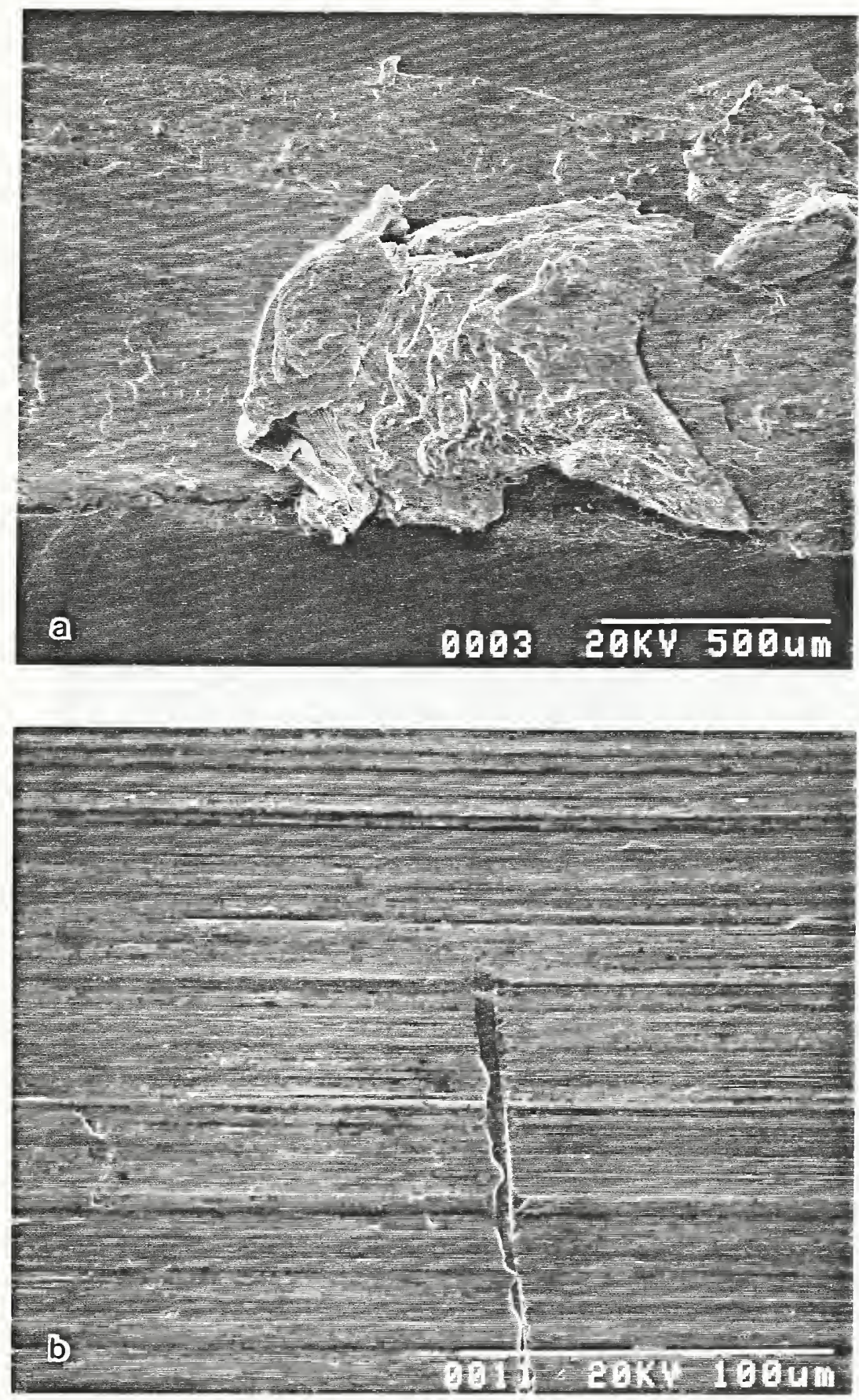

Fig. 39. SEM micrographs of damage on (a) $\mathrm{Cu}$ and (b) Cu-8Al flats near midsection of tracks. Motion of pin was from left to right. 

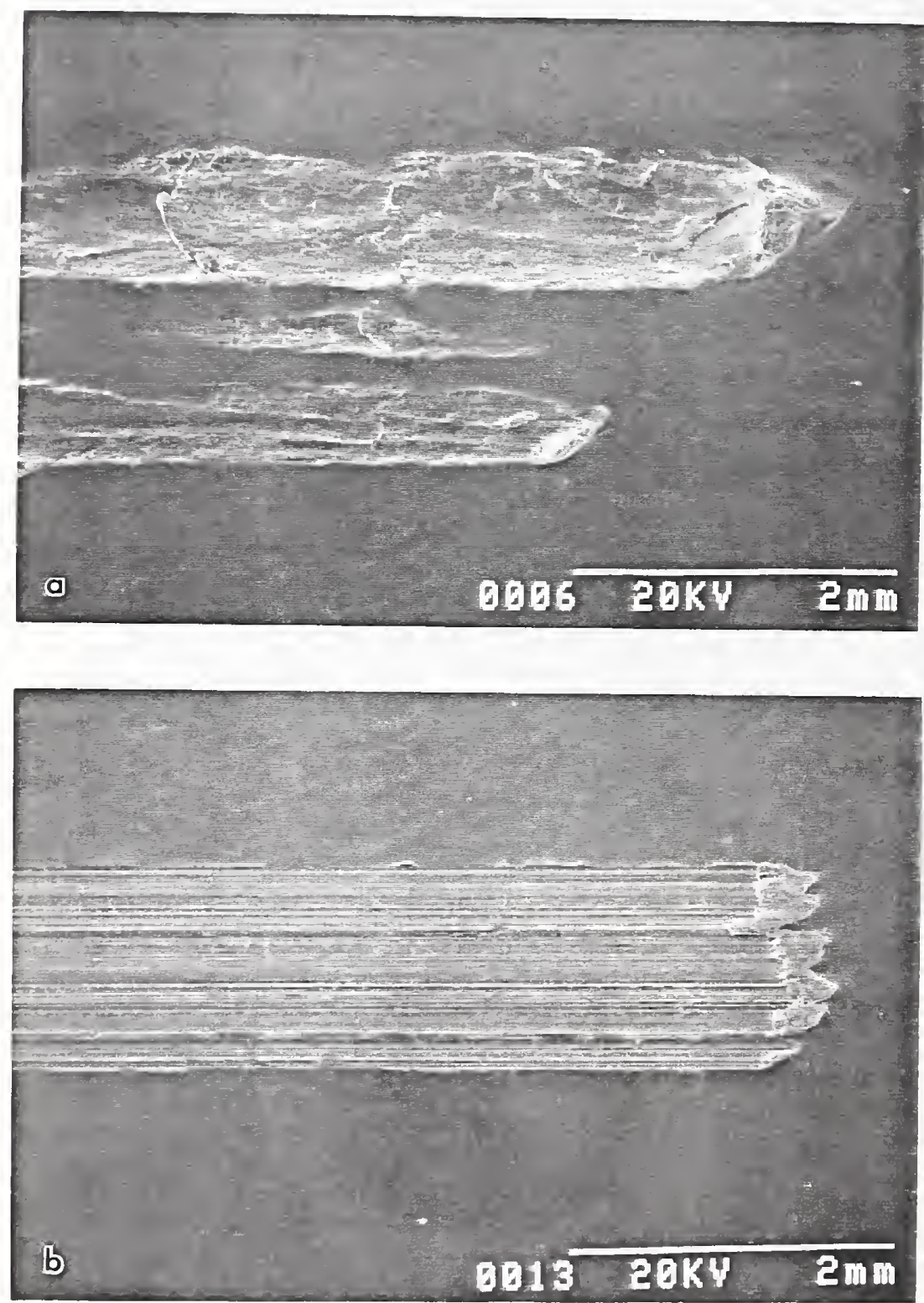

Fig. 40. SEM micrographs of the ends of the tracks on (a) $\mathrm{Cu}$ and (b) Cu8Al flats. 


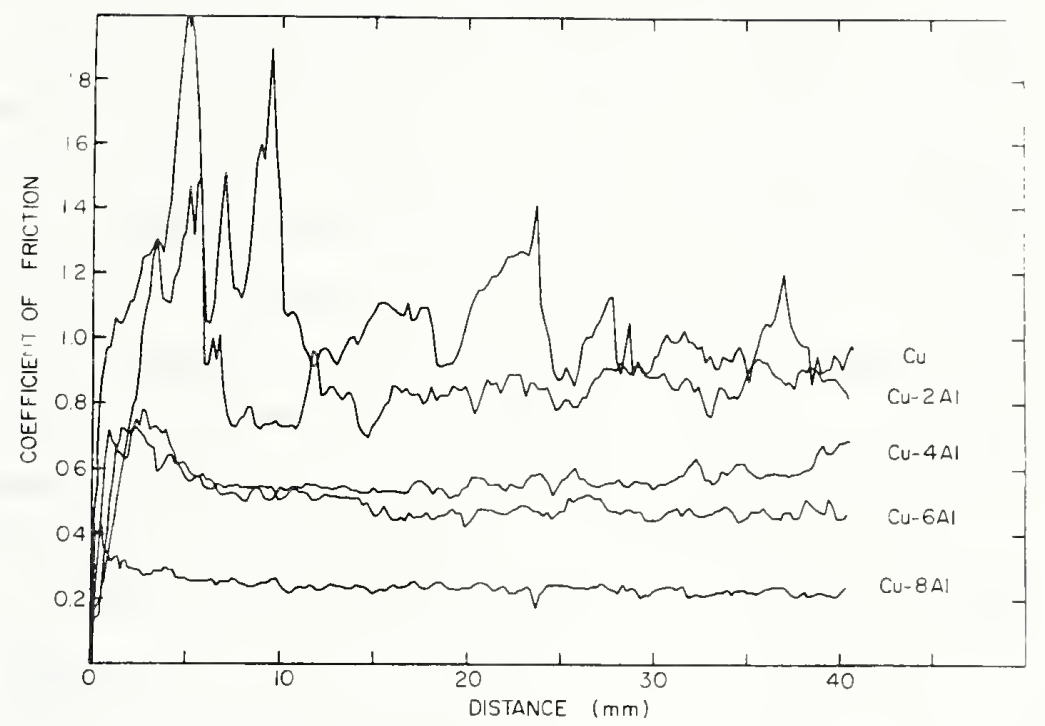

Fig. 41. Coefficient of friction traces for specimens in Cu-Al series.

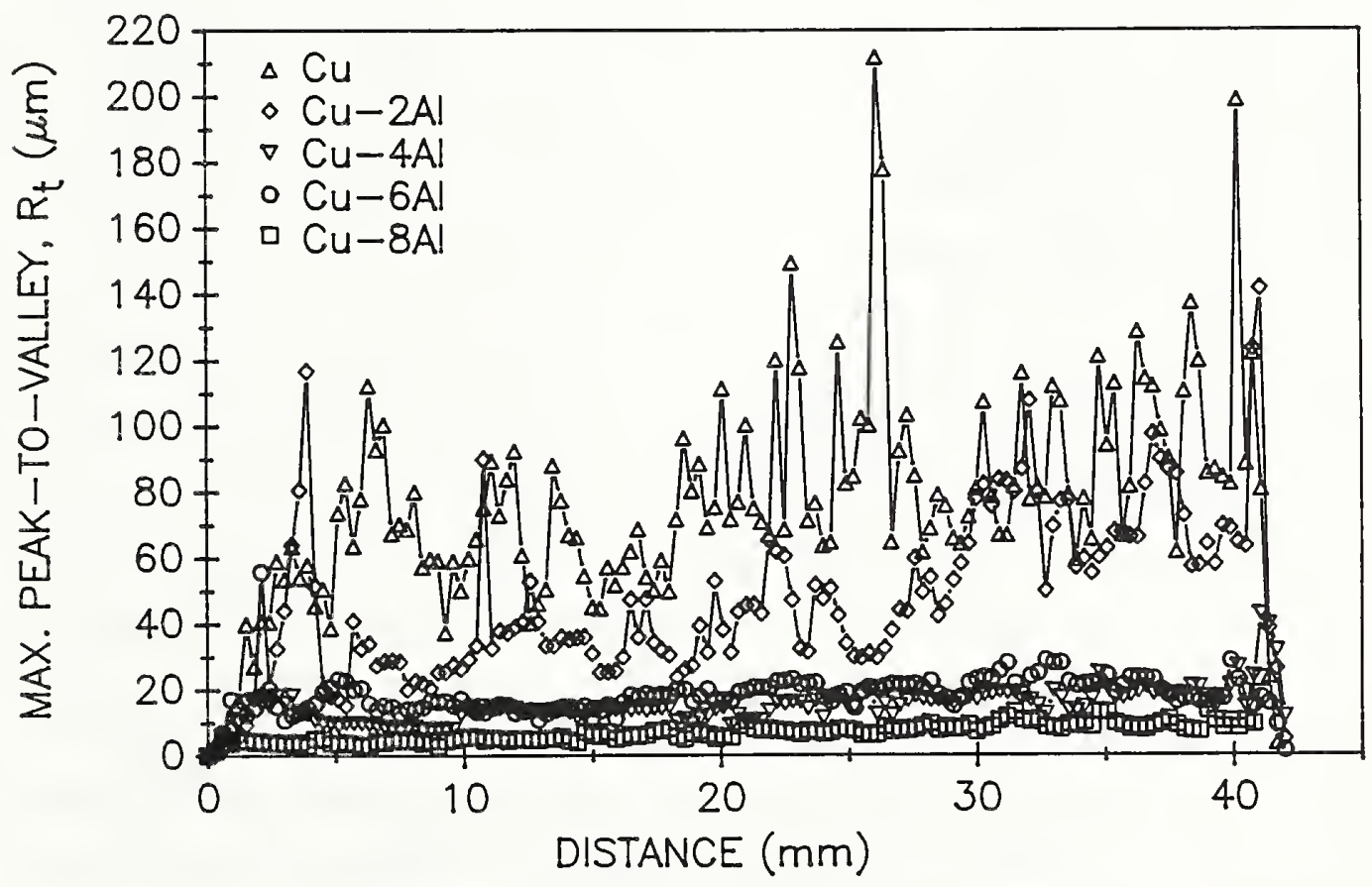

Fig. 42. Maximum peak to valley height, $R_{t}$, of damage on flats in Cu-Al series plotted as function of sliding distance. 
The damage parameters, $\bar{R}_{t}, R_{t}$ (rms), and $D V$, for all of the metals in Table 4 are plotted as a function of stacking fault energy in Figs. $43 a$ - c, respectively. In each case it is seen that the parameter decreases rapidly as the stacking fault energy falls below $-30 \mathrm{~mJ} / \mathrm{m}^{2}$. At higher values, the stacking fault energy seems to have little effect on damage. The aspect ratio parameter, AR, behaves in about the same way as the other parameters; however, for AR the decrease is a result of the change in shape of the topographic features constituting the damage and not of the severity of the damage. Thus, the topographic features tend to be less elongated in the direction of sliding for the metals with high stacking fault energies than for those with low stacking fault energies. This was clearly displayed in the micrographs of damage shown earlier, where for $\mathrm{Cu}$ the topography consisted of lumps and gouges and for $\mathrm{Cu}-8 \mathrm{Al}$ the features were primarily very long alternating grooves and ridges parallel to the sliding direction.

It may be noted in Table 4 that hardness increases with increasing concentration of $\mathrm{Al}$ and $\mathrm{Ge}$ in $\mathrm{Cu}$. Thus, the trend towards reduced damage might be attributed to increasing hardness rather than to decreasing stacking fault energy. However, when $\mathrm{Ni}$ and $\mathrm{Cu}-20 \mathrm{Ni}$ are included, the correlation with hardness is no longer supported. The correlation with stacking fault energy still holds although the sensitivity at high stacking fault energy values is no longer strong, as was pointed out above.

It may be concluded that stacking fault energy, in addition to crystal structure, is an important property influencing the galling behavior of metals. Both crystal structure and stacking fault energy can have a strong influence on deformation characteristics. A low stacking fault energy makes cross-slip of dislocations more difficult and favors coplanar glide. Similarly, glide is favored on the basal plane in hexagonalclose-packed metals, especially when the c/a ratio is large. It appears that this restricted slip behavior, particularly at the extremes of a very low stacking fault energy or for an hcp metal such as Co, results in the localization of shear to the immediate surface during sliding. Roughening and damage to the surface are minimized. 


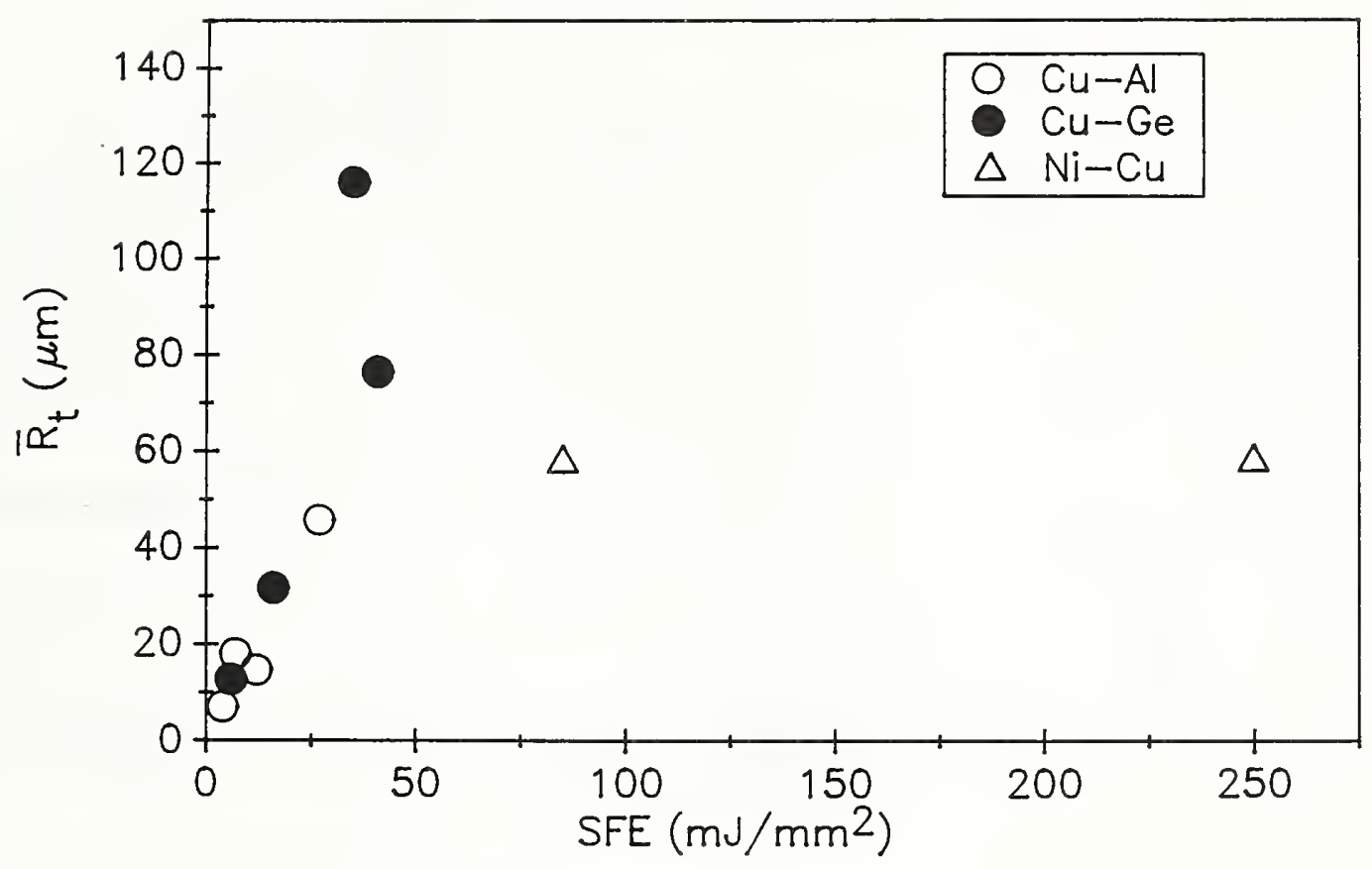

Fig. 43 (a)

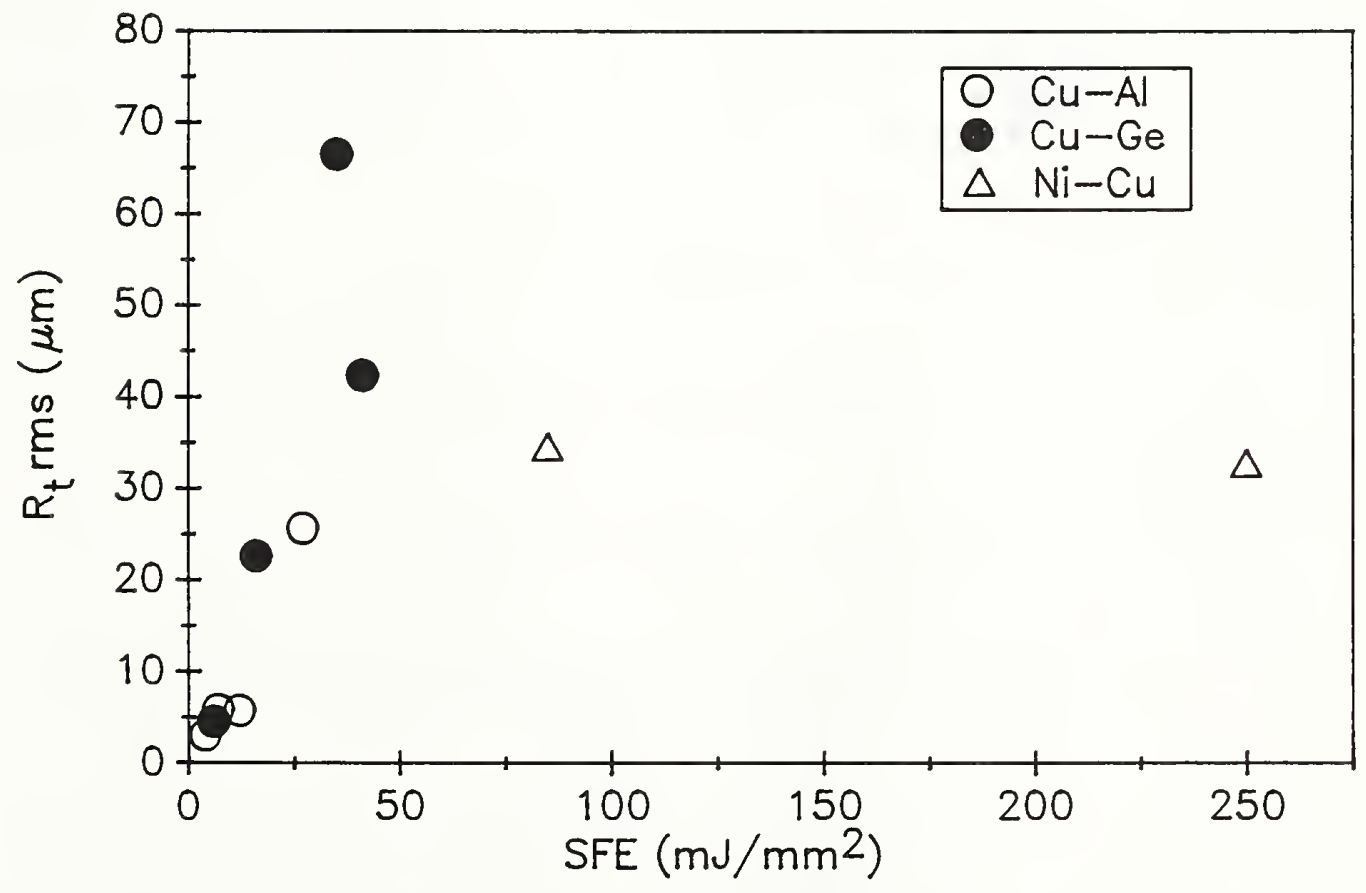

Fig. 43 (b) 


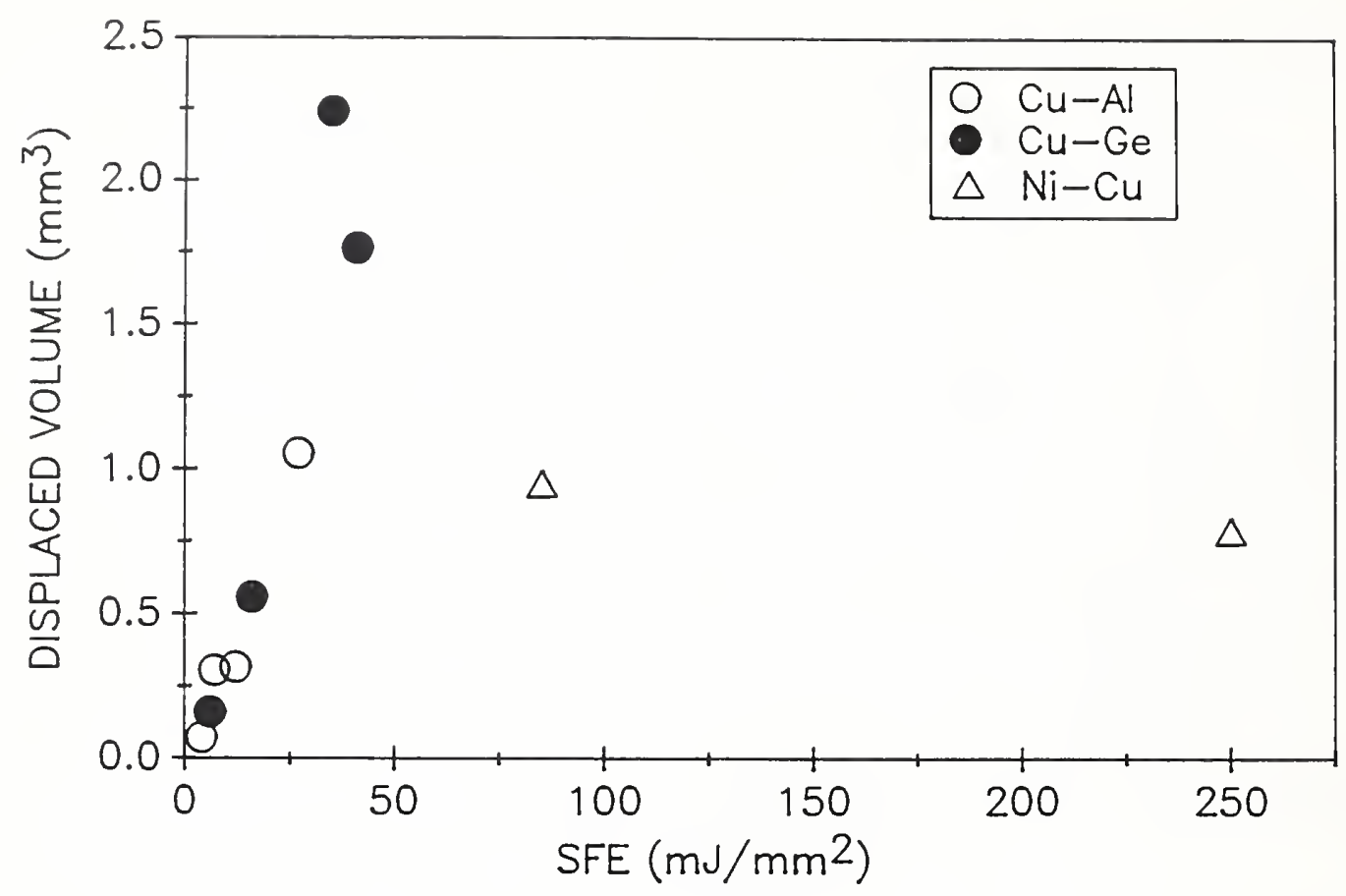

Fig. 43 (c)

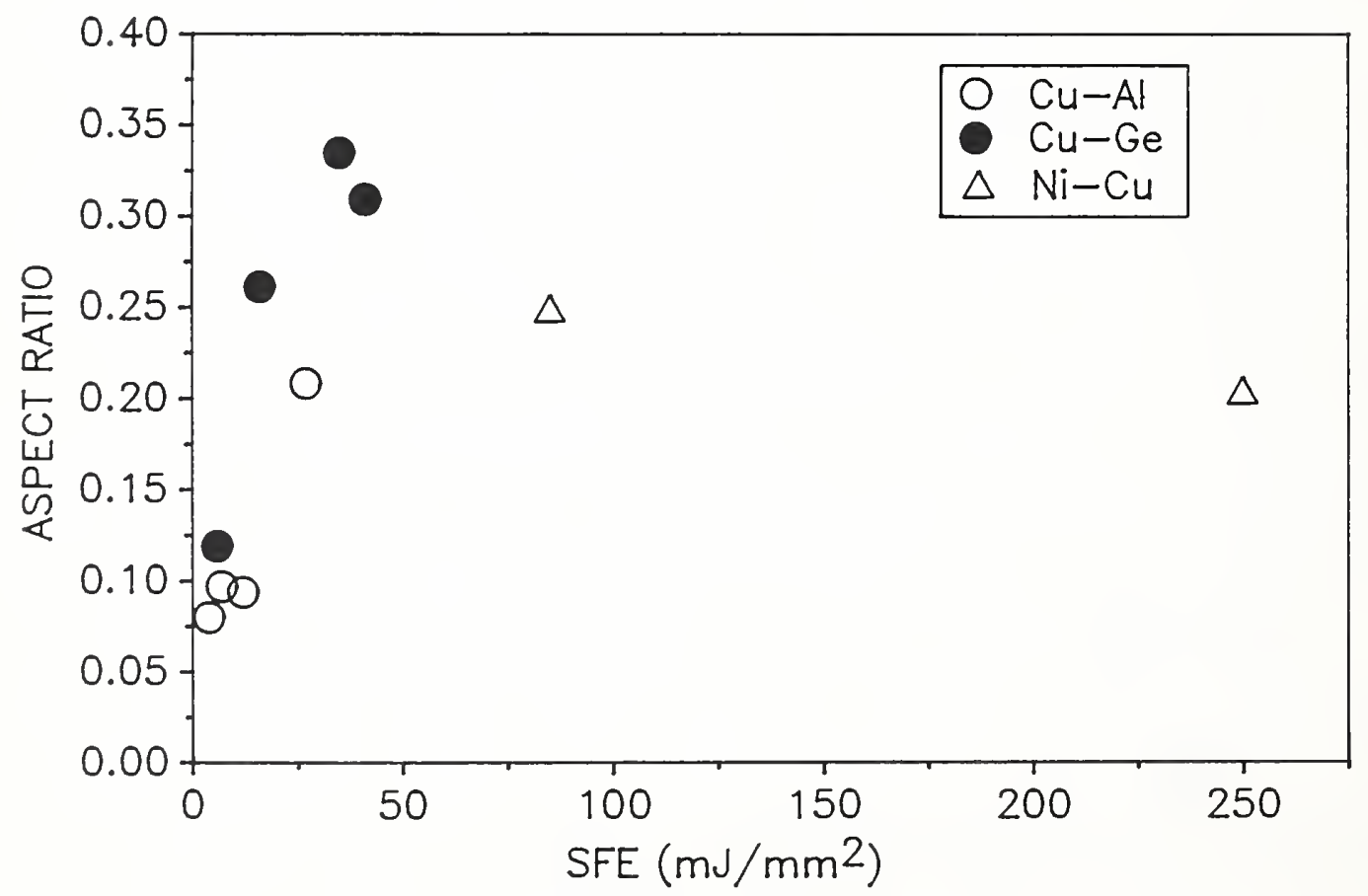

Fig. 43 (d)

Fig. 43. Parameters used to characterize damage are plotted as a function of stacking fault energy for flats in $\mathrm{Cu}-\mathrm{Al}$ series. 


\section{GALLING OF ALLOYS}

The galling behavior of a number of commercial alloys was investigated. The alloys were selected to reveal the effect of specific properties and processing treatments on the severity and character of damage. Two steels were chosen to examine the effect of heat treatment. In addition, two different surface treatments, carburizing and nitriding, were studied. Several stainless steels and corrosion resistant alloys were tested since these classes of metals are of special interest in coal processing systems where exposure is to high temperatures and very corrosive environments. Finally, some alloys that are widely used for bearing applications were included either because of an important property or simply because they were commonly used materials.

\subsection{Effect of Heat Treatment}

The galling behavior of AISI 1541 steel (composition given in Table 5) was studied as a function of load in both the hot-rolled, soft condition ( $94 \mathrm{HRB}$ ) and in the hardened state after quenching from $850^{\circ} \mathrm{C}$ (54 HRC). A detailed discussion of the results is given in [4] and only a brief summary is presented here. Damage severity results for

Table 5 .

Bulk compositions of steels (wt. 8 )

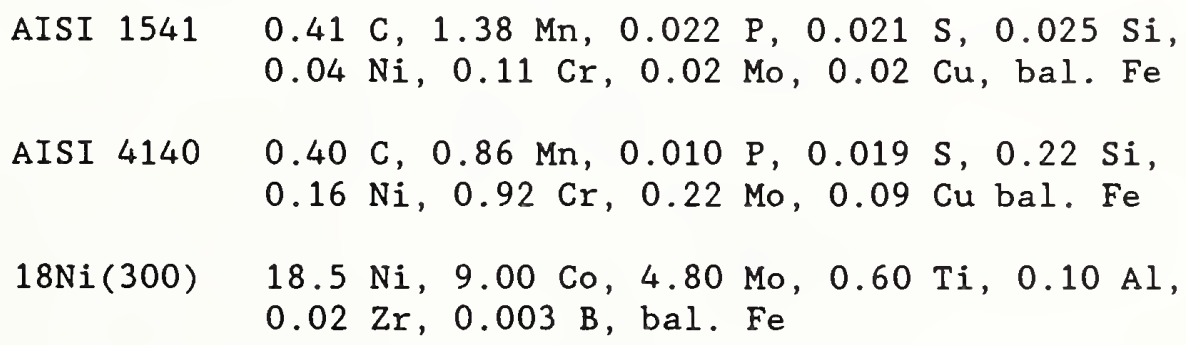

tests at three different loads are given in Table 6. The tests were conducted with the large load capacity hydraulic machine. There was one departure from the standard procedure in that the test surfaces of both the pins and the flats, except in one series of three tests, were 
finished by machine surface grinding rather than hand grinding on SiC papers and polishing with $6 \mu \mathrm{m}$ diamond abrasive.

In most cases three tests were conducted at each applied load. Data for two parameters, $\bar{R}_{t}$ and $R_{t}$ (rms), are given in Table 6 together with the mean and standard deviation of the separate test values for $\bar{R}_{t}$. The coefficient of variation computed for the $\bar{R}_{t}$ values ranges from about 88 to 478 for the different loads. Although rather large compared to many property measurements such as hardness, the values are not excessively large when compared to many other wear measurements. For example, for block-on-ring wear tests the coefficient of variation of the ring wear volume was reported to be 688 and of the block wear volume, 388. [12] The damage severity for the polished specimens tested at $133 \mathrm{~N}$ is seen in Table 6 to be somewhat larger than for the ground specimens at

Table 6.

Results for 1541 Steel

\begin{tabular}{|c|c|c|c|c|c|c|}
\hline $\begin{array}{l}\text { Specimen } \\
\text { Condition }\end{array}$ & $\begin{array}{l}\text { Surface } \\
\text { Finish }\end{array}$ & $\begin{array}{l}\text { Load } \\
(\mathrm{N})\end{array}$ & $\begin{array}{l}\overline{\mathrm{R}}_{\mathrm{t}} \\
(\mu \mathrm{m})\end{array}$ & $\begin{array}{c}\mathrm{R}_{\mathrm{t}}(\mathrm{rms}) \\
(\mu \mathrm{m})\end{array}$ & $\begin{array}{l}\text { Mean } \bar{R}_{\mathrm{t}} \\
(\mu \mathrm{m})\end{array}$ & $\begin{array}{l}\text { Standard } \\
\text { Deviation } \\
\text { in } \bar{R}_{t} \\
(\mu \mathrm{m})\end{array}$ \\
\hline $\begin{array}{c}\text { hot-rolled } \\
" \\
"\end{array}$ & $\begin{array}{c}\text { ground } \\
\text { " } \\
"\end{array}$ & $\begin{array}{l}133 \\
133 \\
133\end{array}$ & $\begin{array}{l}16 \\
22 \\
39\end{array}$ & $\begin{array}{l}17 \\
20 \\
31\end{array}$ & 26 & 12 \\
\hline $\begin{array}{l}" \\
"\end{array}$ & $\begin{array}{l}\text { polished } \\
\text { " }\end{array}$ & $\begin{array}{l}133 \\
133 \\
133\end{array}$ & $\begin{array}{l}35 \\
35 \\
40\end{array}$ & $\begin{array}{l}22 \\
34 \\
33\end{array}$ & 37 & 3 \\
\hline " & $\begin{array}{c}\text { ground } \\
" \\
"\end{array}$ & $\begin{array}{l}1500 \\
1500 \\
1500\end{array}$ & $\begin{array}{l}131 \\
143 \\
140\end{array}$ & $\begin{array}{l}132 \\
112 \\
110\end{array}$ & 138 & 6 \\
\hline $\begin{array}{c}\text { quenched } \\
\text { " }\end{array}$ & $\begin{array}{l}\text { ground } \\
"\end{array}$ & $\begin{array}{l}133 \\
133\end{array}$ & $\begin{array}{l}4 \\
6\end{array}$ & $\begin{array}{l}4 \\
9\end{array}$ & 5 & 1 \\
\hline " & " & $\begin{array}{l}1500 \\
1500 \\
1500\end{array}$ & $\begin{array}{l}51 \\
64 \\
33\end{array}$ & $\begin{array}{l}61 \\
79 \\
20\end{array}$ & 49 & 16 \\
\hline$"$ & $"$ & $\begin{array}{l}6000 \\
6000\end{array}$ & $\begin{array}{r}98 \\
144\end{array}$ & $\begin{array}{r}59 \\
134\end{array}$ & 121 & 32 \\
\hline
\end{tabular}


the same load. This demonstrates the effect of surface finish which was discussed previously.

The $\bar{R}_{t}$ values for both the hot-rolled and the quenched specimens are plotted in Fig. 44 as a function of load. Here it is seen that $\bar{R}_{t}$ increases in a more-or-less linear fashion with increasing load for both treatments. It is also clear that the damage is significantly greater for the relatively soft hot-rolled state.

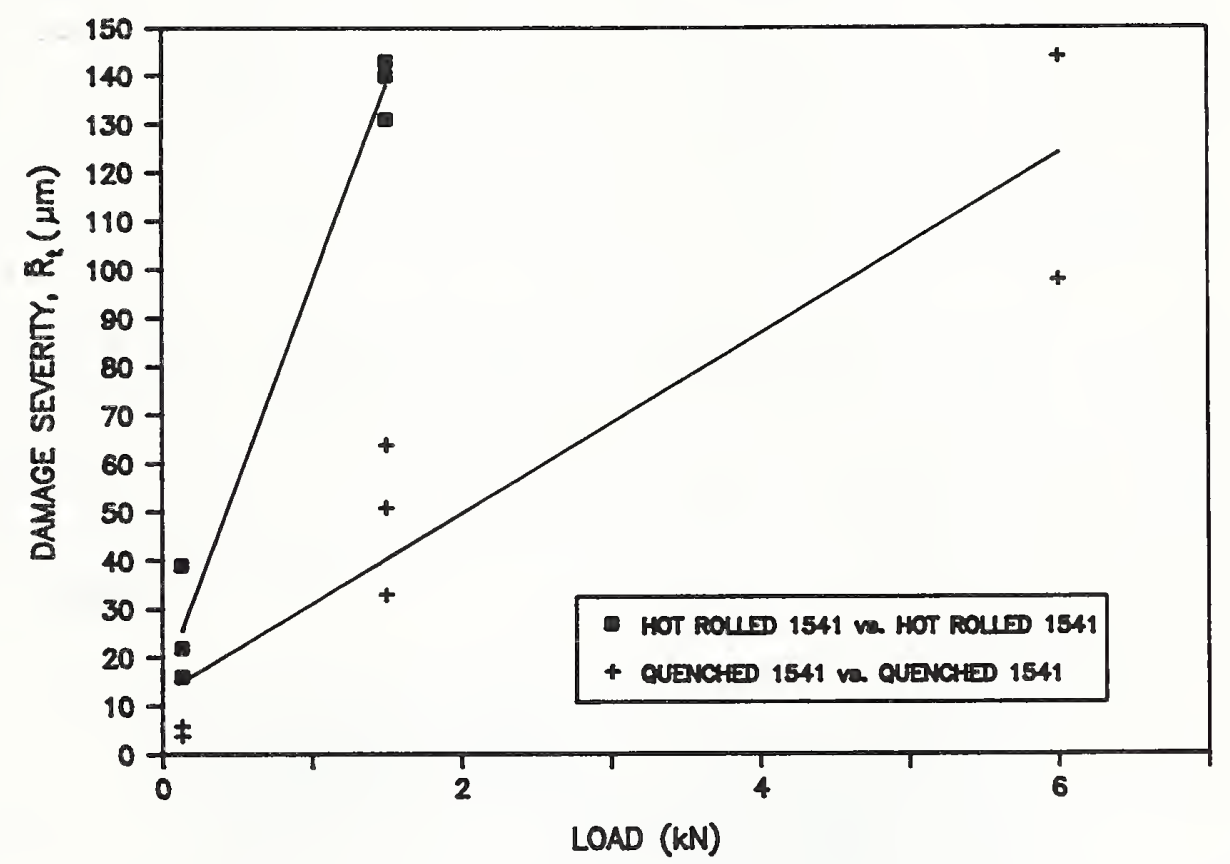

Fig. 44. Damage parameter, $\bar{R}_{t}$, plotted as a function of load comparing hot rolled and quenched 1541 steel.

The influence of heat treatment was also studied for a second alloy, the maraging steel $18 \mathrm{Ni}(300)$. After cooling from the austenitizing temperature, this steel has a structure that is predominantly lath martensite, but in contrast to quenched, high carbon martensitic steels, it is relatively soft, with a hardness of about $30 \mathrm{HRC}$. Aging at an appropriate temperature results in an increase in hardness through a precipitation reaction. For $18 \mathrm{Ni}(300)$ the precipitates are of the type $\mathrm{Fe}_{2} \mathrm{Mo}$ and $\mathrm{Ni}_{3} \mathrm{Ti}$. Table 7 lists the aging treatment, hardness, and damage parameters for specimens tested at $130 \mathrm{~N}$ on the low load capacity 
Table 7.

Effect of aging on damage for $18 \mathrm{Ni}(300)$ steel

$\begin{array}{lccccc}\text { Condition } & \begin{array}{c}\text { Hardness } \\ \text { Knoop 500g }\end{array} & \begin{array}{c}\overline{\mathrm{R}}_{\mathrm{t}} \\ (\mu \mathrm{m})\end{array} & \begin{array}{c}\mathrm{R}_{\mathrm{t}}(\mathrm{rms}) \\ (\mu \mathrm{m})\end{array} & \begin{array}{c}\mathrm{DV} \\ \left(\mathrm{mm}^{3}\right)\end{array} & \mathrm{AR} \\ \begin{array}{l}\text { As-quenched } \\ \begin{array}{l}\text { Aged } 6 \mathrm{~min} . \\ \text { at } 480^{\circ} \mathrm{C}\end{array}\end{array} & 339 & 52 & 14 & 0.28 & .09 \\ \begin{array}{l}\text { Aged } 3 \mathrm{~h} \\ \text { at } 480^{\circ} \mathrm{C}\end{array} & 537 & 4.4 & 1.4 & 0.015 & .04 \\ \begin{array}{l}\text { Aged } 5 \mathrm{~h} \\ \text { at } 600^{\circ} \mathrm{C}\end{array} & 466 & 3.1 & 1.5 & 0.0097 & .04 \\ & & 6.5 & 4.4 & 0.020 & .05\end{array}$

screw driven machine. It is seen that aging leads to a significant reduction in damage severity, i.e., $\bar{R}_{t}$ is reduced from $52 \mu \mathrm{m}$, which is relatively large compared to most alloys, to less than one-tenth that value by aging. Aging for 6 minutes at $480^{\circ} \mathrm{C}$, which results in an underaged condition, is sufficient to reduce the damage parameters to close to their minimum values; aging to peak hardness, 3 hours at $480^{\circ} \mathrm{C}$, leads to little further change despite an appreciable increase in hardness. Overaging treatment, 5 hours at $600^{\circ} \mathrm{C}$, results in an increase in damage severity. Thus, here is a second case where heat treatment leads, overall, to a significant reduction in damage. Comparing as-quenched with aged specimens, it may be noted that the decrease in damage is far greater than the 40 - 608 change in hardness.

As a further point of discussion, it should be recognized for both 1541 steel and $18 \mathrm{Ni}(300)$ maraging steel that the change in damage severity associated with heat treatment is not necessarily just a direct effect of an increase in hardness without other influences. Heat treatment results in substantial changes in microstructure. In the case of hot rolled 1541 steel, a mixture of ferrite and pearlite is converted to martensite by heating and quenching, and, as already mentioned, martensite is changed to precipitation hardened martensite for $18 \mathrm{Ni}(300)$ steel. An apparent indication of the influence of microstructural effects is demonstrated by the results on underaged $\left(6 \mathrm{~min}\right.$. at $480^{\circ} \mathrm{C}$ ) and overaged 
$\left(5 \mathrm{~h}\right.$ at $\left.600^{\circ} \mathrm{C}\right) 18 \mathrm{Ni}(300)$ steel. While these treatments resulted in about the same hardness, the damage severity was greater in the overaged condition. In comparing specimens where the hardness varied, it would not be possible to conclude how much of the effect was associated with a change in hardness and how much was due to microstructural effects without a quantitative measure of the microstructural changes. Indeed, stating that microstructure influences galling severity is an indirect way of indicating that flow and fracture properties, to which hardness is not sensitive, do affect galling severity.

It is interesting to compare the damage morphologies of the different heat treated specimens. Figures 45 and 46 show SEM micrographs of damage for quenched and hot-rolled specimens of 1541 steel, respectively. Although the severity of the damage was significantly different for these two specimens the form of the damage is essentially identical. Prows develop in both cases, however the prows on the heat treated specimen do not grow to nearly as large a size as those on the hot rolled specimen. The result was similar for $18 \mathrm{Ni}(300)$ in the aged versus not aged condition.

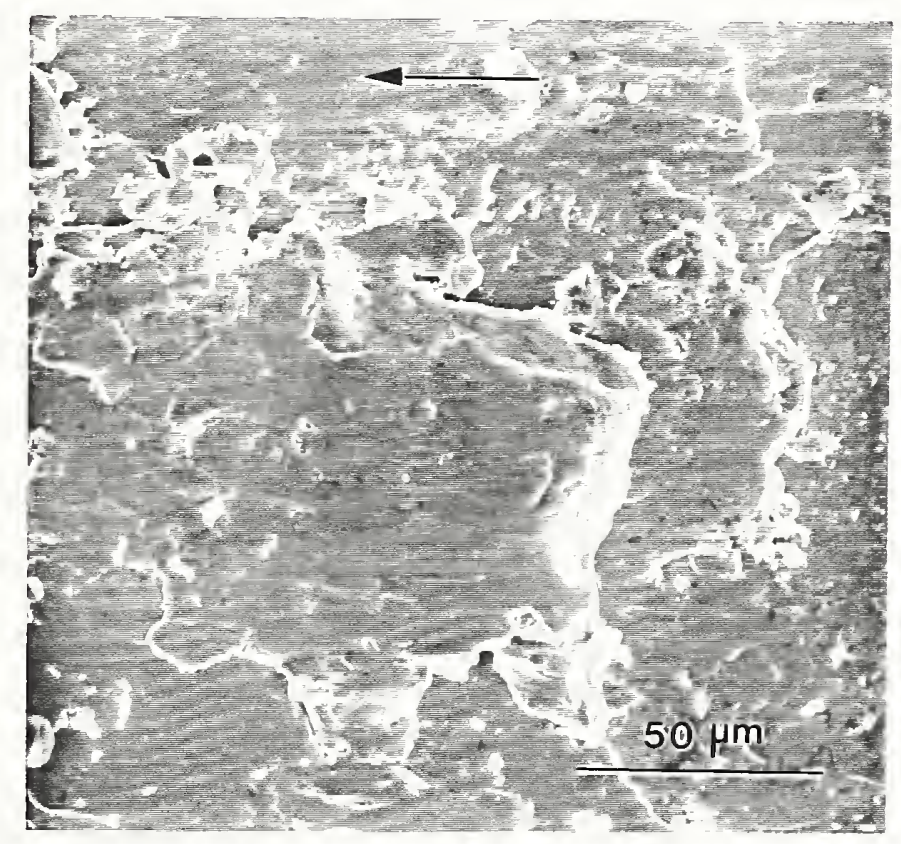

Fig. 45. Damage on quenched 1541 steel flat in self-mated test at 1500 N. Arrow indicates direction of pin motion. 


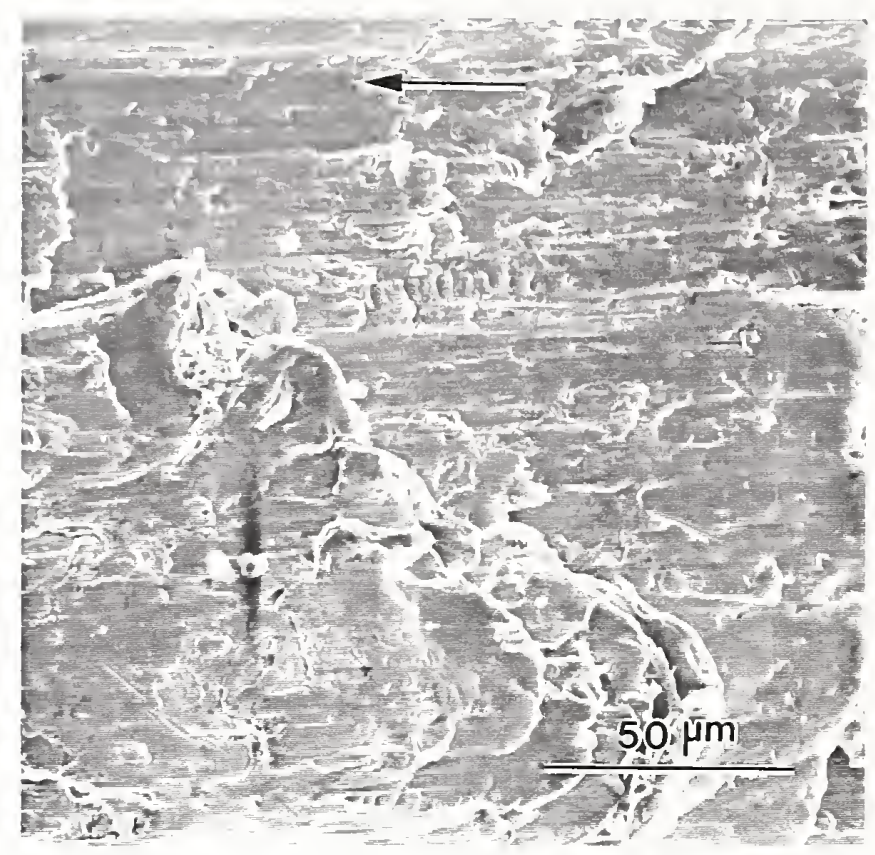

Fig. 46. Damage on hot rolled 1541 steel flat after self-mated test at $1500 \mathrm{~N}$ load. Arrow indicates direction of pin motion.Fig. 47. Hardness profile across carburized case on 8620 steel.

\subsection{Effect of Carburizing and Nitriding}

The galling behavior of carburized 8620 steel and nitrided 4140 steel were studied. The bulk compositions of these steels are given in Table 5 and the processing conditions are given in Table 8 . Results for carburized 8620 steel are discussed in detail in [4] and will be treated in less detail here. Both steels were tested under self-mated conditions and in combination with heat treated 1541 steel. The results for carburized 8620 steel will be presented first.

Table 8 .

Carburizing and nitriding treatments

8620 steel Gas carburized at $930^{\circ} \mathrm{C}$ for 4.5 hours, oil quenched and tempered at $180^{\circ} \mathrm{C}$ for 1 hour

4140 steel Quenched and tempered to 27 HRC; gas nitrided at $527^{\circ} \mathrm{C}$ for 40 hours. 
The carburizing treatment given to 8620 resulted in a martensite case with approximately 28 retained austenite at the outer surface. A hardness profile across the carburized case is shown in Fig. 47. The hardness at the surface is about $700 \mathrm{HV}$. Below the surface there is a slight initial increase in hardness followed by decreasing hardness to a depth of about $2 \mathrm{~mm}$ where the core value of approximately $350 \mathrm{HV}$ is reached.

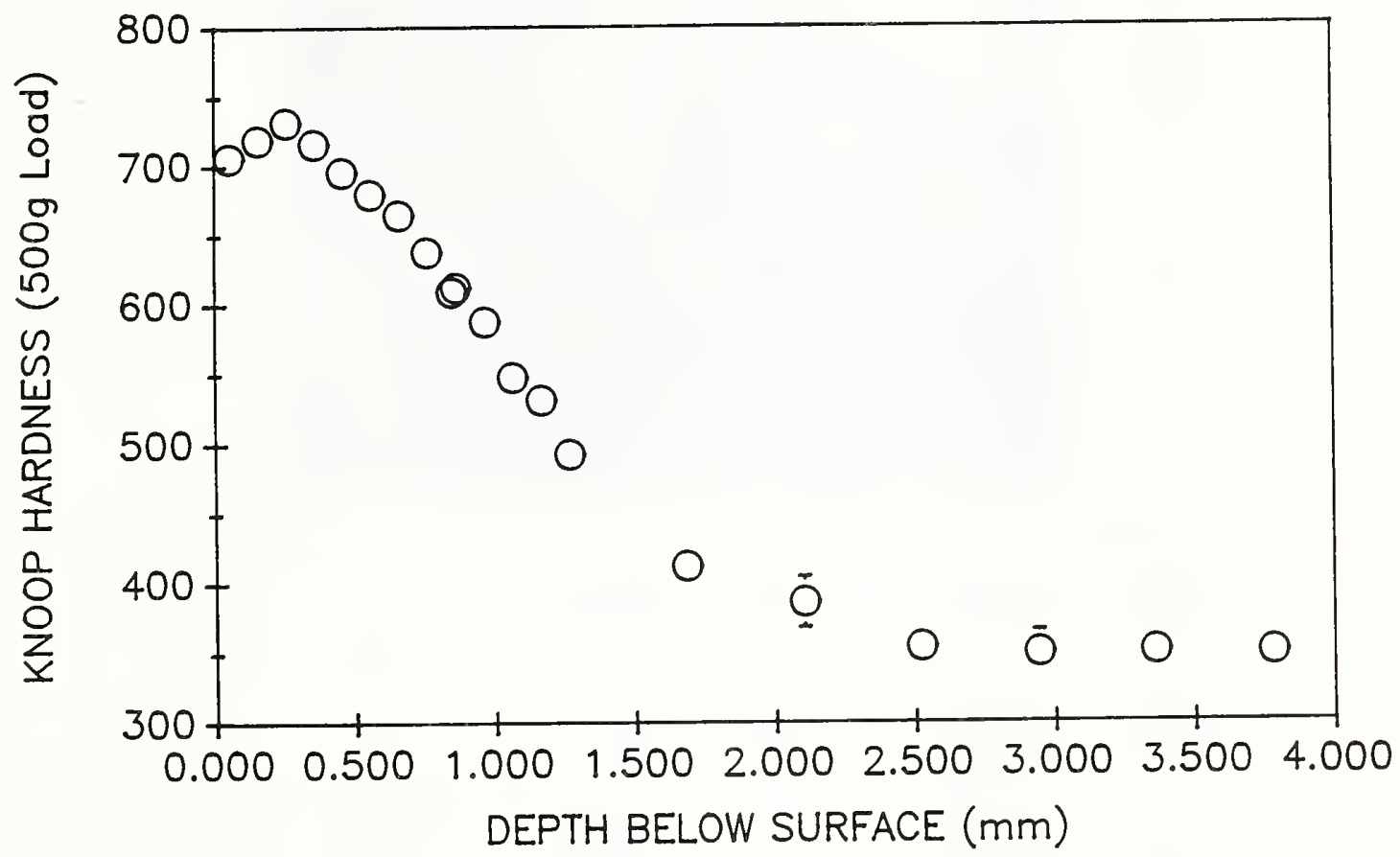

Fig. 47. Hardness profile across carburized case on 8620 steel.

Test results are summarized in Table 9. For the combinations 1541 vs. 8620 three loads were employed: $1500 \mathrm{~N}, 3000 \mathrm{~N}$, and $6000 \mathrm{~N} .8620$ vs. 8620 was tested at only one load, $1500 \mathrm{~N}$. The damage at $1500 \mathrm{~N}$ was small for all combinations, so additional tests at lower loads were not conducted. It can be seen that the damage sustained by the 1541 steel flat when slid against an 8620 pin was substantially greater on average than that experienced by the 8620 flat slid against a 1541 pin. This might be expected based on the hardness difference between the two materials. Indeed, as was true in the case of the pure metal combinations discussed earlier, a significant part of the damage measured for the 
Table 9 .

Results on carburized and nitrided steels.

\begin{tabular}{|c|c|c|c|c|c|}
\hline & nen & Load & $\overline{\mathrm{R}}_{\mathrm{t}}$ & $\begin{array}{c}\text { Mean } \\
\overline{\mathrm{R}}_{\mathrm{t}}\end{array}$ & $\begin{array}{l}\text { Standard } \\
\text { Deviation } \\
\text { in } \bar{R}_{\mathrm{t}}\end{array}$ \\
\hline Pin & Flat & $(\mathrm{N})$ & $(\mu \mathrm{m})$ & & \\
\hline 1541 & 8620 & 1500 & 9.1 & & \\
\hline 1541 & 8620 & 1500 & 3.0 & & \\
\hline 1541 & 8620 & 1500 & 3.3 & 5.1 & 3.5 \\
\hline 1541 & 8620 & 3000 & 5.0 & & \\
\hline 1541 & 8620 & 3000 & 11.7 & & \\
\hline 1541 & 8620 & 3000 & 13.7 & 10.1 & 4.6 \\
\hline 1541 & 8620 & 6000 & 32.3 & & \\
\hline 1541 & 8620 & 6000 & 18.8 & & \\
\hline 1541 & 8620 & 6000 & 9.8 & 20.3 & 11.3 \\
\hline 8620 & 1541 & 1500 & 23.0 & & \\
\hline 8620 & 1541 & 1500 & 1.9 & & \\
\hline 8620 & 1541 & 1500 & 12.0 & 12.3 & 10.6 \\
\hline 8620 & 1541 & 3000 & 37.9 & & \\
\hline 8620 & 1541 & 3000 & 35.3 & & \\
\hline 8620 & 1541 & 3000 & 23.6 & 32.3 & 7.6 \\
\hline 8620 & 1541 & 6000 & 50.2 & & \\
\hline 8620 & 1541 & 6000 & 52.6 & 51.4 & 1.7 \\
\hline 8620 & 8620 & 1500 & 2.5 & & \\
\hline 8620 & 8620 & 1500 & 8.6 & & \\
\hline 8620 & 8620 & 1500 & 10.6 & 7.2 & 4.2 \\
\hline
\end{tabular}

harder carburized 8620 steel flat was a result of transfer from the 1541 pin. This is demonstrated in Fig. 48 which shows a prow and trailing groove on an $8620 \mathrm{flat}$. An energy dispersive $\mathrm{x}$-ray spectrum from region $A$ in the prow displayed no nickel peak whereas a nickel peak was obtained at $B$ in the trailing groove. The absence of detectable nickel in the prow can be attributed to the transfer of 1541 steel which contains only a trace concentration of nickel compared to a small but readily detectable concentration in 8620 steel.

When a carburized 8620 steel pin was slid against a carburized 8620 steel flat at $1500 \mathrm{~N}$ load, the damage sustained by the flat, $\overline{\mathrm{R}}_{\mathrm{t}}=7.2 \pm$ $4.2 \mu \mathrm{m}$, was greater than that obtained when a 1541 steel pin was employed, 


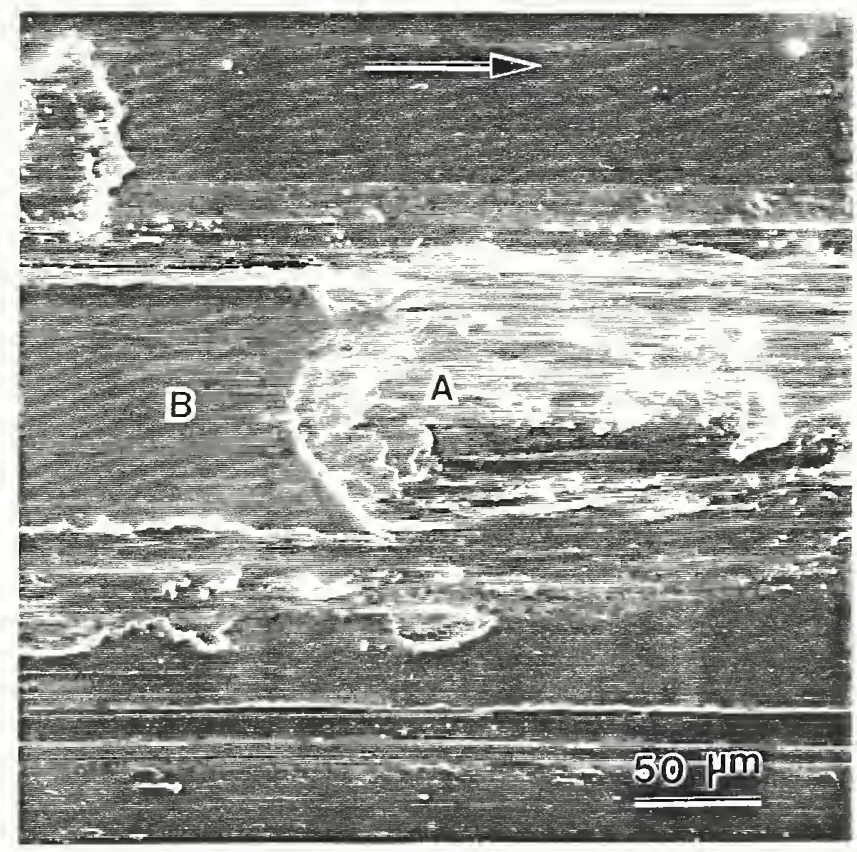

Fig. 48. Prow on 8620 steel flat produced by sliding against a quenched 1541 steel pin at $1500 \mathrm{~N}$. A and B identify locations analyzed by EDS. Arrow indicates direction of pin motion.

$\bar{R}_{\mathrm{t}}=5.1 \pm 3.5 \mu \mathrm{m}$. This may be compared to the results obtained for different pins against the quenched 1541 steel flats. Under selfmated conditions, $\overline{\mathrm{R}}_{\mathrm{t}}=23 \pm 11 \mu \mathrm{m}$ was obtained, while with the 8620 pin, $\bar{R}_{t}=12.3 \pm 10.6 \mu \mathrm{m}$. This behavior suggests that more damage is sustained by the flat under self-mated conditions than when either a harder or softer pin is used. In terms of damage to the flat, the most favorable condition seems to occur when the pin is softer than the flat; the damage to the flat is primarily due to transfer from the pin. Finally, under self-mated conditions, the trend noted in the case of 1541 steel for damage to decrease with increasing hardness continues with carburized 8620 steel. The results for 1541 steel and carburized 8620 steel are summarized in Fig. 49 for tests at a load of $1500 \mathrm{~N}$. A less extensive series of tests, similar to those conducted on carburized 8620 steel, was carried out on nitrided 4140 steel. Only two combinations were evaluated. Nitrided 4140 steel was studied as a 


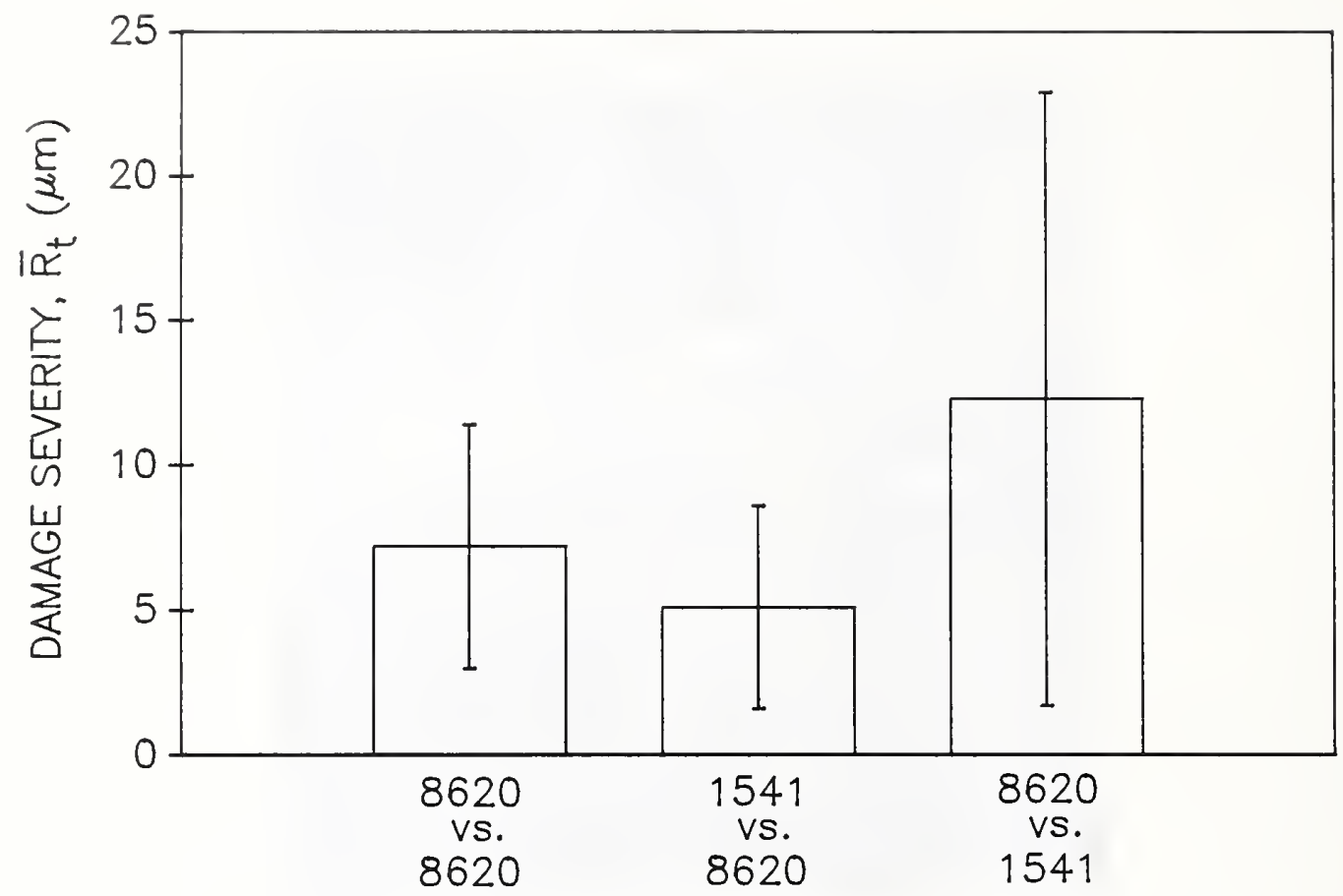

Fig. 49. Comparison of damage results for different steel combinations in tests at $1500 \mathrm{~N}$.

self-mated pair and heat treated 1541 steel pins were slid against nitrided 4140 steel flats. The nitrided surface of 4140 steel consisted of a $15 \mu \mathrm{m}$ thick outer "white" or "compound" layer, probably of $\mathrm{Fe}_{2}-{ }_{3} \mathrm{~N}$, overlying a mixed structure of various nitride precipitates and martensite with the nitride precipitate concentration decreasing with increasing depth. The nitrided case extended to a total depth of about $500 \mu \mathrm{m}$ below the original surface. Prior to nitriding, the test surfaces were machine surface ground. Nitriding resulted in a slight increase in roughness together with a thin layer of scale. For testing, the surfaces were prepared in the standard way by first grinding on a series of SiC abrasive papers followed with final polishing on a lap charged with 6 $\mu \mathrm{m}$ diamond compound. After testing it was noticed that there was a small but varying amount of white layer remaining on some surfaces. The effect of this variation in surface condition on the test results is not known at this time. Resolution of this uncertainty would require additional tests on specimens both with and without the white layer. 
Four parameters, DV, $\bar{R}_{t}, R_{t}$ (rms), and AR, characterizing the damage on each flat were calculated. These parameters are plotted as a function of applied load in Fig. $50-53$.

In Fig. 50 it is seen that the two different pin and flat combinations behave in about the same way with respect to displaced volume. There is a large, approximately 10 times increase in DV between $3000 \mathrm{~N}$ and $6000 \mathrm{~N}$.

The changes in $\bar{R}_{t}$ are shown in Fig. 51. Again, increasing the applied load from $3000 \mathrm{~N}$ to $6000 \mathrm{~N}$ results in a marked increase in damage for both combinations. Similar to $\mathrm{DV}, \overline{\mathrm{R}}_{\mathrm{t}}$ at $3000 \mathrm{~N}$ is greater for nitrided 4140 self-mated than for 1541 vs. 4140. This difference is even larger for $R_{t}$ (rms), Fig. 52. The basis for the increased sensitivity can be explained as follows: The damage topography of the 4140 steel flat consisted primarily of a shallow groove corresponding more-or-less to the contour of the pin tip. The size of the groove increased with increasing load. Within the groove there were scratches parallel to the direction of sliding and in some cases transverse cracks. The volume of the scratches and cracks, being relatively small compared to that of the primary groove, had little effect on DV, i.e., DV is mainly determined by the size of the primary groove. However, a relatively deep but narrow scratch or crack which contributes little to volume could have a large effect on $\bar{R}_{t}$. Similarly, large variations in the depths of the cracks or scratches would lead to large $R_{t}$ (rms) values. Thus, the scratches and cracks were increasingly important features in determining $\bar{R}_{t}$ and $\mathrm{R}_{\mathrm{t}}$ (rms).

Figure 53 shows the behavior in the aspect ratio parameter, AR, as a function of load for the two specimen combinations. We see that AR does not vary markedly among the tests and is relatively small ( $<1$ ) indicating that the topography consists primarily of long ridges and/or grooves parallel to the direction of sliding.

Photographs of the damage sustained by the nitrided 4140 steel flats after sliding against 1541 steel pins are shown in Figs. 54 a-c for loads of $1500 \mathrm{~N}, 3000 \mathrm{~N}$, and $6000 \mathrm{~N}$, respectively. Nomarski interference contrast was employed to enhance the visibility of the small changes in 


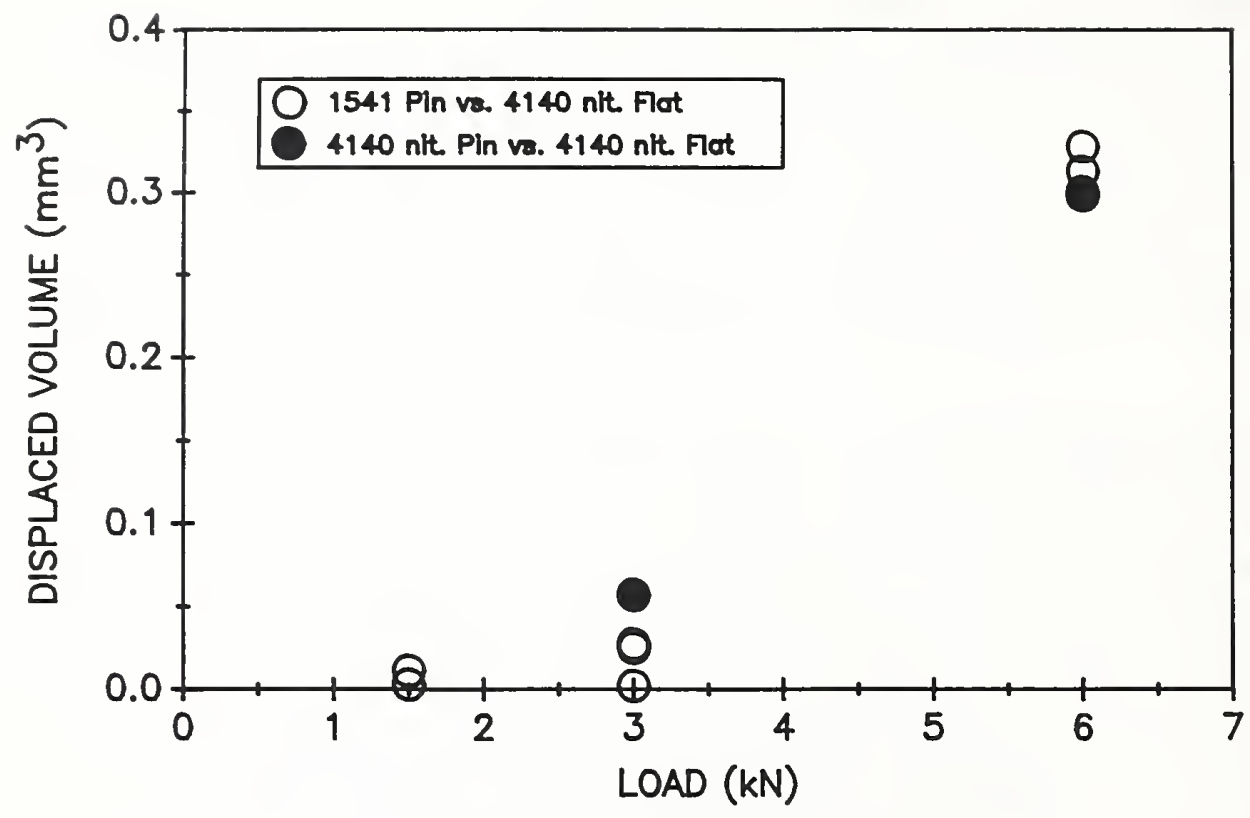

Fig. 50. Variation in displaced volume parameter, DV, with applied load on flats for different sliding combinations.

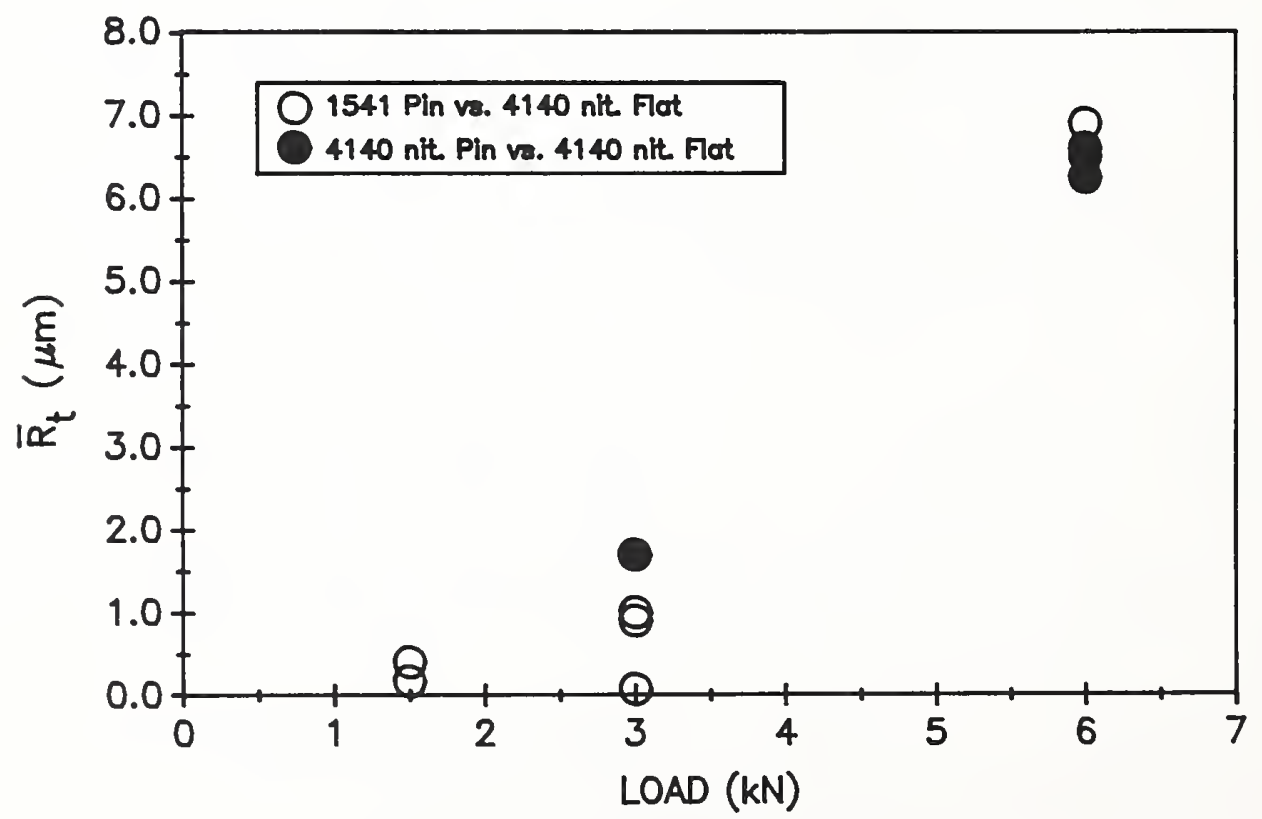

Fig. 51. Variation in average maximum peak to valley parameter, $\bar{R}_{t}$, with applied load for different sliding combinations. 


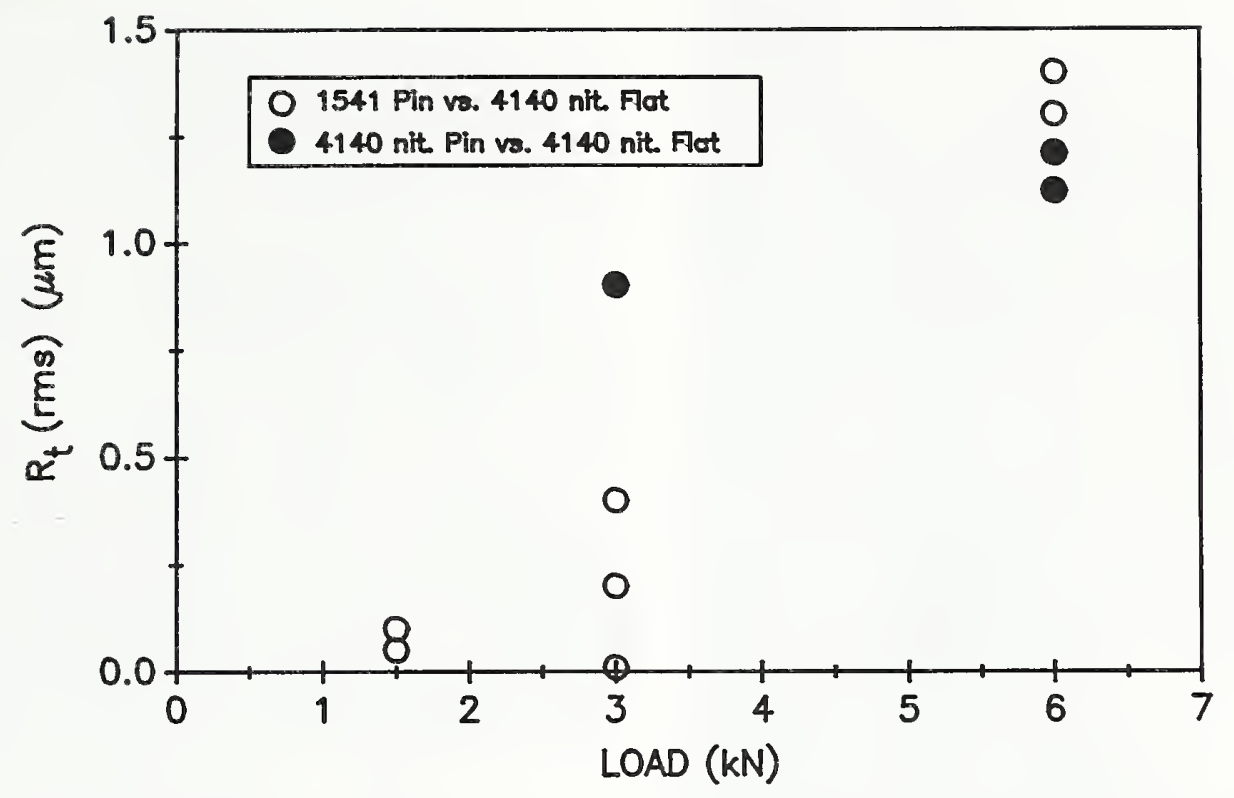

Fig. 52. Variation $R_{t}$ (rms) as a function of applied load for different sliding combinations.

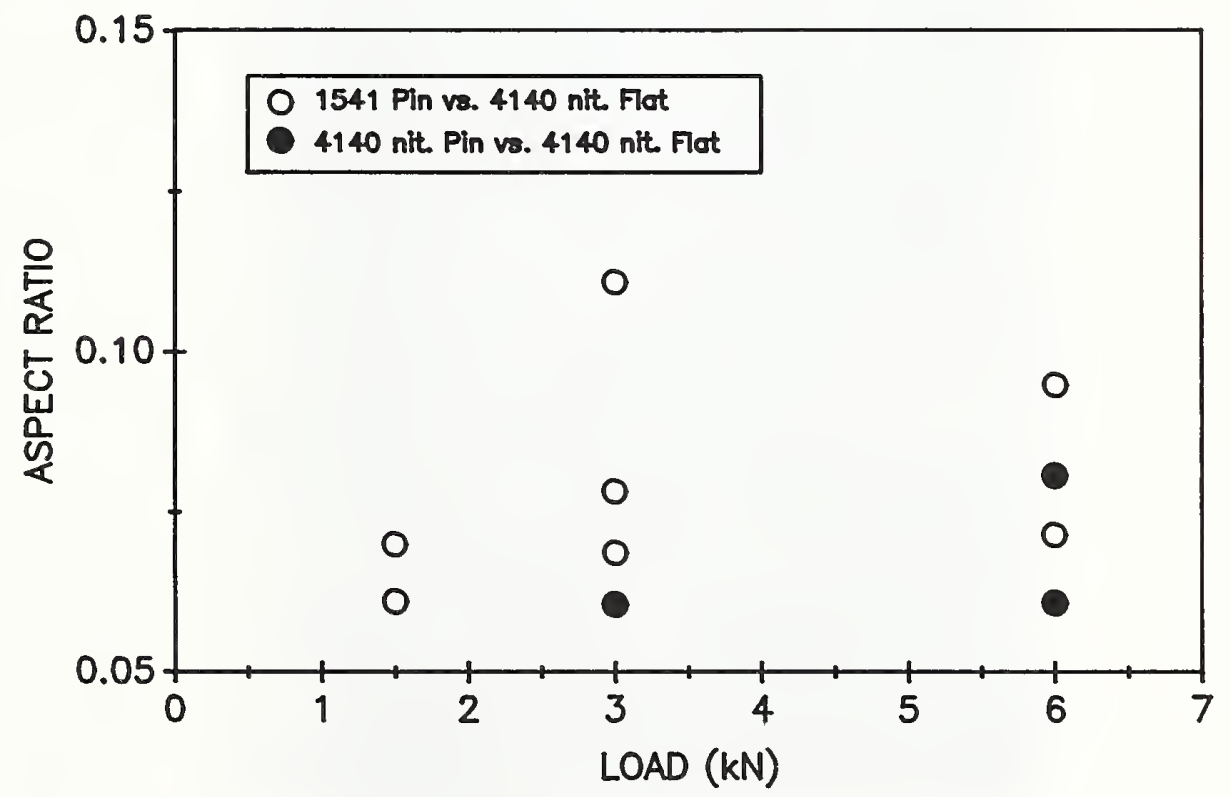

Fig. 53. Variation in aspect ratio parameter, $A R$, as a function of applied load for specimen flats. The low values, all $\ll 1$, indicate damage is primarily in the form of long grooves and ridges parallel to the direction of sliding. 

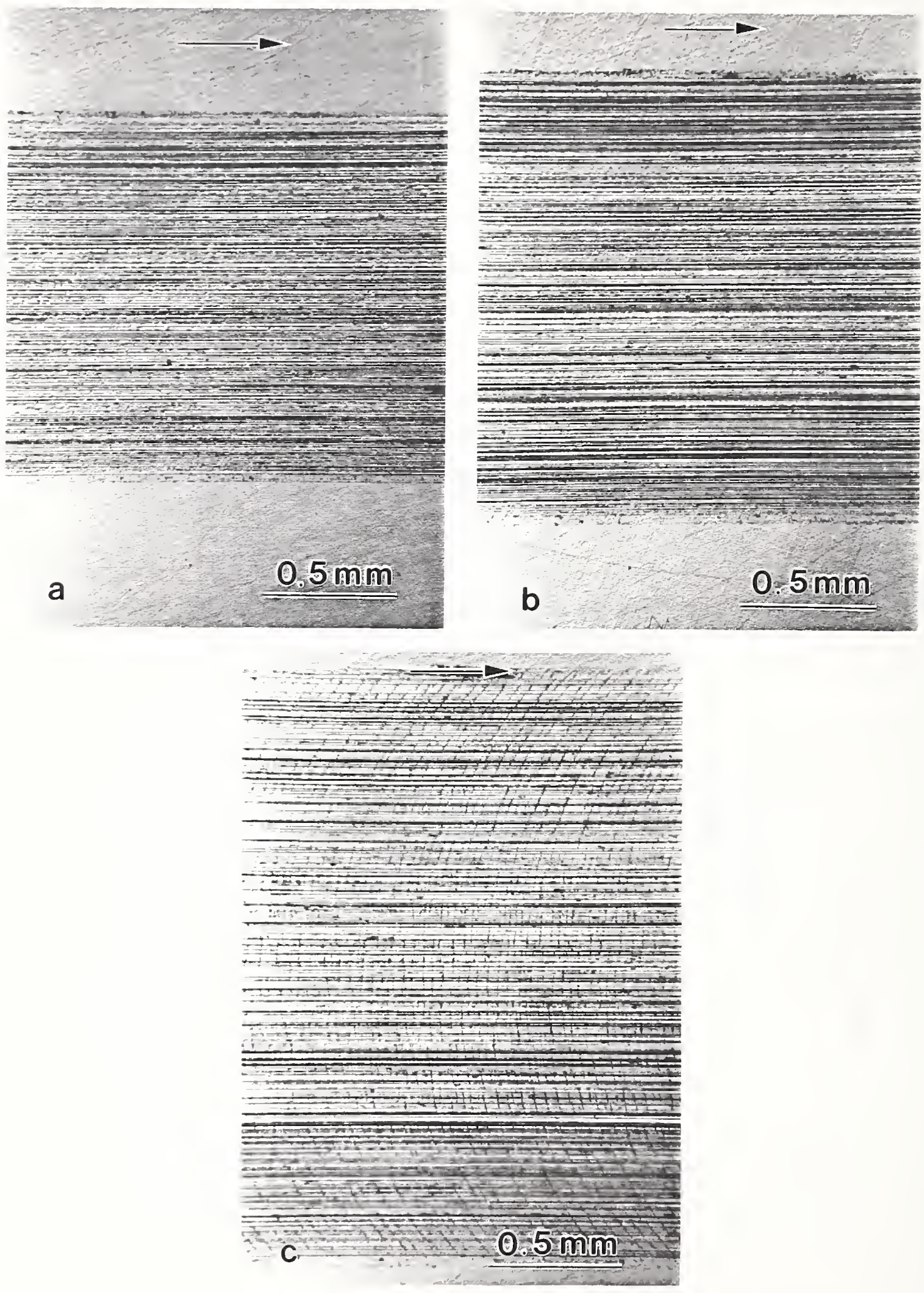

Fig. 54. Optical micrographs (Nomarski contrast) showing section of track on nitrided 4140 specimen flat after sliding against 1541 pin.
(a) $1500 \mathrm{~N}$ load.
(b) $3000 \mathrm{~N}$ load.
(c) $6000 \mathrm{~N}$ load. 
surface topography. The surfaces shown in Fig. 54 are not severely damaged, and, despite the presence of an occasional small prow (none are present in Fig. 54), would not be referred to as galled. The damage in all cases is seen to consist of fine grooves and ridges lying parallel to the direction of sliding, as was indicated by the small value of the aspect ratio parameter discussed above. Cracks perpendicular to the direction of sliding are quite prominent in the specimen tested at $6000 \mathrm{~N}$. These cracks are undoubtedly due to the tensile fracture of the hard, nitrided case. Similar cracks, smaller in size and much fewer in number, could also be found in the specimens tested at $3000 \mathrm{~N}$ and $1500 \mathrm{~N}$. For example, cracks in a nitrided 4140 flat after testing at $1500 \mathrm{~N}$ are shown in Fig. 55.

The damage to the nitrided 4140 flats after sliding against 4140 pins was quite similar in appearance to that produced by sliding against 1541 pins. An example of the damage is shown in Fig. 56.

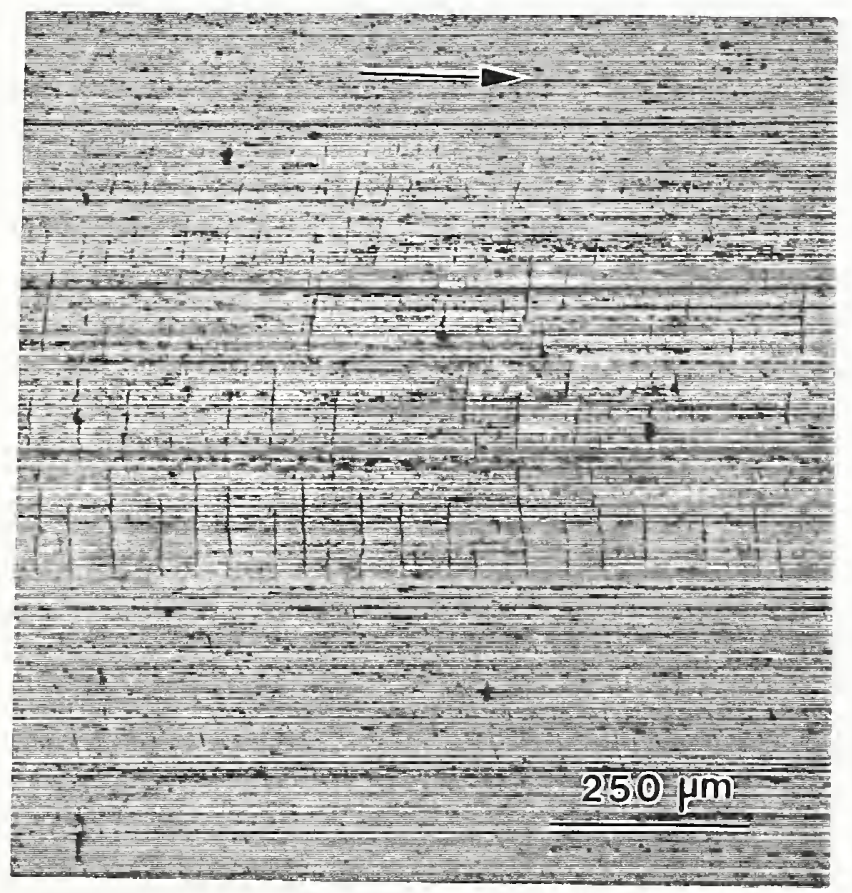

Fig. 55. Transverse cracks in wear track on nitrided 4140 specimen flat after sliding against 1541 steel pin at $1500 \mathrm{~N}$. Nomarski contrast. Arrow indicates direction of pin motion. 


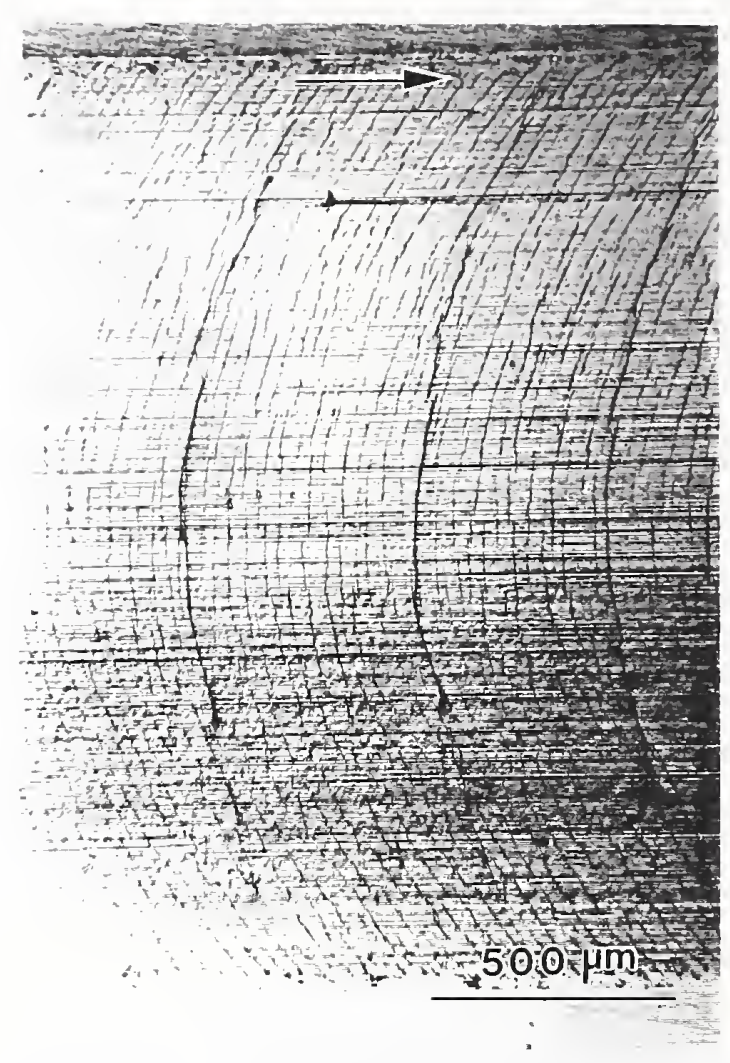

Fig. 56. Optical micrograph (Nomarski contrast) showing section of track on nitrided 4140 specimen flat after sliding against nitrided 4140 pin at $6000 \mathrm{~N}$ load. Arrow indicates direction of pin motion.

The presence of the cracks probably did not have much influence on the damage parameters. First, the cracks were very narrow compared to the size of the stylus tip ( $\sim 10 \mu$ m radius spherical shape) that was used to measure the surface topography, and second, at the highest load where the cracks were most frequent, the relatively large size of the grooves and ridges as well as the overall size of the track probably off-set the effect of the cracks.

The fine grooves parallel to the direction of sliding seen on all flats may be attributed to the presence small scale variations in both roughness and hardness of the original surfaces. Another, perhaps important, contribution to the development of this topography was the formation of small lumps of transferred material at the front of the contact region on the pin, as shown in Fig. 57a. The lumps were formed 

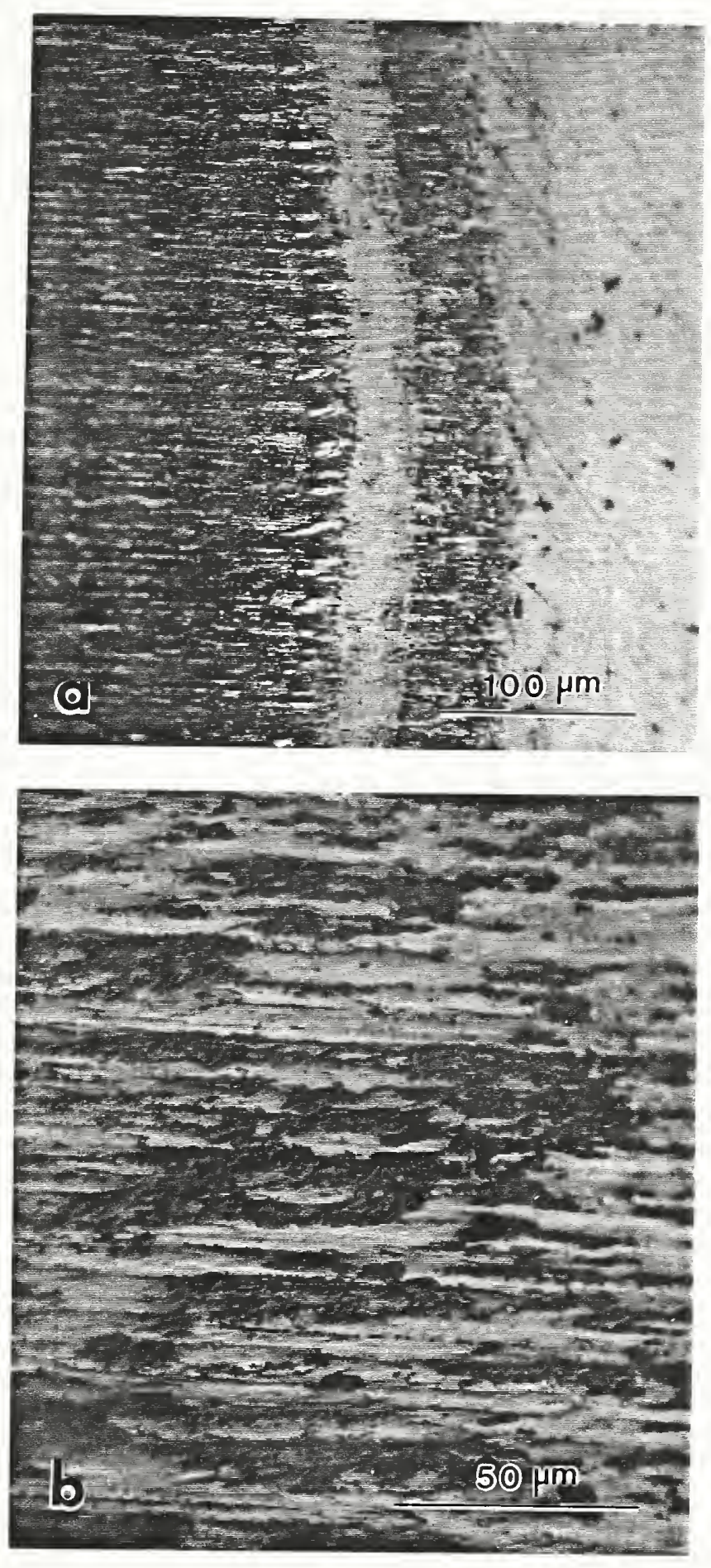

Fig. 57. Optical micrographs of scar on 1541 pin after sliding on nitrided 4140 flat. (a) Front part of contact showing transferred lumps and oxide. (b) Oxide near center of contact area on pin. 
early during initiation of sliding and remained throughout the sliding process. Also observed on the pin contact surface was the apparent accumulation of oxide debris (Fig. 57a and b). Some oxide debris was also seen on the flats. The presence of oxide debris indicates a "mild" form of wear as opposed to severe wear or galling which results in the formation of metallic debris.

\subsection{Corrosion Resistant and Other Alloys}

In this section results on the galling behavior of a number of commercial alloys are presented. Both ferritic and austenitic stainless steels and several other corrosion resistant alloys are included in the group. An aluminum bronze bearing alloy found to be highly resistant to galling is analyzed in detail. A list of the alloys and their nominal compositions is given in Table 10. Some of the alloys in Table 10 were discussed in previous sections; however, they are included here to facilitate comparison.

Table 10 .

Nominal Compositions of Alloys (wt. $\frac{8}{8}$ principal elements)

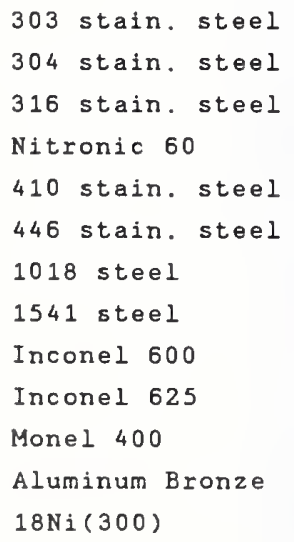

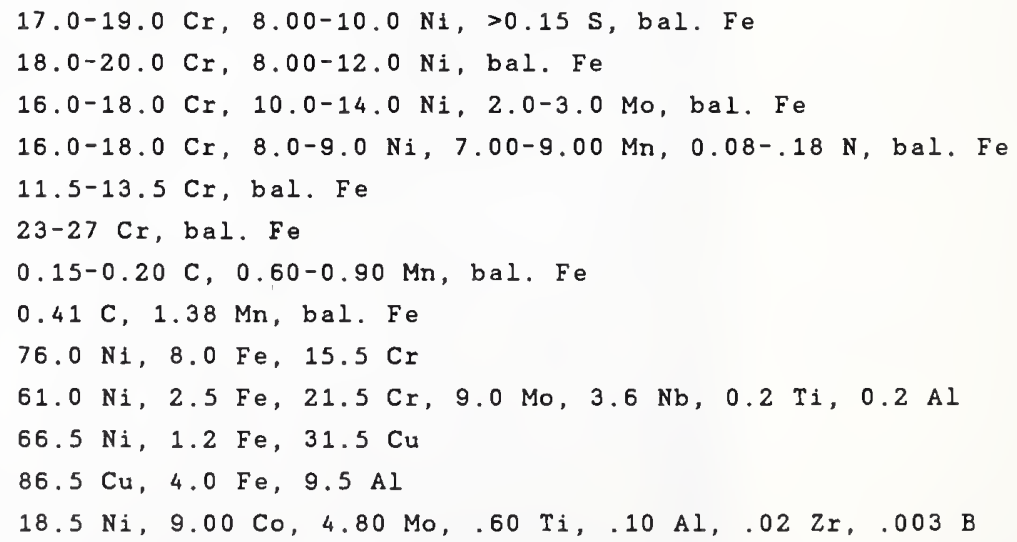

With the exception of the aluminum bronze alloy, all materials were obtained in the form of $1 / 2$ inch diameter rods. Pin and flat specimens were machined directly from these rods. The aluminum bronze 
specimens were machined from 1 inch diameter rod stock. After machining, the test surfaces of all specimens were prepared in the standard manner. Only self-mated combinations were studied. Tests were conducted with the screw-driven machine at a load of $130 \mathrm{~N}$ unless otherwise indicated. The test load of $130 \mathrm{~N}$ exceeded by a factor of from 1.5 to 3.3 the critical Hertz loads for yielding of these alloys.

Damage severity results are given in Table 11 . In general, the severity parameters $\bar{R}_{t}, R_{t}$ (rms), and $D V$ vary in a consistent way from alloy to alloy. For example, $\bar{R}_{t}$ for 446 stainless steel is larger than $\bar{R}_{t}$ for Monel 400, and it follows that $R_{t}$ (rms) and $D V$ are also larger for 446 stainless steel. Some discrepancies do exist however. For

Table 11.

Damage Results for some commercial alloys

$\begin{array}{lccccc}\text { Alloy } & \begin{array}{c}\text { Hardness } \\ \text { Knoop } 5008\end{array} & \begin{array}{c}\bar{R}_{\mathrm{t}} \\ (\mu \mathrm{m})\end{array} & \begin{array}{c}\mathrm{R}_{\mathrm{t}} \text { (rms) } \\ (\mu \mathrm{m})\end{array} & \begin{array}{c}\mathrm{DV} \\ \left(\mathrm{mm}^{3}\right)\end{array} & \text { AR } \\ 303 & 308 & 23 & 18 & - & - \\ 304 & 315 & 39 & 23 & - & - \\ 316 & 336 & 36 & 23 & - & - \\ \text { Nitronic 60 } & 356 & 1.4 & 1.2 & - & - \\ 446 & 248 & 109 & 151 & 2.51 & 0.46 \\ 410 \text { annealed } & 246 & 81 & 67 & - & - \\ 1018 \text { cold rolled } & 250 & 53 & 54 & - & - \\ 1541 \text { hot rolled } & 221 & 36.7 & - & - & - \\ \text { Inconel 600 } & 256 & 54 & 30 & 0.65 & 0.28 \\ \text { Inconel 625 } & 351 & 19 & 10 & 0.19 & 0.12 \\ \text { Monel 400 } & 245 & 31 & 15 & 0.22 & 0.16 \\ \text { Aluminum bronze } & 218 & 0.41 & 1.1 & 0.0062 & 0.05 \\ \text { 18Ni(300) quenched } & 339 & 52 & 14 & 0.28 & 0.09\end{array}$

example, compare $18 \mathrm{Ni}(300)$ and 304 stainless where $\bar{R}_{t}$ is larger for $18 \mathrm{Ni}\left(300\right.$ ) than for 304 but $\mathrm{R}_{\mathrm{t}}$ (rms) is smaller. This inconsistency results from the effect that different types of topography can have on the damage parameters as discussed previously.

The AR parameter is <1 for all alloys listed in Table 11. Thus there is an overall tendency for the damage features to be elongated in the direction of sliding. This is quite pronounced for alloys with low damage severity values, for example, aluminum bronze. 
Perhaps the most interesting alloys are those that exhibit very low damage severity values, most notably, aluminum bronze and Nitronic 60. As an example of a commercial alloy that exhibits almost no evidence of galling, aluminum bronze will be examined in detail. A photograph of the track on the aluminum bronze flat is shown in Fig. 58a. The topography obtained from profilometry data is shown in Fig. 58b and a graph of the maximum peak-to-valley height values, $\mathrm{R}_{\mathrm{t}}$, plotted as a function of sliding distance is shown in Fig. 58c. The large peak at the end of the track in Fig. $58 \mathrm{~b}$ is not the result of galling or the presence of a prow but is due to debris accumulated during sliding. In another test the debris, rather than remaining on the flat, was attached to the pin when it was lifted from the flat.
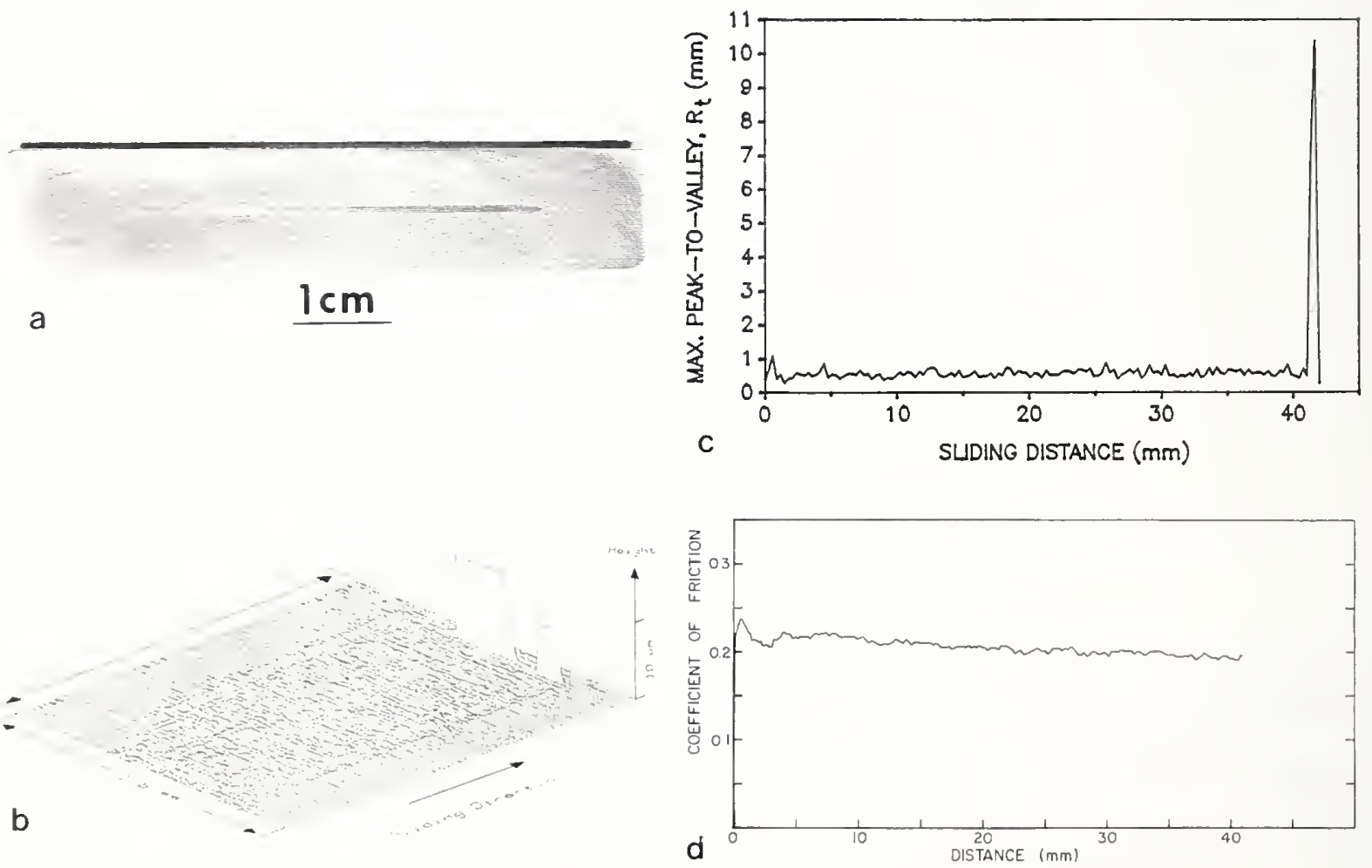

Fig. 58. (a) Optical photograph of track on an aluminum bronze flat. (b) Profilometer tracing of damage. (c) Plot of the maximum peakto-valley heights as a function of distance along the track. (d) Coefficient of friction plotted as a function of sliding distance. 
The coefficient of friction recorded during a test on aluminum bronze is plotted as a function of sliding distance in Fig. 58d. On average, the coefficient of friction is about 0.2 and fluctuates very little. A coefficient of friction value of 0.2 is quite low for nonlubricated metal-on-metal sliding and is consistent with the apparent lack of galling exhibited by this metal.

Examination in the SEM of the initial part of the track on an aluminum bronze flat revealed the presence of very small prows, shown in Fig. 59a. These prows were present on the flat for a sliding distance no greater than approximately the diameter of the pin contact area. Individual prows, shown at higher magnification in Fig. 59b, seem to be
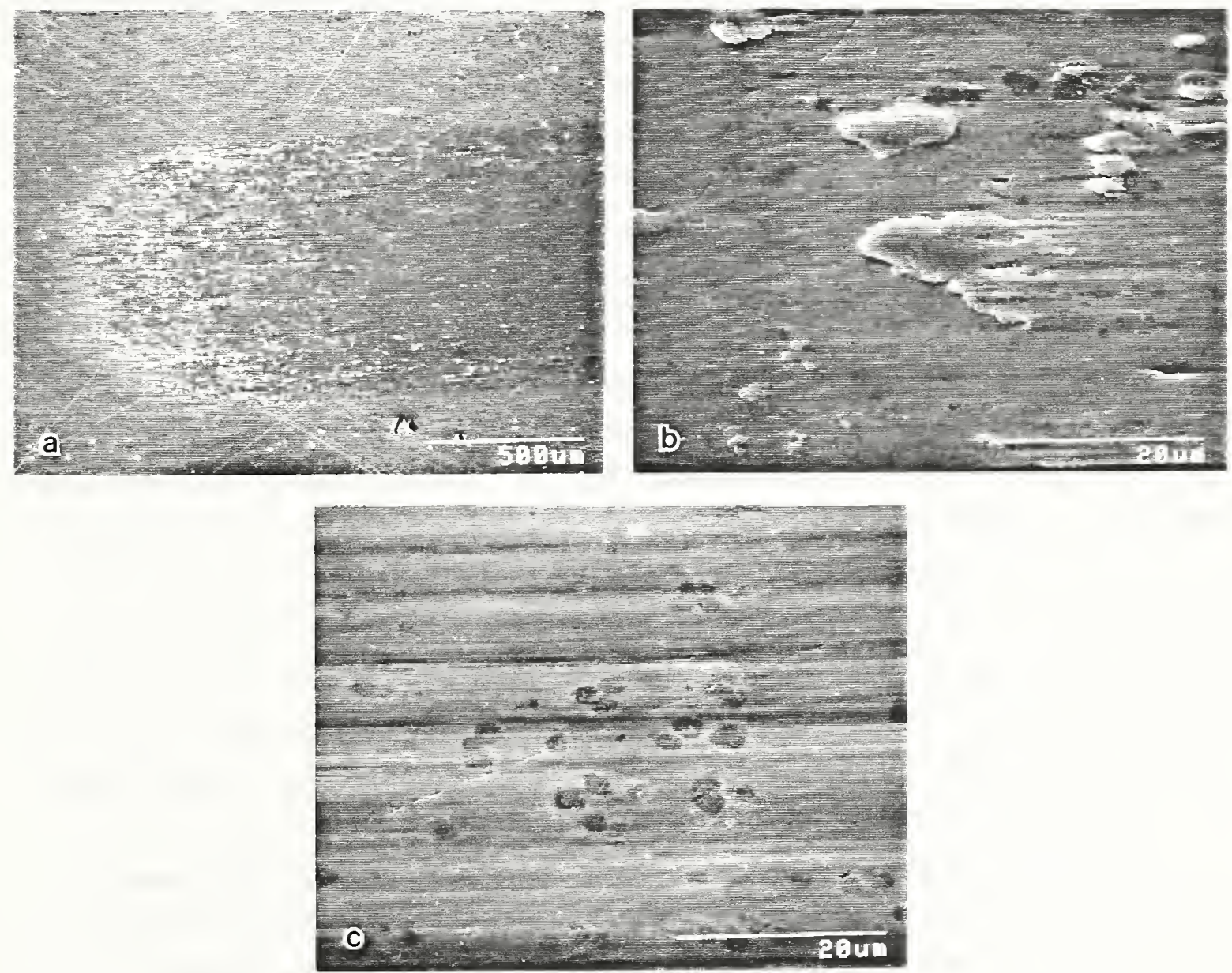

Fig. 59. (a) SEM micrograph of initial part of track on aluminum bronze flat. (b) Small prows present at beginning of track.

(c) Typical appearance of track past initiation point. 
quite similar to the much larger prows that are associated with severe galling damage in other metals (see Fig. 63). Aside form this slight initial damage, the track on the aluminum bronze flat was quite smooth and, typically, was like that shown in Fig. 59c. (The dark circular features visible in Fig. 59c are iron rich precipitates contained in the alloy.) It may be noted that most of the original polishing scratches have been "smoothed over". Remnants of one polishing scratch can be seen in Fig. 59c.

It might be suggested that the presence of an oxide layer or contaminant with lubricating properties could be responsible for the lack of galling observed in the case of aluminum bronze. To explore this hypothesis, a test was conducted at a load ten times higher (1300 N) than previously. With the increased deformation brought about by this larger load it would be expected that the effectiveness of a thin oxide layer or contaminant film would be considerably diminished. Although the track on the flat at this high load, as would be expected, was wider, the surface topography was almost identical to that at the lower load: Very small prows were present in the initial contact area, followed by a smooth surface over the remainder of the track. The coefficient of friction was nearly identical to that at the lower load. Thus, it appears that the resistance of aluminum bronze to galling is not due to the presence of a surface film but is related to the deformation response of the material. With a concentration of $10 \mathrm{wt}$. $\% \mathrm{Al}$, aluminum bronze is a two phase alloy (three phases including the iron rich precipitates). Metallographic examination indicated that the material studied had about equal volume concentrations of the primary solid solution $\alpha$-phase and of the bcc $\beta$-phase. The $\alpha$-phase would be expected to have a low stacking fault energy, and almost certainly this contributes to the high resistance to galling exhibited by the alloy.

Among the alloys listed in Table 11 there are three widely used austenitic stainless steels $-304,316$, and 303. In this group the least damage was exhibited by 303 stainless steel. This stainless steel is essentially a free machining modification of 304 stainless steel obtained by the addition of sulfur. The improved resistance to galling may be due to the free machining characteristic; however, the improvement is 
relatively small and could simply be the result of a somewhat different microstructure possessed by the alloy.

Monel 400 is also a face-centered cubic (austenitic) alloy and exhibits about the same level of damage as the above stainless steels. On the other hand, Nitronic 60 stands out among the alloys in this group. Its high resistance to galling is well known [13] and is confirmed here. Examination of specimens of this alloy in the transmission electron microscope showed that glide dislocations were widely extended, indicating a low stacking fault energy. This is almost certainly responsible for the high resistance to galling. The low stacking fault energy of Nitronic 60 is achieved by substituting manganese and silicon for a large fraction of the nickel that is present in the other austenitic stainless steels.

Inconel 600 and 625 are high temperature, oxidation resistant and corrosion resistant alloys. They are similar to the austenitic stainless steels but have very high concentrations of nickel and only a small concentration of iron. In terms of galling behavior, both alloys can be placed in a group with the 300 series stainless steels and Monel 400. The severity of the damage is less for Inconel 625 than for Inconel 600. This could be associated with the greater hardness of Inconel 625. The general effect of hardness will be discussed in the next section. Two ferritic stainless steels were studied. They are 410, a hardenable alloy which was tested in the annealed condition, and 446 which does not harden by heat treatment. Both alloys exhibited severe galling damage, with 446 showing the highest damage values of all the materials in Table 11 .

The two carbon steels, 1018 and 1541 (hot rolled), exhibit relatively severe galling. It is interesting that the stainless steels as a group are often considered to gall more severely than other alloys. The results obtained here indicate that this is not necessarily true. The reason for their bad reputation is that stainless steels do not respond well to most ordinary lubricants and are not covered by a thick oxide layer which can protect against galling. Thus, in ordinary situations they are more likely to gall than many other non-galling resistant alloys. 
When galling is encountered in practical applications, increasing the hardness of the contacting surfaces is one of the first remedies considered. As has been pointed out, however, there is little evidence of correlation between hardness and galling severity for self-mated pure metals. On the other hand, we have demonstrated that hardening of steels by heat treatment results in a significant reduction in galling severity. In order to examine the influence of hardness in general, galling severity is plotted against pretest hardness in Fig. 60 for all self-mated tests conducted at a load of $130 \mathrm{~N}$. We see that there is an upper bound in damage severity that decreases with increasing hardness.

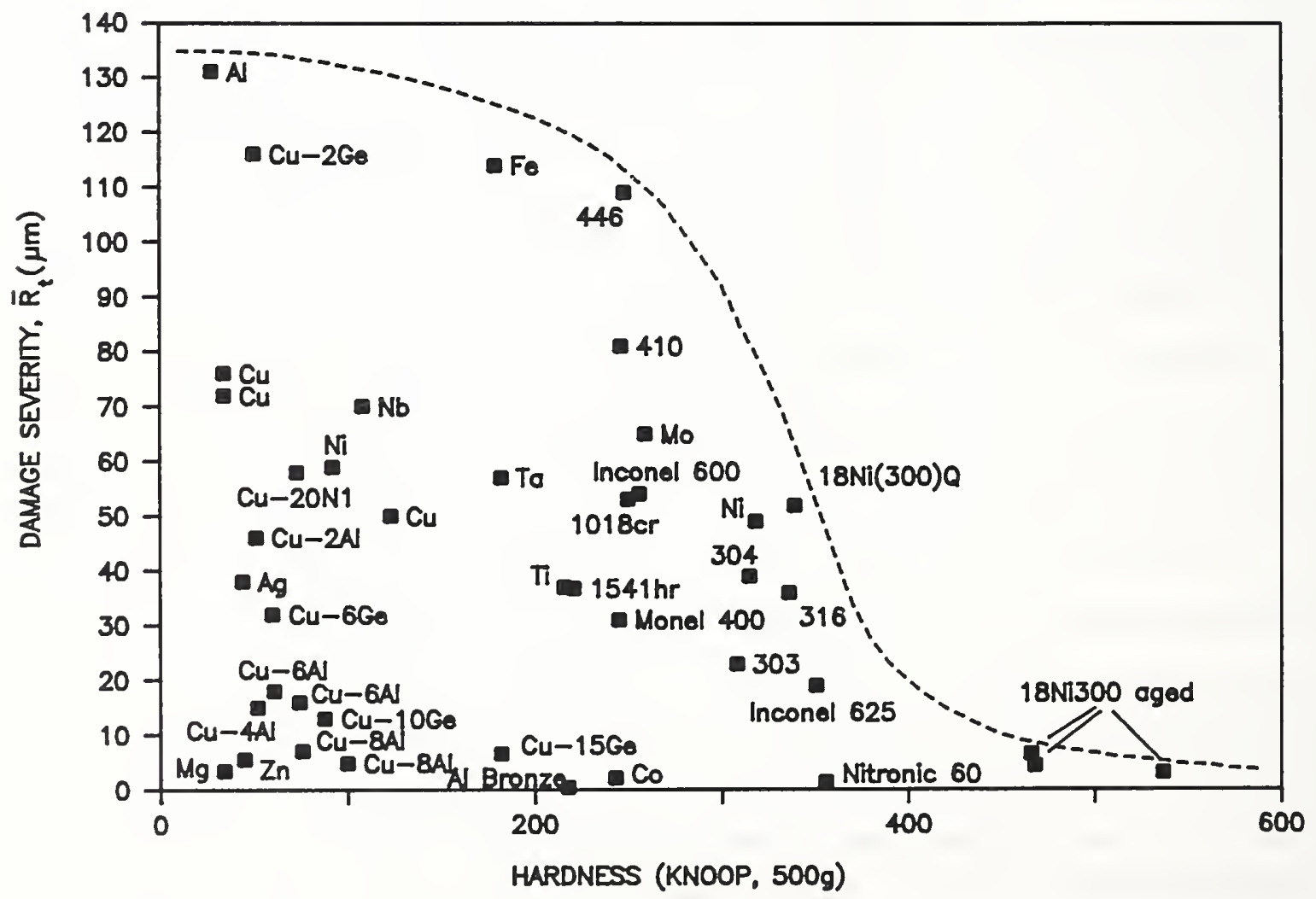

Fig. 60. Damage severity, $\bar{R}_{t}$, plotted against pretest hardness for selfmated metals at $130 \mathrm{~N}$. 
A low value is reached at about $450 \mathrm{~kg} / \mathrm{mm}^{2}$. Viewed in this way, it appears that choosing metals with hardness greater than $450 \mathrm{~kg} / \mathrm{mm}^{2}$ would tend to minimize damage should galling occur. For metals with hardness less than about $350 \mathrm{~kg} / \mathrm{mm}^{2}$, there is a large variation in damage severity, and one can not reliably make a choice based on hardness. Assuming a linear proportionality between damage severity and load, as was demonstrated for 1541 steel, the above relationships would also hold for loads other than $130 \mathrm{~N}$.

Figure 60 again emphasizes the significant improvement that can be gained by selecting metals that have a high resistance to galling irrespective of hardness.

\section{THE MECHANISM OF GALLING}

If a broad view is taken of the phenomenon of galling, it is clear that it involves the process by which the surface deforms and fractures under imposed contact stresses. This is a topic that has been the subject of a great deal of study and is fundamental to the understanding of friction and wear. Of course, in connection with galling one still has to differentiate between processes that do not lead to galling and those that do. That is, surface deformation and fracture do not always lead to a phenomenon that would be described or defined as galling.

A definition of the term galling that appears to us to include most of the recognized aspects of the phenomenon is as follows: Galling is a form of severe sliding wear which is characterized by a significant increase in surface roughness as a result of the plastic deformation and fracture of one or both contacting surfaces. Transfer of material from one surface to the other is usually involved but may not be critical to the operation of the process. As was noted earlier, other terms have been used to describe damage that in many cases is essentially the same as galling. Among these are severe adhesive wear, scuffing, scoring and seizure. Severe adhesive wear is an ambiguous term and could describe unusually rapid wear as well as galling damage. Scuffing, it seems, refers to galling damage in a lubricated system, for example, at the piston ring cylinder wall contact. Scoring is also ambiguous in 
that it describes the presence of grooves or scratches that are often characteristic of galling damage but could be a result of abrasion or plowing without galling. Seizure, the last term mentioned, appears to originate from the concept that under certain conditions, particularly at high loads or sliding speeds, local welding or seizing of the asperities occurs and thus sliding by seizure is said to take place. The damage seems to be closely related to if not identical to galling under such conditions.

Under a given set of operating conditions of load, speed and environment, there are three factors that have a critical influence on galling. Perhaps the most important is the presence of a lubricant film, or, alternatively, of a contaminant or chemically reacted layer that functions as a lubricant. The lubricant acts by both distributing the load and relieving the shear stresses. The latter effect is a result of the film itself shearing at a lower stress than that required to deform the underlying surface. With a highly reactive lubricant, for example one containing an EP (extreme pressure) additive, the effect may be somewhat different. The lubricant may not actually prevent surface deformation but by limiting its spread, perhaps through a fracture mechanism, effectively minimize galling.

The second factor which affects galling is the roughness of the surface. If sliding results only in shearing off of the tips of asperities and does not involve material at a level below the asperities, then galling has not occurred. Referring to the definition of galling presented above, removal of the tips of asperities would result in a smoother surface rather than a rougher surface as required. The texture of the roughness, in addition to its magnitude as measured by a parameter such as $\mathrm{Rs}$ or $\mathrm{Ra}$, also has a strong effect on galling severity. This was demonstrated by experiments on stainless steel where damage was compared for surfaces ground parallel to the direction of sliding and perpendicular to the direction of sliding.[14] The damage was less severe when the direction of sliding was parallel to the direction of grinding.

In connection with lubrication, surface roughness can have an additional effect. The lubricant can be trapped or held by an 
appropriately rough surface. The cross-hatching on cylinder walls of an internal combustion engine is considered to prevent scuffing by this means. When the cross-hatching is removed by wear leaving a polished surface, scuffing is much more likely to occur.

Finally, the factor which has been the main focus of this program concerns the influence of the properties of the materials themselves, particularly their mechanical properties, on galling. The effect is not simply one of harder or higher strength materials being more resistant to galling than softer less strong materials. For example, it was found that under the same self-mated conditions relatively soft copper exhibited about the same galling severity as much harder nickel.

A number of examples of galled surfaces have been given throughout this report for different metals and combinations of metals. We have emphasized that the primary event in galling was that of prow formation. The prow formation process is illustrated schematically in Fig. 61. Here, attention is focussed on the flat although with a pin and flat of the same material both would be expected to undergo deformation in about the same way on initiation of sliding. Beyond initiation, where the sliding distance exceeds the contact diameter of the pin, large

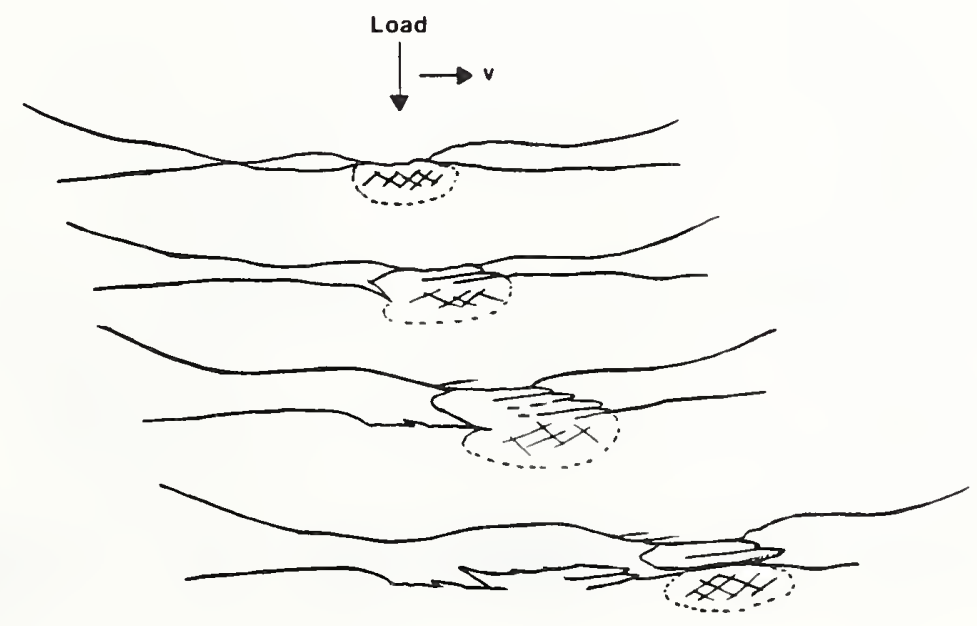

Fig. 61. Schematic drawing illustrating basic wedge formation process responsible for galling. 
differences would be anticipated in flat and pin damage. This is because sliding takes place on the same region of the pin while new contact area is traversed on the flat. In Fig. 61 it is assumed that the pin is harder than the flat and therefore not subject to damage.

When a tangential force is applied causing the pin to be translated with respect to the flat, there are several possible effects. As mentioned above, the pin may slid along the surface of the flat with damage confined entirely to the tips of the asperities. Alternatively, if traction forces are sufficiently high, material below the asperities may be deformed. This is the situation depicted in Fig. 61. The variation in the normal stress $\sigma_{x}$ in the plane of contact is shown in Fig. 62a without the application of a tangential force and in Fig. 62b with the application of a tangential force.[15] With a tangential force, as is intuitively expected, the stress is tensile behind the slider and compressive in front of it. As a result, material will tend to move along with the slider, being subject to tensile fracture behind the slider. Evidence of a tensile mode of fracture was demonstrated by the dimple structure in Fig. 16. Beneath the pin, as is illustrated in Fig. 61, shear occurs on a plane that is slightly inclined to the surface. This shear process results in the formation of a wedge or

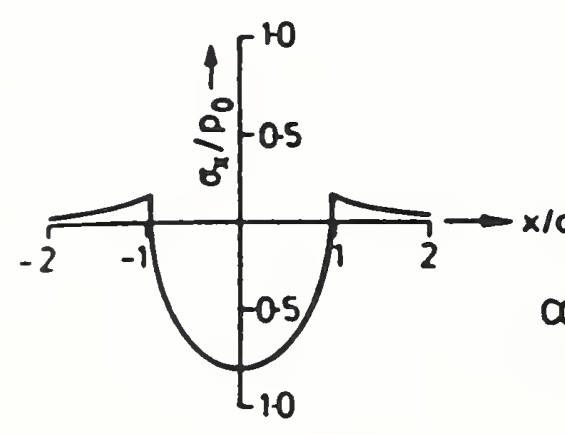

(a) NORMAL FORCE ONLY

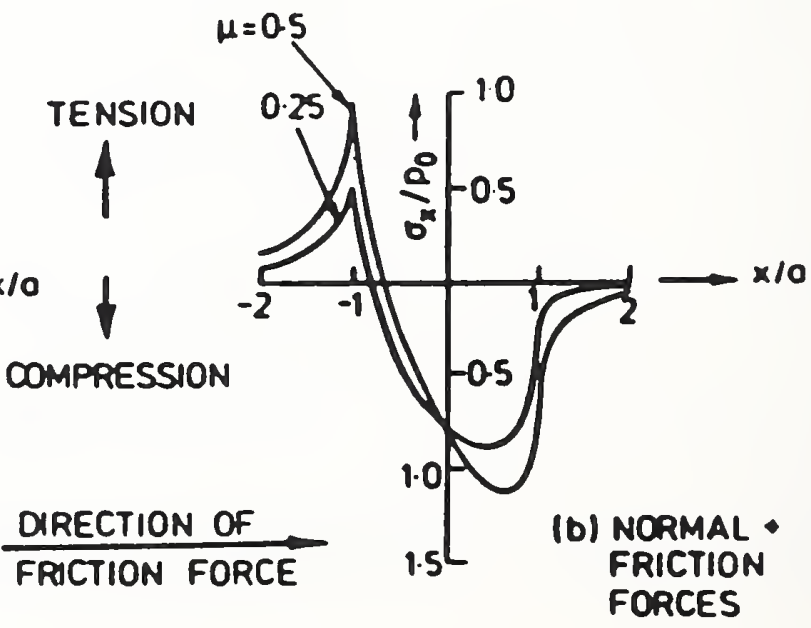

Fig. 62. Variation in normal component of stress $\sigma_{\mathrm{x}}$ in contact plane for spherical indenter: (a) with out tangential force and (b) with tangential force. 
prow of material beneath the pin. The prow, as noted earlier, is much like the chip which is formed in machining with a tool having a very large negative rake angle. As the prow increases in size beneath the pin a stage is reached in which the traction stresses between the pin and prow are not sufficiently strong to move the prow, and the pin is torn away leaving the prow behind. The prow formation process may then start anew.

Once a prow is formed, other processes may contribute in a substantial way to the further development of damage. For example, the prow is often, in effect, a work hardened lump of material. If it is sufficiently hard the prow may plow a groove in the mating surface. When the bulk hardness of the two surfaces are about the same, especially with selfmated contacts, sliding may occur intermittently by the prow formation process and by plowing.

The process illustrated in Fig. 61 and described above was first identified by Cocks [6] and elaborated on in later work [7]. In experiments with a hemispherically tipped copper pin sliding on a copper cylinder, Cocks observed the formation of a wedge and noted that the pin was raised from the surface by the growth of the wedge. Sliding took place entirely by the wedge growth process. From time-to-time the slider broke away from the wedge, and a new wedge was formed. At about the same time that Cocks made his observations, Antler [16] also reported on what was apparently a similar if not the same phenomenon. Antler, however, used the term "prow" instead of wedge to describe the lump of material beneath the slider. Prow is the term that is now most frequently employed in the literature. Initially, Antler attributed the formation of prows to the accumulation of debris [16], but in later work [17] he recognized that prows could be generated both by the debris accumulation mechanism and the wedge growth mechanism of Cocks. The distinction to be made here is that debris accumulation in itself does not necessarily constitute galling although it could lead to galling. If the debris are generated by the shearing-off of asperity tips, then the resulting surface is likely to be smoother than before. If the wedge of debris grows between the surfaces and accepts an increasingly large proportion 
of the load, then the resulting high contact stresses could lead to galling.

In the model of galling shown in Fig. 61 the wedge of material is generated entirely from the flat, the presence of a layered structure which has been described by Cocks [7], can be inferred from the micrograph in Fig. 15 of a prow at the end of a track on the Fe flat. Layered structures can also develop by other mechanisms. Sasada et al. [18] have found that prows consist of layers of material from both surfaces. Thus, when iron was slid on zinc, the prows consisted of layers of zinc and iron. In the experiments of Sasada et al. this is probably associated with the fact that debris from both surfaces is accumulated into a prow without galling.

There is, however, a mechanism involving galling which could lead to alternating layers of material from both surfaces. This mechanism is a consequence of work hardening. As a wedge is generated from one surface its strength may exceed that of the mating surface material on account of work hardening. Wedge formation may cease in that surface and take place in the mating surface. Work hardening of the mating surface material may then occur. As a consequence, the process may alternate back and forth between the surfaces leading to a wedge composed of layers from both surfaces. This would only occur between surfaces having the appropriate work hardening characteristics and balances of strengths.

A close connection is often made between galling and transfer. However, our experiments have shown that, while in some cases there is extensive transfer with galling, in other cases there is very little. It is well known that even incidental sliding contact can lead to transfer, although very sensitive analytical methods, for example radiographic techniques, may be required for its detection. [19] Thus, some transfer is certain to occur with galling. An important observation is that substantial transfer can occur without galling, that is, the sliding surfaces remain smooth in the presence of transfer. Galling is determined by the way plastic flow and fracture occur in a given material 
in response to applied stresses. If a wedge forms as described by Cocks, then this constitutes galling. Smooth transfer does not constitute galling.

There are two important additional issues to be discussed in connection with the mechanism of galling. The first concerns the magnitude of the observed damage. In particular, is there a size scale below which the damage should not be referred to as galling? ASTM Standard G 98 [20] states that only the unaided eye should be used in determining whether or not a test specimen has galled. Experiments have shown, however, that damage which can only be resolved at high magnification in the SEM appears identical in topography and apparent mechanism of formation to damage on a much larger scale that is referred to as galling and is resolvable by the unaided eye. An example of this "size-scale" effect is shown in Fig. 63 where damage on a nickel flat and at the initial part of the track on an aluminum bronze flat are compared. In this investigation damage was considered to be galling if the process occurred by the wedge (prow) mechanism of Cocks, regardless of the magnification required for its observation.

The second issue concerns the meaning and significance of the threshold stress for galling. The threshold stress for galling can be defined as the apparent normal contact stress or pressure that just marks the onset of galling. It is a quantity that is often used to characterize the tendency of a sliding combination of materials to gall. Whether or not galling occurs at a given load depends on the three factors discussed earlier: 1) the presence of a lubricant, contamination, or oxide film on the surface; 2) the surface roughness; and 3 ) the propensity of the material itself to gall. Also, of course, if galling is identified on the basis of a certain size scale of the damage-that is, if the damage must be above a certain size to be considered galling-then this would be an additional factor. If the material itself does not gall then the other factors are irrelevant. Cobalt and aluminum-bronze are two metals that appear very nearly to fit into the category of non-galling materials. In single pass experiments both exhibited what appeared to be slight galling on initial sliding contact but thereafter did not exhibit damage that could be recognized as galling. 

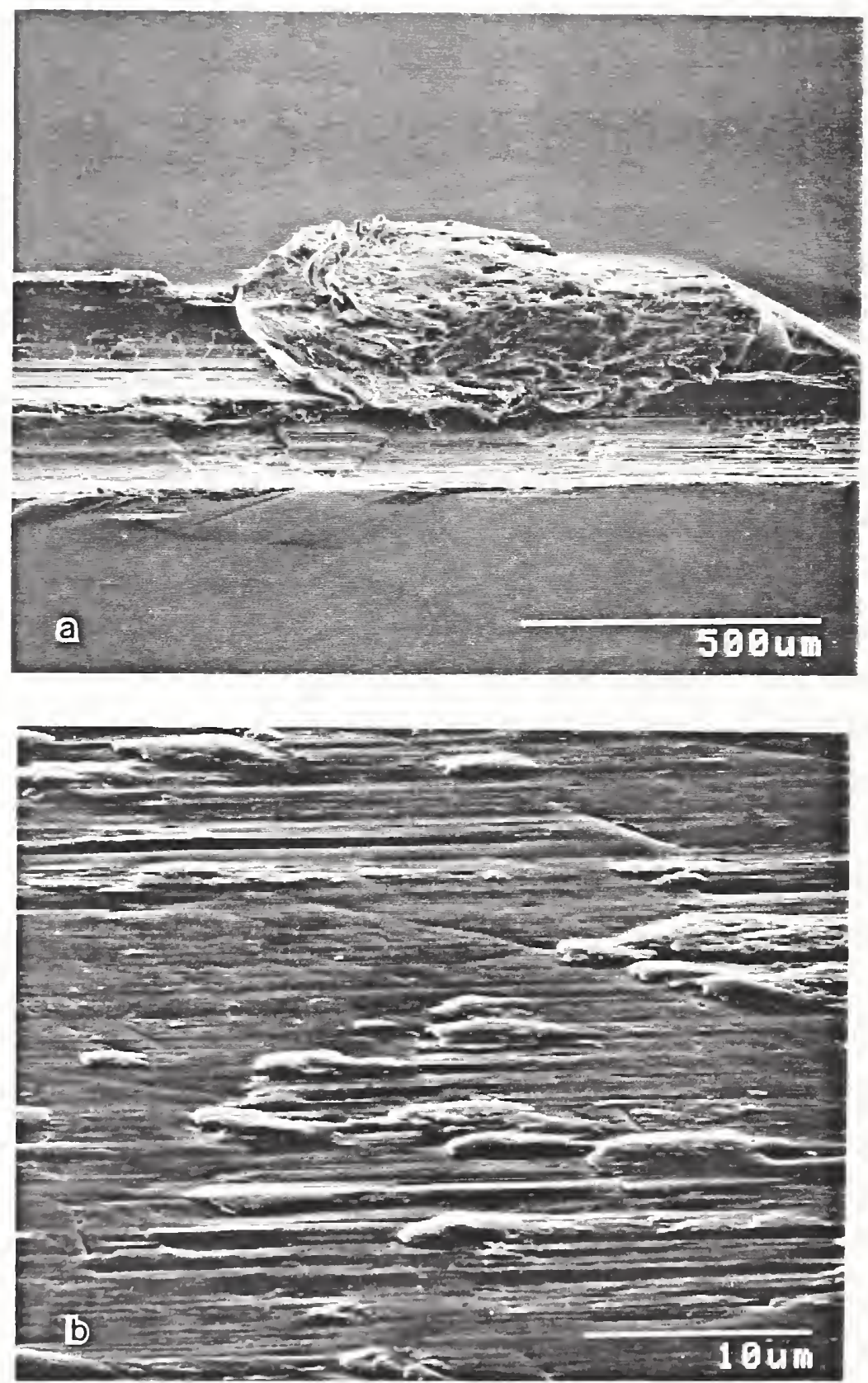

Fig. 63. Similar appearance of damage at different scales: (a) Ni flat and (b) aluminum-bronze flat. $130 \mathrm{~N}$ load. 
Undoubtedly, for many materials, surface films play a critical role in determining the existence of a threshold stress for galling. It is well recognized that most materials under unlubricated conditions in air can slide without galling when the load is sufficiently low. In vacuum, however, after the oxide film has been removed, many of the same materials will not slide without galling, regardless of how small the load.

In terms of materials selection for practical applications, knowledge that a given combination of materials will not gall below a specified stress level under a given set of conditions is of great importance. At the same time, the designer must be aware that the threshold stress does not necessarily represent an intrinsic property of the material. If the exposure conditions change, galling could well occur.

In addition to surface films, surface roughness, by limiting damage to the tips of asperities, may influence threshold galling stress. When a sufficiently large load is applied, deformation may extend to material below the asperities and galling can occur. Also, in the presence of a lubricant, a suitably rough surface serves to "hold" the lubricant and thereby improve galling resistance. In addition, the effective thickness of an oxide film on a rough surface would be greater than on a smooth surface, and for this reason a rough surface might also be less prone to galling than a smooth surface.

A major challenge in the study of galling is the development of a theory to describe galling which is based on contact conditions and fundamental materials properties. Ideally, such a theory should be capable of predicting the stress state that would lead to galling. Furthermore, at least in the early stages of the process, the theory should also be able to describe the flow or displacement of material that leads to the development of surface features that are characteristic of galling. In an early study, Burweil and Strang [21] concluded that when the applied stress exceeded one-third the hardness of a soft rider there is a marked increase in wear rate, a condition that we might ascribe to galling. (Burwell and Strang considered galling and adhesive wear to be synonymous and also to be the fundamental process by which wear occurs at sliding contacts.) Interestingly, Burwell and Strang 
attributed this load-related transition to the point at which the stress fields of individual asperities began to overlap. Thus, not just asperities but a volume of material including asperities and material below asperities was involved in the wear process. The one-third hardness criteria is undoubtedly a consequence of the materials and conditions that Burwell and Strang employed: steel with a relatively inert lubricant fluid, hexadecane. It may also be noted that the yield strength of a metal is approximately equal to the one-third its hardness. Burwell and strang themselves state that severe wear could occur in a vacuum at much lower loads than predicted or would require higher loads with a good lubricant. This seems to be an admission that the severe wear criteria is not an intrinsic materials property.

Some progress has been made in identifying the conditions under which simple contact geometries may lead to galling-like materials displacement behavior. Using slip line field theory, Chalen and Oxley [22] have investigated the different regimes of deformation which occur when a hard wedge slides on a softer surface. The soft surface is assumed to be perfectly plastic and the wedge perfectly rigid. Three different models are proposed which can be related to the different regimes of sliding wear in practice. These are illustrated in Fig. 64. [23] Depending on the wedge angle, the soft material responds either 1) as a plastic wave, termed the rubbing model, 2) as a sheared asperity, referred to as the wear model, or 3 ) as a cut chip at high wedge angles, called the cutting model. Galling, it seems, would correspond to the wear model where, instead of a plastic wave travelling along the surface or a chip curling from the surface, the wave or prow is torn from the surface .

Although models such as that of Challen and Oxley may provide much insight into the process of galling, their applicability is severely limited by the fact that the model materials are highly idealized, that is, most real solids can not be treated as being perfectly plastic. That real materials gall seems to be strongly related to work hardening processes and the details of the shear and fracture mechanisms. 


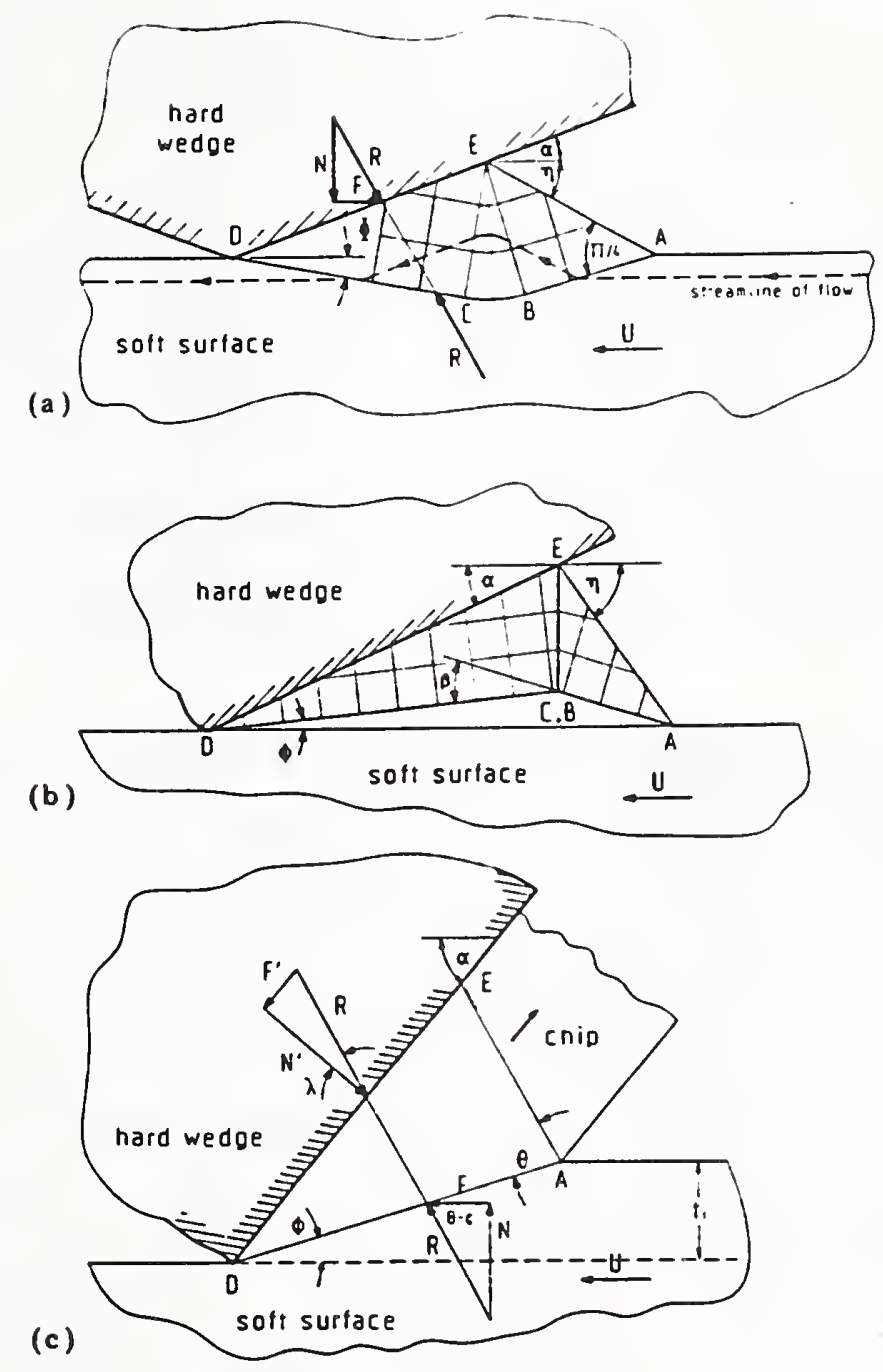

Fig. 64. Slip-line field models used by Black, Koplansky and Oxley [20] to study the different regimes of sliding deformation: (a) plastic wave formation, (b) wave removal, and (c) chip formation. 
In this report we have described the results obtained in an extensive program to investigate the process of galling. The main purpose of the program was to study the mechanism of galling. It was pointed out that, although galling is often treated as a unique form of extremely severe damage, it is in fact a general form of wear, with damage, depending on conditions, ranging from microscopic to easily resolvable by the unaided eye. The primary event in the process of galling is prow or wedge formation. Prow formation can be likened to chip formation in machining at a very large negative rake angle. However, in contrast to machining, prow formation does not necessarily require the penetration of a hard tool into the surface but only that the surfaces be locked together such that shear deformation occurs in subsurface material. The process of galling was illustrated and analyzed for a number of metals in self-mated and nonself-mated sliding throughout the investigation.

The principal specimen configuration employed in the investigation was a spherically tipped pin sliding against a flat. A test consisted of a single pass or stroke of the pin against the flat.

of great importance in accomplishing the goals of this project was the development of a method to measure quantitatively the amount and character of surface damage. To this end, a method based on surface topography was developed. Stylus profilometry was used to map the damage topography on the specimen flat. A number of parameters calculated from the topographic data were used as quantitative measures of the damage.

The galling behavior of twelve different pure metals was studied in self-mated sliding. The effects of crystal structure and hardness were examined. It was found for the pure metals, when viewed as a group, that there was no correlation between galling severity and hardness among the metals examined. However, there was a substantial effect of crystal structure. Hexagonal-close-packed metals were damaged much less severely than body-centered- or face-centered-cubic metals. In fact, it could be said that cobalt and magnesium did not gall under the conditions of the test. 
The galling behavior of several nonself-mated pure metal combinations was studied. One of the most important factors influencing the response of different metal combinations was the relative hardness of the component specimens. The harder specimen was not plastically deformed during sliding, except of course when work hardening of the softer specimen eliminated the original difference. In the absence of the latter occurrence, damage to the harder specimen took the form of transferred material. When the pin was harder than the flat, damage to the flat was less than in self-mated sliding. This difference was probably due to transfer of pin material in the self-mated case and to the fact that a badly distorted pin surface caused more damage than a hard pin that was not plastically deformed by sliding.

Nonself-mated couples of pure metals were also selected to examine the effect of chemical compatibility. The chemically incompatible combinations, $\mathrm{Ag} / \mathrm{Co}$ and $\mathrm{Cu} / \mathrm{Co}$ were compared with the compatible couples $\mathrm{Ag} / \mathrm{Ni}$ and $\mathrm{Cu} / \mathrm{Ni}$. In this comparison more damage was registered by the compatible pairs than by the incompatible pairs.

Three series of $\mathrm{Cu}$ based solid solution alloys, $\mathrm{Cu}-\mathrm{Al}, \mathrm{Cu}-\mathrm{Ge}$, and $\mathrm{Cu}-\mathrm{Ni}$, were studied to determine the effect of stacking fault energy on damage severity. With $\mathrm{Al}$ and $\mathrm{Ge}$ additions to $\mathrm{Cu}$, the stacking fault energy decreases with increasing solute concentration. Alloying with $\mathrm{Ni}$, however, results in an increase in stacking fault energy. Selfmated tests with these alloys showed that damage severity decreased with decreasing stacking fault energy.

Results showed that the amount of galling damage increased linearly with increasing load at lower loads, but at the highest load tested $(10,000 \mathrm{~N})$ damage tended to level off.

Surface finish also affected galling severity. Polished surfaces galled more severely than rougher, ground surfaces. Also, a surface lay parallel to the sliding direction resulted in less severe damage than a lay perpendicular to the sliding direction.

Although hardness did not seem to influence damage severity in the case of self-mated pure metals, damage severity was found to depend on hardness for heat treated steels. It was also observed that the surface treatments, carburizing and nitriding, resulted in very low damage 
severities both in self-mated and nonself-mated experiments. When damage severity for all self-mated couples tested at $130 \mathrm{~N}$ was plotted against hardness, a significant decrease in damage severity was observed above a hardness of $-450 \mathrm{~kg} / \mathrm{mm}^{2}$.

Finally, the galling behavior of a variety of different commercial alloys was studied. The results indicated that most single phase corrosion resistant alloys are likely to exhibit relatively severe galling unless their stacking fault energy is low.

\section{ACKNOWLEDGMENTS}

The study of the effect of heat treatment on the galling of 1541 steel and the investigation of the effects of nitriding and carburizing were carried out in collaboration with Paul A. Swanson of Deere and Company, Inc.

\section{REFERENCES}

1. Peterson, M. B., Ives, L. K. and Bhansali, K. J., "A Literature Review of the Galling Process", in Metal Transfer and Galling in Metallic Systems, H. D. Merchant and K. J. Bhansali, eds., PP. 1-26, The Metallurgical Society, Warrendale, PA (1987).

2. Hamilton, G. M. and Goodman, L. E., "The Stress Field Created by a Circular Sliding Contact," ASME Journal of Applied Mechanics 33, pp. 371 $376(1966)$.

3. Whitenton, E. P., Peterson, M. B. and Ives, L. K., "Method for Quantitative Measurement of Galling Damage," in Metal Transfer and Galling in Metallic Systems, H. D. Merchant and K. J. Bhansali, eds., The Metallurgical Society, Warendale, PA (1987) pp. 155-170.

4. Swanson, P. A., Ives, L. K., Whitenton, E. P. and Peterson, M. B., "A Study of the Galling of Two Steels Using Two Test Methods," in Wear of 
Materials-1987, K. C. Ludema, ed., Pp. 49-58, ASME, New York (1987). Also in Wear 122, 207-223 (1988).

5. Peterson, M. B. and Winer, W. O., ed., Wear Control Handbook, ASME, New York (1980) 44.

6. Cocks, M., "Wear Debris in the Contact between Sliding Surfaces," J. Appl. Phys. 29, 1609-10 (1958).

7. Cocks, M., "Interaction of Sliding Metal Surfaces", J. Appl. Phys. 33 , 2152-61 (1962).

8. Roach, A. E., Goodzeit, C. L., and Hunnicutt, R. P., "Scoring Characteristics of Thirty-Eight Different Elemental Metals in High-Speed Sliding Contact with Steel," Trans. ASME 78 (1956) pp. 1659-1667.

9. Bhansali, K. J. and Miller, A. E., "Role of Stacking Fault Energy on the Galling and Wear Behavior of a Cobalt Base Alloy", in Wear of Materials-1981, ASME, New York (1981) 179-185.

10. Carter, C. B. and Ray, I. L. F., "On the Stacking-Fault Energies of Copper Alloys," Phil. Mag., 35 (1977) 189-200.

11. Gallagher, P. C. J., "The Influence of Alloying, Temperature, and Related Effects on the Stacking Fault Energy," Met. Trans., 1 (1970) $2429-61$.

12. G77-83, Standard Practice for Ranking Resistance of Materials to Sliding Wear Using Block-on-Ring Wear Test, Annual Book of ASTM Standards, Vol. 3.02: Erosion and Wear; Metal Corrosion, ASTM (1988) 330-341.

13. Schumacher, W. J., "Metals for Non-Lubricated Wear", Machine Design, March 11, 1976, pp.57-59. 
14. Peterson, M. B., Bhansali, K. J., Whitenton, E. P. and Ives, L. K., "Galling Wear of Metals", Wear of Metals 1985, K. C. Ludema, Ed., ASME, New York, 1985, pp. 293-301.

15. O'Connor, J. J., "The Role of Elastic Stress Analysis in the Interpretation of Fretting Fatigue Failures," in Fretting Fatigue, R. B. Waterhouse, ed., Applied Science, London (1981) pp. 23-66.

16. Antler, M., "Wear, Friction, and Electrical Noise Phenomena in Severe Sliding Systems," ASLE Trans. 5 (1962) pp. 297-307.

17. Antler, M., "Processes of Metal Transfer and Wear", Wear I, 181-203 (1964).

18. Sasada, T., Norose, S. and Mishina, H., "The Behavior of Adhered Fragments Interposed Between Sliding Surfaces and the Formation Process of Wear Particles," J. Lub. Tech. 103 (1981) 195-202.

19. Rabinowicz, E. and Tabor, D., "Metallic Transfer Between Sliding Metals: An Autoradiographic Study," Proc. Roy. Soc. A, 208 (1951) 455-475.

20. G98, Standard Test Method for Galling Resistance of Materials, Annual Book of ASTM Standards (to be published).

21. Burwell, J. T. and Strang, C. D., "Metallic Wear," Proc. Roy. Soc. A, $\underline{212}$ (1952) $470-477$.

22. Challen, J. M. and Oxley, P. L. B., "An Explanation of the Different Regimes of Friction and Wear Using Asperity Deformation Models," Wear, $\underline{53}$ (1979) 229-243.

23. Black, A. J., Koplansky, E. M. and Oxley, P. L. B., "An Investigation of the Different Regimes of Deformation Which Can Occur When a Hard Wedge Slides Over a Soft Surface: The Influence of Wedge Angle, Lubrication and Prior Plastic Working of the Surface," Wear $\underline{123}$ (1988) 97-114. 
AIR PRODUCTS AND CHEMICALS P.O. Box 538

Allentown, PA 18105

S. W. Dean

S. C. Weiner

ARGONNE NATIONAL LABORATORY

9700 S. Cass Avenue

Argonne, IL 60439

W. A. Ellingson

K. Natesan

AVCO RESEARCH LABORATORY

2385 Revere Beach Parkway

Everett, MA 02149

R. J. Pollina

BABCOCK \& WILCOX

1562 Beeson St.

Alliance, $\mathrm{OH} 44601$

T. I. Johnson

T. Modrak

BABCOCK \& WILCOX

Domestic Fossil Operations

20 South Van Buren Avenue

Barberton, OH 44023

M. Gold

BABCOCK \& WILCOX

Lynchburg Research Center

P.O. Box 11165

Lynchburg, VA 24506

H. Moeller

BATTELLE-COLUMBUS LABORATORIES

505 King Avenue

Columbus, OH 43201

V. K. Sethi

I. G. Wright

BRITISH COAL CORPORATION

Coal Research Establishment

Stoke Orchard, Cheltenham

Glochester, England GL52 4RZ

M. Arnold

C. Bower

A. Twigg
BRITISH GAS CORPORATION

Westfield Development Centre

Cardenden, Fife

Scotland KY5OHP

J. E. Scott

BROCKHAVEN NATIONAL LABORATORY

Department of Applied Science

Upton, Long Island, NY 11973

T. E. O'Hare

CANADA CENTER FOR MINERAL \& ENERGY TECHNOLOGY

568 Booth Street

Ottawa, Ontario

Canada K1A OG1

R. Winston Revie

Mahi Sahoo

COMBUSTION ENGINEERING

911 W. Main Street

Chattanooga, TN 37402

D. Canonico

CONSOLIDATION COAL COMPANY

4000 Brownsville Road

Library, PA 15129

$S$. Harding

EBASCO SERVICES, INC.

P.O. Box 1002

Glen Rose, TX 76043

T. A. Flynn

ELECTRIC POWER RESEARCH INSTITUTE

P.0. Box 10412

3412 Hillview Avenue

Palo Alto, CA 94303

W. T. Bakker

R. L. S . Chang

J. T. Stringer

EUROPEAN COMMUNITIES JOINT RESEARCH CENTRE

Petten Establishment

P.O. Box 2

1755 ZG Petten

The Netherlands

M. Van de Voorde 
FOSTER WHEELER DEVELOPMENT CORPORATION

Materials Technology Department John Blizard Research Center

12 Peach Tree Hill Road

Livingston, NJ 07039

J . L. Blough

GAS RESEARCH INSTITUTE

8600 West Bryn Mawr Avenue

Chicago, IL 60631

H. S. Meyer

GENERAL ELECTRIC COMPANY

Bldg. 55, Room 115

1 River Road

Schenectady, NY 12345

R. W. Haskell

GEORGIA INSTITUTE OF TECHNOLOGY

Georgia Tech Research Institute

Atlanta, GA 30332

T. L. Starr

LANXIDE CORPORATION

1 Tralee Industrial Park

Newark, DE 19711

E. M. Anderson

LAWRENCE BERKELEY LABORATORY

University of California

Berkeley, CA 94720

A. V. Levy

LAWRENCE LIVERMORE LABORATORY

P.O. Box 808, L-325

Livermore, CA 94550

W. A. Steele

MOBIL RESEARCH \& DEVELOPMENT

CORPORATION

P.O. Box 1026

Princeton, NJ 08540

R. C. Searles

NATIONAL INSTITUTE OF STANDARDS AND TECHNOLOGY

Materials Building

Gaithersburg, MD 20899

S. J . Dapkunas
NATIONAL MATERIALS ADVISORY BOARD

National Research Council

2101 Constitution Avenue

Washington, DC 20418

K. M. Zwilsky

NEW ENERGY DEVELOPMENT ORGANIZATION Sunshine $60 \mathrm{Bldg}$.

P.O. Box 1151

1-1, Higashi-Ikebukuro 3-chrome

Toshima-Ku

Tokyo, 170

Japan

S. Ueda

OAK RIDGE NATIONAL LABORATROY

P.0. Box 2008

Oak Ridge, TN 37831

P. J. Blau

D. N. Braski

P. T. Carlson

W. N. Drewery, Jr. (8)

R. R. Judkins

J. R. Keiser

RISOE NATIONAL LABORATORY

P.O. Box 49

DK-4000, Roskilde

Denmark

Aksel Olsen

SHELL DEVELOPMENT COMPANY

P.O. Box 1380

Houston, TX 77251-1380

L. W. R. Dicks

TENNESSEE VALLEY AUTHORITY

Energy Demonstration \& Technology MR 2N58A

Chattanooga, TN 37402-2801

C. M. Haung

TENNESSEE VALLEY AUTHORITY

1101 Market Street

MR 3N57A

Chattanooga, TN 37402

R. Q. Vincent 
UNITED ENGINEERS \& CONSTRUCTORS

30 South 17 th Street

P.O. Box 8223

Philadelphia, PA 19101

A. J. Karalis

UNIVERSAL ENERGY SYSTEMS, INC.

4401 Dayton-Zenia Road

Dayton, OH 45432

V. Srinivasan

UNIVERSITY OF CALIFORNIA AT BERKELEY

Department of Mechanical Engineering Berkeley, CA 94720

J. A. C. Humphrey

UNIVERSITY OF NOTRE DAME

Department of Materials Science and Engineering

P.O. Box E

Notre Dame, IN 46556

T. H. Kosel

WESTINGHOUSE ELECTRIC CORPORATION

Research and Development Center

1310 Beulah Road

Pittsburgh, PA 15235

S. C. Singhal

WESTINGHOUSE HANFORD COMPANY

P.O. Box 1970

W/A -65

Richland, WA 99352

R. N. Johnson

DEPARTMENT OF ENERGY

OAK RIDGE OPERATIONS OFFICE

P.O. BoX 2001

Oak Ridge, TN 37831

Assistant Manager for Energy

Research and Development

E. E. Hoffman

DEPARTMENT OF ENERGY

OFFICE OF BASIC ENERGY SCIENCES

Materials Sciences Division

ER-131, GTN

Washington, DC 20545

J. B. Darby
DEPARTMENT OF ENERGY

OFFICE OF FOSSIL ENERGY

Washington, DC 20545

D. J. Beecy (FE-14)

J. P. Carr (FE-14)

R. T. King (FE-14)

F. M. Glaser (FE-14)

T. B. Simpson $(F E-25)$

DEPARTMENT OF ENERGY

MORGANTOWN ENERGY TECHNOLOGY CENTER

P.O. Box 880

Morgantown, WV 26505

R. A. Bajura

R. C. Bedick

F. W. Crouse, Jr.

N. T. Holcombe

W. J. Huber

M. J. Mayfield

J. E. Notestein

J. S. Wilson

DEPARTMENT OF ENERGY

PITTSBURGH ENERGY TECHNOLOTY CENTER

P.O. Box 10940

Pittsburgh, PA 15236

S. Akhtar

T. C. Rupel

R. Santore

T. M. Torkos 
NBS-114A (REV. 2-8C)

U.S. OEPT. OF COMM.

BIBLIOGRAPHIC DATA

SHEET (See instructions)

1. PUBLICATION OR

REPORT NO.

NISTIR $89-4064$

2. Performing Organ. Report Nof 3. Publication Date

DECEMBER 1989

4. TITLE AND SUBTITLE

The Mechanism, Measurement, and Influence of Properties on the Galling of Metals

5. $A U T H O R(S)$

L. K. Ives, M. B. Peterson and E. P. Whitenton

6. PERFORMING ORGANIZATION (If joint or other than NBS, see instructions)

NATIONAL BUREAU OF STANDARDS

U.S. DEPARTMENT OF COMMERCE

GAITHERSBURG, MD 20899

9. SPONSORING ORGANIZATION NAME AND COMPLETE ADDRESS (Street, City. Stote, ZIP)

Oak Ridge National Laboratory

Oak Ridge, TN 37831-6084

10. SUPPLEMENTARY NOTES

Document describes a computer program; SF-185, FIPS Software Summary, is attached.

11. ABSTRACT (A 200-word or less factual summary of most significant information. If document includes a significant bibliography or literature survey. mention it here)

This report presents the results of an extensive investigation of the process of galling. The work was motivated by the need to develop a better understanding of the process of galling as it affects various fossil energy related systems, and by the need to find solutions to the problem of galling in these systems. Three areas were emphasized: 1) the elucidation of the mechanism of galling, 2) the quantitative characterization and measurement of the amount of damage associated with galling, and 3) the determination of relationship between galling and materials properties. On the basis of a review of the literature and experiments on a variety of different metals it was concluded that the primary event in the process of galling is that of prow or wedge formation. A method based on surface topography was developed to measure quantitatively the amount and character of galling. By studying a range of pure metals and selected experimental alloys it was demonstrated that among the most important properties influencing galling are crystal structure and stacking fault energy. Hardness and strength do not in general correlate with galling severity, but it was shown that hardening steels by heat treatment is an effective means of reducing the damage due to galling. Carburizing and nitriding were also shown to diminish significantly the damage due to galling.

12. KEY WORDS ( $S$ Ix to twelve entries; alphabetical order; capitalize only proper names; and separate key words by semicolons) adhesive wear; carburized; $\mathrm{Cu}-\mathrm{Al}$; $\mathrm{Cu}-\mathrm{Ge}$; friction; galling; nitrided; profilometry; prow formation; stacking fault energy; steel; wear

13. AVAILABILITY

[] Unlimited

For Official Distribution. Do Not Release to NTIS

Order From Superintendent of Documents, U.S. Government Printing Office, Washington, D.C. 20402.

14. NO. OF PRINTED PAGES 110

Order From National Technical Information Service (NTIS), Springfield, VA. 22161 

